UNIVERSIDADE DE SÃO PAULO

FACULDADE DE FILOSOFIA, CIÊNCIAS E LETRAS DE RIBEIRÃO PRETO PROGRAMA DE PÓS-GRADUAÇÃO EM PSICOBIOLOGIA

MARCIA REGINA MOTTA

Efeitos da manipulação de uma obra de arte sobre o tempo subjetivo de pacientes com Doença de Parkinson

Ribeirão Preto/SP

2016 



\section{Efeitos da manipulação de uma obra de arte sobre o tempo subjetivo de pacientes com Doença de Parkinson}

Dissertação apresentada à Faculdade de Filosofia, Ciências e Letras de Ribeirão Preto da Universidade de São Paulo para obtenção do título de Mestre em Ciências.

Área de concentração: Psicobiologia.

Orientador: Prof. Dr. José Lino Oliveira Bueno

Ribeirão Preto/SP

2016 
Autorizo a reprodução e divulgação total ou parcial deste trabalho, por qualquer meio convencional ou eletrônico, para fins de estudo e pesquisa, desde que citada à fonte.

Catalogação na publicação

Serviço de Biblioteca e Documentação

Departamento de Psicologia da Universidade de São Paulo - Ribeirão Preto

Motta, Marcia Regina.

Efeitos da Manipulação de uma Obra de Arte sobre o Tempo Subjetivo de Pacientes com Doença de Parkinson/ Marcia Regina Motta; orientador Prof. Dr. José Lino Oliveira Bueno - Ribeirão Preto, 2016.

$100 \mathrm{pp}$.

Dissertação (Mestrado) - Faculdade de Filosofia, Ciências e Letras de Ribeirão Preto da Universidade de São Paulo. Departamento de Psicologia. Programa de PósGraduação em Psicobiologia. Área de concentração: Psicobiologia.

1. Percepção do tempo; 2. Doença de Parkinson; 3. Movimento; 4. Obra de arte. 
Nome: Motta, Marcia Regina

Título: Efeitos da Manipulação de uma Obra de Arte sobre o Tempo Subjetivo de Pacientes com Doença de Parkinson.

Dissertação apresentada à Faculdade de Filosofia,

Ciências e Letras de Ribeirão Preto da

Universidade de São Paulo para obtenção do título de Mestre em Ciências.

Aprovado em:

Banca Examinadora

Prof. Dr.

Instituição:

Assinatura:

Prof. Dr.

Instituição:

Assinatura:

Prof. Dr.

Instituição:

Assinatura: 

Á Deus e aos meus pais, aos quais admiro $e$ amo muito. 



\section{AGRADECIMENTOS}

Aos meus pais, Miguel e Jocélia, que me apoiaram desde o início desta jornada e que sempre estiveram perto, mesmo que a distância, oferecendo carinho, atenção, compreensão e amenizando cada passo que foi dado.

Ao Prof. Dr. José Lino Oliveira Bueno que apostou em mim possibilitando que eu realizasse esse estudo e pela oportunidade de caminhar com alguém que me ensina e inspira não somente na vida acadêmica, mas também enquanto profissional e pessoa.

Ao Prof. Dr. Vitor Tumas por ter aceitado ser colaborador neste trabalho e pelos apontamentos importantes para a execução e elaboração da pesquisa, e à sua equipe do ambulatório de Distúrbios do Movimento Extrapiramidal do Hospital das Clínicas da Faculdade de Medicina de Ribeirão Preto-USP, por terem me acolhido muito bem e por se mostrarem sempre muito dispostos a ajudar na coleta dos dados. Agradecimento especial a Ângela Vieira Pimentel por toda atenção e amizade e à Manuelina Mariana Capelari Macruz Brito pela ajuda com as avaliações.

Ao João Luís Segala Borin, por toda a ajuda, paciência e principalmente, amizade.

A todos os amigos do laboratório que sempre se mostraram dispostos a ajudar, especialmente ao David Andrés Casilimas Díaz que pacientemente me auxiliou na análise estatística dos dados.

Ao Hugo Cézar Palhares pela ajuda com o E-prime e a Lilian Luchesi pelo auxílio com o EthoLog.

Às minhas irmãs, Monica e Melissa, por me apoiarem, ainda que às vezes de um jeito estranho. E aos meus sobrinhos, Júlia e Mateus, por alegrarem a minha vida.

À minha avó, Tereza de Jesus Serafim Motta, pelas orações.

A todos os meus amigos, em especial a Jessica Alpendre Felinto, Franciele Guedes e Adriane Cristine pela força, pelas risadas, pela amizade sincera e por sempre me enviarem mensagens carinhosas que chegavam no momento certo.

À Natália Claro da Silva pela amizade e apoio espiritual.

À Danusa Ariete da Silva e Jéssica Montes pelo companheirismo na reta final deste trabalho e pelas boas risadas que demos juntas.

À Coordenação de Aperfeiçoamento de Pessoal de Nível Superior - CAPES - pela concessão da bolsa de mestrado e conseguinte apoio financeiro para realização desse estudo. 



\section{RESUMO}

Motta, M. R. (2016). Efeitos da Manipulação de uma Obra de Arte sobre o Tempo Subjetivo de Pacientes com Doença de Parkinson. Dissertação de Mestrado, Faculdade de Filosofia, Ciências e Letras de Ribeirão Preto, Universidade de São Paulo, Ribeirão Preto-SP.

A temporalidade compõe as ações do indivíduo no mundo, portanto, a subjetividade assume papel importante, pois a partir dela é que o tempo ganha sentido e significado. Assim, a percepção subjetiva do tempo torna-se fundamental para a concepção da realidade, traçando uma distinção entre o decurso temporal dos muitos eventos vivenciados ao longo da vida, o que implica que o processamento da informação temporal é imprescindível no cotidiano. Um campo de pesquisa que tem se dedicado a investigações sobre o tempo subjetivo é a Nova Estética Experimental, que estuda obras de arte ou outros fenômenos estéticos através de experimentos, nos quais atributos das obras são manipulados, visando verificar quais são seus efeitos sobre algum aspecto do comportamento do indivíduo. Nas artes, a artista plástica Lygia Clark considerava que a obra só teria significado na relação com o espectador através de sua manipulação; deste modo, ela cria a série "Bichos", que são esculturas que modificam suas configurações em resposta à ação do espectador, isto é, podem ser exploradas manualmente. $\mathrm{O}$ tempo subjetivo se altera em função da densidade de movimento percebido. Uma obra de arte em que seu movimento é induzido por manipulação pode alterar o tempo subjetivo. Questiona-se qual seria a influência da atividade exploratória destas obras sobre a experiência temporal e como essa relação se daria em condições nas quais os participantes apresentassem alterações dos padrões motores, como os observados em pessoas com Doença de Parkinson (DP). Assim, a proposta deste trabalho foi examinar os efeitos da manipulação de uma obra de arte móvel sobre o tempo subjetivo em indivíduos que apresentam o diagnóstico de DP. No experimento 1, estudantes de pós-graduação julgaram modelos de obras de arte da série "Bichos" de Lygia Clark, para os atributos: Complexidade, Regularidade, Quantidade de Material, Interesse e Agradabilidade. Os julgamentos mostraram que os estímulos apontados com maior quantidade de material foram considerados com maior nível de complexidade e interesse, no entanto, com menor nível de agradabilidade; por outro lado, os estímulos avaliados com menor quantidade de material foram indicados com menor nível de complexidade e interesse, entretanto, com maior nível de agradabilidade. Este resultado foi importante para a determinação dos estímulos que foram utilizados no experimento 2. Participantes com diagnóstico de DP e participantes sem a doença manipularam duas reproduções, alteradas no número de faces, de obras da série "Bichos" de Lygia Clark e realizaram a estimação temporal verbal da duração de suas manipulações. $\mathrm{O}$ manuseio foi registrado sendo analisadas quatro categorias comportamentais: Tocar, Movimentar, Soltar e Deslocar o estímulo. A análise da atividade exploratória dos participantes revelou que os participantes com DP tocam e soltam mais os estímulos e os movimentam e deslocam menos em relação aos participantes sem a doença. As estimações temporais realizadas pelos participantes apontaram que a manipulação de uma obra de arte móvel altera a percepção subjetiva de tempo. Todos os participantes superestimaram o tempo de manipulação dos estímulos, no entanto, os indivíduos com DP apresentaram uma menor superestimação quando comparados aos participantes sem a doença.

Palavras-chave: Percepção do tempo. Doença de Parkinson. Movimento. Obra de arte. 



\begin{abstract}
Motta, M. R. (2016). Effects of the manipulation of a work of art on subjective time in patients with Parkinson's Disease. Dissertação de Mestrado, Faculdade de Filosofia, Ciências e Letras de Ribeirão Preto, Universidade de São Paulo, Ribeirão Preto-SP.

The temporality makes up individuals' actions in the world, therefore, subjectivity plays an important role, because time makes sense and meaning based on it. Thus, the subjective perception of time is fundamental to the conception of reality, drawing a distinction between the temporal course of the many events experienced throughout life, which implies that processing of temporal information is essential in daily life. A field of research that has been devoted to research on the subjective time is the New Experimental Aesthetics, studying works of art or other aesthetic phenomena through experiments in which some attributes of the works are handled in order to verify which are their effects on some aspects of individuals' behavior. In the field of arts, the artist Lygia Clark considered that the work would only have meaning in relation to the spectator through their manipulation; thus she creates the "Bichos" series, which are sculptures that modify its settings in response to the action of the viewer, that is, can be operated manually. The subjective time changes depending on the density perceived movement. A work of art in which its movement is induced by manipulation can change subjective time. One wonders what would be the influence of the exploration activities of these works on the temporal experience and how this relationship would be in conditions in which participants present changes in their motor patterns, as seen in people with Parkinson's disease (PD). Thus, the purpose of this study was to examine the effects of the manipulation of a work of mobile art on subjective time in people who have a diagnosis of PD. In experiment 1, graduate students judged models of works of art from the series "Bichos" by Lygia Clark, for rating the following attributes: Complexity, Regularity, Material Amount, Interest and Agreeableness. Trials showed that the stimuli that indicated larger amount of material were considered with a higher level of complexity and interest, however, with lower level of agreeableness; On the other hand, the stimuli evaluated as having less material were also indicated with lower complexity and interest, however, with higher levels of agreeableness. This result was important to determine the stimuli that were used in experiment 2. Participants diagnosed with PD and participants without the disease manipulated two reproductions of some works from the series "Bichos" by Lygia Clark with the number of faces altered, and performed a verbal estimation of the temporal duration of their manipulations. The handling was recorded and four behavioral categories were analyzed: Touch, Move, Displace work's position, and Drop the piece of art (stimulus). The analysis of the exploratory activity of the participants showed that those with PD touched and dropped more the stimulus, and, in contrast, they moved and displaced it less than the participants without the disease. The time estimates made by the participants pointed out that handling the work of mobile art altered the subjective perception of time. All participants overestimated the handling time of the stimuli, however, subjects with PD showed a lesser overestimation than participants without the disease.
\end{abstract}

Keywords: Time perception. Parkinson's disease. Movement. Work of art. 



\section{SUMÁRIO}

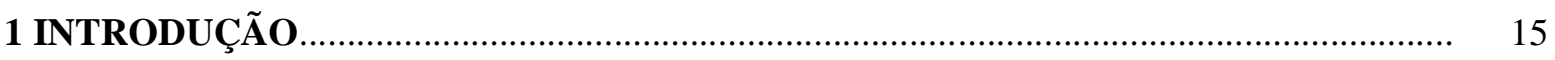

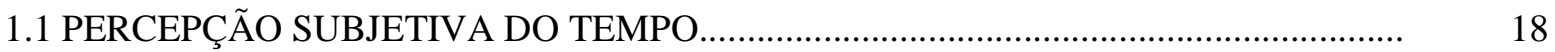

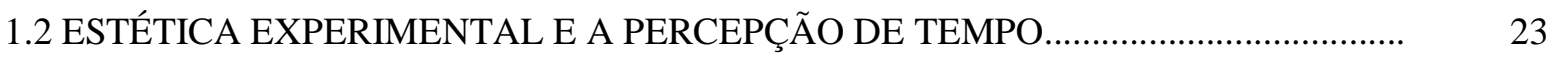

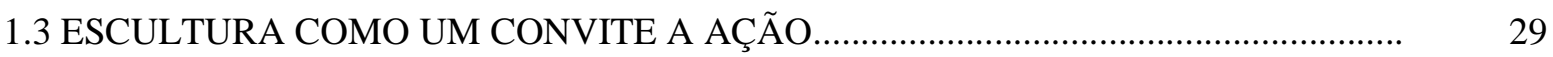

1.4 DOENÇA DE PARKINSON E PERCEPÇÃO DO TEMPO................................................ 33

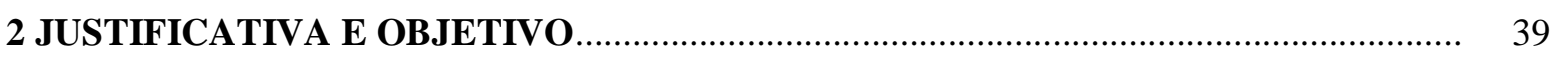

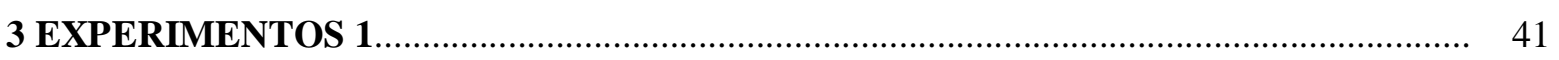

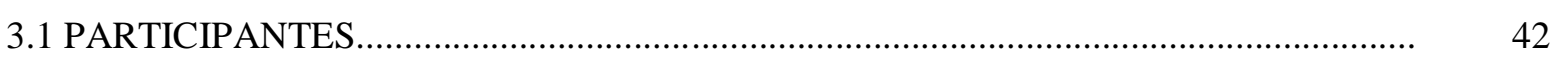

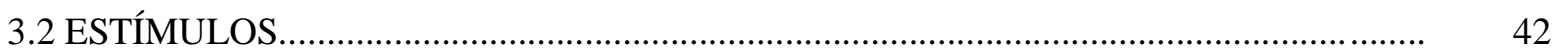

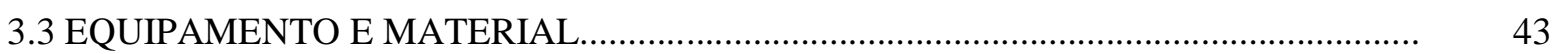

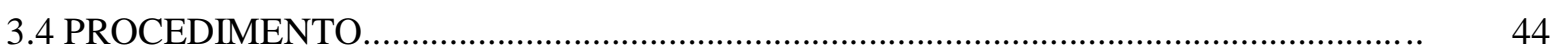

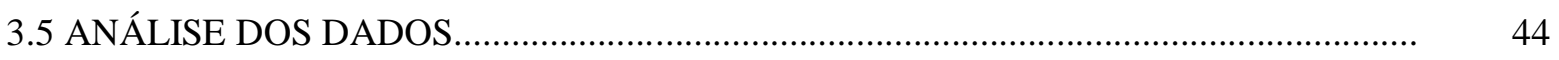

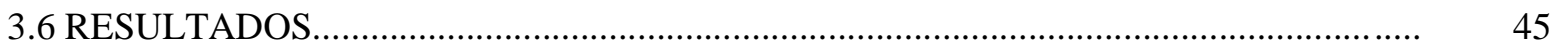

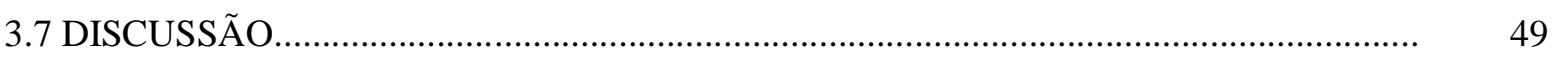

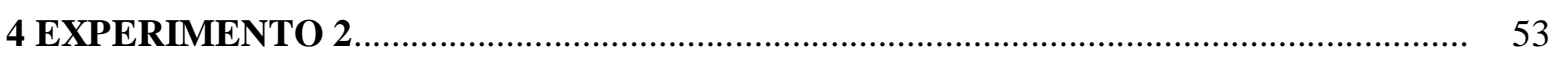

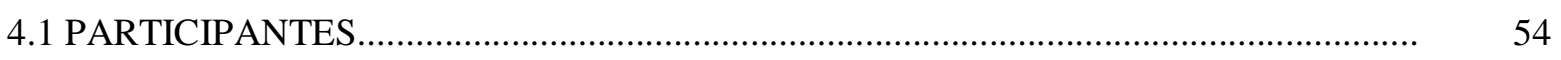

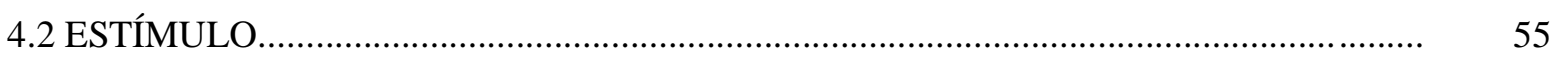

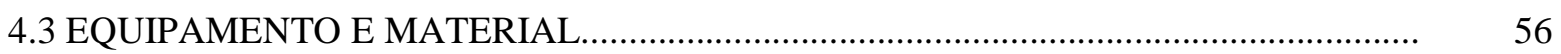

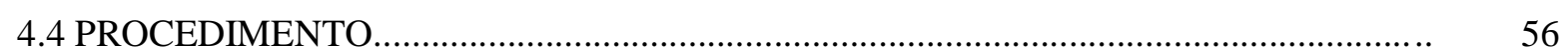

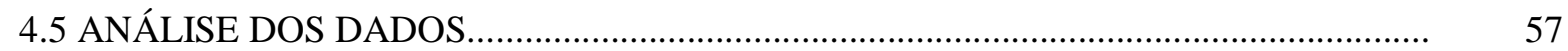

4.5.1 Análise da estimativa verbal do tempo de manipulação e do tempo real de manipulação dos estímulos...................................................................... 57

4.5.2 Análise das filmagens das manipulações e das categorias de manipulação dos

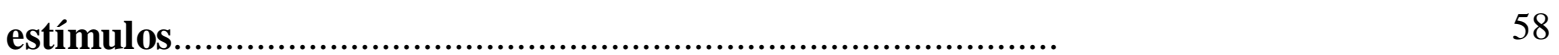

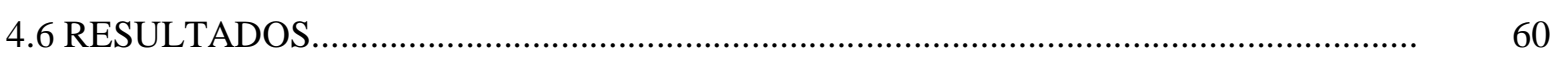

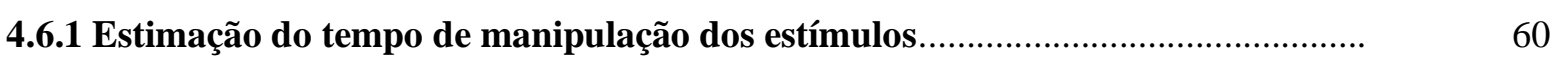

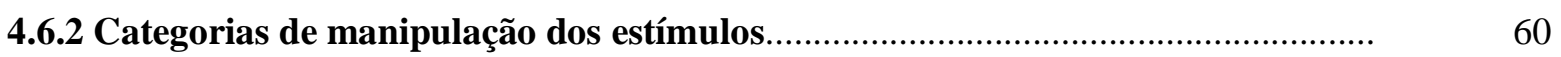

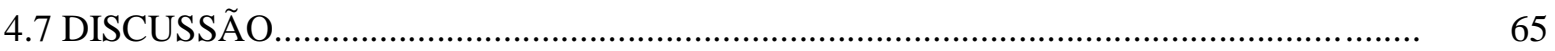

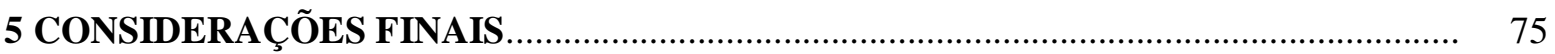

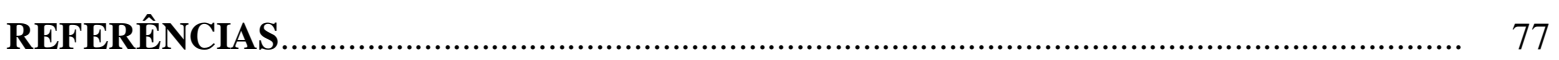

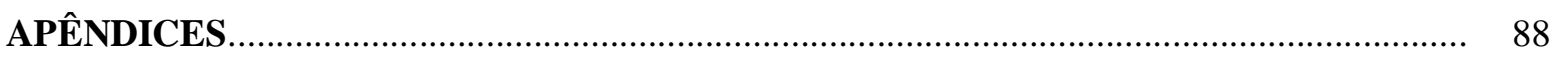

ANEXOS 



\section{INTRODUÇÃO}

Quer estejamos conscientes ou não, o tempo desempenha um fator essencial na vida, seja explícita ou implicitamente, ele determina o movimento humano, compõe as ações do indivíduo no mundo. Neste contexto, a subjetividade assume papel importante, pois a partir dela é que o tempo ganha sentido e significado, e a realidade vai sendo constituída. Assim, a percepção subjetiva do tempo torna-se fundamental para a concepção da realidade, traçando uma distinção entre o decurso temporal dos muitos eventos vivenciados ao longo da vida, o que implica, portanto, que o processamento da informação temporal é imprescindível no cotidiano.

Investigações a respeito da percepção do tempo têm sido realizadas, de modo que as experiências subjetivas de percepção temporal são especialmente apresentadas em termos da lembrança da duração de uma experiência vivenciada ou da estimação da duração de algo que está sendo vivido. Dentro destes paradigmas, diferentes modelos de tempo subjetivo são propostos na tentativa de explicar como o tempo é percebido pelos indivíduos. Nesta linha, os principais modelos apresentam em comum a concepção de que fatores perceptivos e psicológicos estariam envolvidos no processo de estimação temporal.

Um campo de pesquisa que tem se dedicado a investigações a respeito do tempo subjetivo é a estética experimental, originalmente definida por Gustav Fechner em 1876. De acordo com Berlyne (1974) a Nova Estética Experimental estuda obras de arte ou outros fenômenos estéticos através de experimentos, na qual um experimentador sistematicamente manipula atributos das obras, visando verificar quais são seus efeitos sobre algum aspecto do comportamento do indivíduo. Assim, sua característica essencial é a análise das propriedades estruturais ou formais da obra relacionadas com questões de ordem motivacional e cognitiva. Nesta linha de estudo se encontram trabalhos que partem de uma perspectiva psicológica para abordar a questão do tempo subjetivo, estabelecendo ligações com fenômenos estéticos, e assim, utilizam de diferentes modalidades de estímulos, apontando que determinadas características dos mesmos podem alterar a percepção temporal.

Nas artes visuais e na música, a utilização de atributos das obras tem sido usada na busca por identificar fatores que afetam a experiência subjetiva do tempo. Por intermédio de distintos modelos de tempo subjetivo é possível explicar, por exemplo, porque na comparação de fotografias de objetos artísticos tridimensionais apresentando diferentes representações de movimento, expostos para apreciação durante o mesmo intervalo de tempo, algumas são 
percebidas como tendo maior tempo de exposição ou menor tempo do que a outra. Ou ainda, é possível propor hipóteses que expliquem porque uma música desagradável pareceu ter durado mais que o seu tempo real de apresentação.

Considerando trabalhos que intentam explorar fatores que afetam a experiência subjetiva de tempo através do contato com obras de arte, é possível levantar a questão de que para além dos aspectos estáticos da obra, a interação direta com ela poderia alterar a percepção temporal, isto é, a possibilidade de manipular uma obra de arte afetaria a percepção subjetiva do tempo?

$\mathrm{Na}$ linha da estética experimental uma obra de arte pode ser estudada através de diferentes parâmetros de análise, por meio da observação do comportamento não-verbal, através de julgamentos e relatos expressos verbalmente. Entretanto, pouco se sabe a respeito da relação entre manipulação de uma obra de arte e percepção subjetiva do tempo.

Frente a isto, é possível considerar a proposta inovadora apresentada pelo movimento artístico neoconcretista, que se destacou no Brasil a partir da metade do século XX, que enfatizava a arte enquanto campo aberto à experimentação, capaz de estabelecer um envolvimento entre artista, obra e público. Dentre os artistas expoentes deste movimento está Lygia Clark.

Lygia Clark considerava que a obra de arte só teria significado na relação com o participante (não mais espectador) através da manipulação no aqui e agora, tornando a experiência multissensorial. Deste modo, a artista produz a série "Bichos", que são esculturas que permitem o movimento em resposta à ação do participante, portanto, podem ser exploradas manualmente. Entretanto, não foi encontrado na literatura nada sobre a representação temporal que a atividade exploratória de suas obras poderia suscitar.

No que tange à atividade exploratória, há um amplo escopo de pesquisas que apontam a influência de propriedades específicas dos estímulos que influenciariam diretamente a atividade exploratória. No entanto, como essa relação se daria em condições nas quais os participantes do estudo apresentassem alterações dos padrões motores, como os observados em pessoas com Doença de Parkinson (DP)?

É solidamente estabelecido que a DP é uma patologia crônica e progressiva do sistema nervoso central que atinge principalmente o sistema motor, o que repercute diretamente na resposta motora das pessoas acometidas por ela, e claro, que vai implicar em alteração da atividade de manipulação de objetos. Além deste aspecto, estudos indicam que o mecanismo neural afetado na DP estaria intimamente envolvido na percepção do tempo. Levando em conta estes fatores, é que investigações tem buscado esclarecer o processo de percepção do tempo em indivíduos com DP relacionando-o a atividade motora. 
Assim, proposta deste trabalho foi examinar os efeitos da manipulação de uma obra de arte móvel sobre o tempo subjetivo em indivíduos que apresentam o diagnóstico de DP, e contribuir com estudos da percepção subjetiva do tempo em humanos.

Para tanto, foram realizados dois experimentos. No primeiro, estudantes de pós-graduação avaliaram modelos de obras de arte da série "Bichos" de Lygia Clark, sendo que a finalidade do estudo foi identificar como os sujeitos julgam os atributos estruturais da obra. No segundo experimento, participantes com diagnóstico de DP manipularam reproduções alteradas de obras da série e artista citadas e realizaram a estimação temporal verbal da duração de suas atividades de manipulação. Os experimentos foram realizados de acordo com os procedimentos e abordagens da nova estética experimental e paradigmas metodológicos propostos nas pesquisas de tempo subjetivo.

Portanto, serão discutidos a seguir, alguns aspectos de como a percepção subjetiva do tempo vêm sendo estudada (1), apresentando estudos realizados no campo da estética experimental com destaque para aqueles que envolvem a percepção do tempo e a exploração de obras de arte (2). Foi elaborada uma discussão sobre a obra de Lygia Clark, conhecida por defender que o trabalho artístico deveria ser uma experiência multissensorial. Foi também enfatizada a série "Bichos", cuja proposta é possibilitar a interação do expectador com a obra (3). E, no sentido de considerar a Doença de Parkinson no campo de estudos da percepção do tempo e da atividade motora, é que estes assuntos foram discutidos (4). 


\subsection{PERCEPÇÃO SUBJETIVA DO TEMPO}

O tempo se apresenta como um fator essencial na vida, de modo que a percepção subjetiva do tempo é fundamental para a concepção da realidade e permite distinguir o curso temporal dos eventos vivenciados. Muitos comportamentos no cotidiano dependem, portanto, de um adequado processamento da informação temporal (Allman \& Meck, 2012; Merchant, Luciana, Hooper, Majestic, \& Tuite, 2008).

Investigações a respeito da percepção do tempo têm sido realizadas, de modo que as experiências subjetivas de percepção temporal são especialmente apresentadas de acordo com dois paradigmas diferentes: o prospectivo e o retrospectivo. No paradigma prospectivo, o indivíduo sabe antecipadamente que será solicitado a realizar a estimação do tempo, apresentando desta forma, a duração de algo que está sendo vivenciado no momento presente (Zakay \& Block, 2004). Considerando esta consciência da necessidade do julgamento do tempo, Block (1990) se referiu a este paradigma como a "duração experienciada". No paradigma retrospectivo, distintamente, o indivíduo não sabe que será solicitado a realizar a estimação temporal, apresentando, assim, a duração recordada de algo que já aconteceu (Zakay \& Block, 2004). Como neste paradigma o indivíduo somente toma conhecimento da necessidade de julgar a duração após esta ter acabado, Block (1990) considera que a estimação temporal é baseada principalmente em informações recuperadas da memória, e, portanto, seria a "duração lembrada". Vários estudos investigam os efeitos destes diferentes paradigmas na percepção subjetiva do tempo (Block, 1978, 1985; Block \& Reed, 1978; Brown, 1995; Brown \& Stubbs, 1992; Hicks, Miller, \& Kinsbourne, 1976).

Para Gibson (1975), não existe a percepção do tempo como tal, mas somente a percepção de eventos e movimentos que ocorreriam em um ambiente que é rígido e permanente. Em direção semelhante, Fraisse (1984) afirma que a noção de tempo pode ser aplicada ao conceito de duração, que seria o intervalo entre dois eventos sucessivos, não existindo por ela mesma, mas como característica intrínseca daquilo que perdura.

Os processos subjacentes ao julgamento de duração prospectiva diferem daqueles subjacentes ao julgamento de duração retrospectiva. No primeiro a quantidade de atenção deslocada para o tempo ganha proeminência para a estimação temporal (Block \& Zakay, 1996; Zakay \& Block, 2004). No segundo, a atenção assume outro caráter, e a estimação é

principalmente associada com processos de memória, ou seja, é baseada na informação temporal que tenha sido processada e armazenada como parte de uma estrutura temporal 
geral, na qual sequências de eventos e experiências são organizadas (Block \& Zakay, 1996; Zakay \& Block, 2004).

Brown (1985), ao investigar o componente atencional nos dois paradigmas apresentados, encontrou que os participantes submetidos à condição prospectiva demonstram monitorar ativamente os sinais temporais, e prestam maior atenção a passagem do tempo. Em contraste, os participantes sob a condição retrospectiva, processam os sinais temporais de modo mais incidental, como parte de informações básicas extraídas do fluxo normal e contínuo dos eventos. No entanto, informações não temporais, como o envolvimento em tarefas que demandam maior processamento cognitivo e que conduzem a atenção para longe dos sinais temporais, minimizam a consciência do tempo, e afetam tanto a condição prospectiva, quanto à retrospectiva.

Grondin (2010) destaca que, de modo geral, a memória está envolvida tanto no paradigma prospectivo, quanto no retrospectivo, pois é preciso lembrar a duração de um evento ou atividade, o que compreende dois processos principais, sendo um a localização, que utiliza de associações contextuais para julgar os eventos, e o outro processo é a distância, que envolve estimar a quantidade de tempo que decorreu entre o evento experienciado e o momento presente, ou a relativa recência de dois eventos passados.

Alguns métodos têm sido propostos para avaliar as estimações temporais, e a adequação de cada um depende da extensão da duração investigada. São quatro os principais métodos: (1) estimação verbal: acarreta na apresentação de um intervalo alvo e em solicitar ao participante que realize uma estimação verbal da duração usando unidades temporais, como segundos ou minutos, isto é, que o participante traduza uma duração vivenciada (duração subjetiva) em unidades cronométricas (duração objetiva); (2) reprodução: um experimentador apresenta um intervalo alvo e o participante deve reproduzir a duração do intervalo através de alguma operação, como por exemplo, pressionando um botão para marcar a duração que é julgada equivalente ao intervalo alvo; (3) produção: o experimentador especifica um intervalo alvo em unidades temporais, então, o participante produz este intervalo, geralmente batendo com os dedos em uma superfície marcando o início e o fim do intervalo. Neste método, o indivíduo traduz uma duração objetiva para uma duração experienciada subjetivamente; (4) método de comparação: basicamente consiste no fato de que o participante deve julgar a duração relativa de intervalos apresentados sucessivamente e indicar se um foi mais longo ou mais curto do que o outro, ou apontar se o segundo intervalo foi mais curto ou mais longo do que o primeiro. Este método geralmente é usado em 
investigações de mecanismos que envolvem o processamento de intervalos temporais breves (Grondin, 2008, 2010).

No campo da percepção temporal tem-se enfatizado a distinção entre intervalos acima e abaixo de 1 segundo. Segundo Grondin (2010) a diferença fundamenta-se principalmente no fato de que o processamento de intervalos mais curtos são baseados em componentes sensoriais ou em processos fisiológicos automáticos, enquanto o processamento de intervalos mais longos requer um suporte de recursos cognitivos, tais como memória e atenção.

Assim, para explicar como o tempo é percebido pelos indivíduos, diferentes modelos de percepção do tempo são propostos, os principais se enquadram em duas diferentes abordagens: a abordagem de processamento sensorial e a abordagem de processamento cognitivo (Block \& Zakay, 1996).

Os modelos de processamento sensorial postulam que um tipo de tempo-base, repetitivo e cumulativo, seria armazenado em forma de pulsos por um dispositivo que, então, geraria sinais internos de tempo. Este mecanismo constituiria um "órgão do tempo" (Block \& Zakay, 1996), chamado de "relógio interno" (Church, 1984; Gibbon \& Church, 1984; Gibbon, Church, \& Meck, 1984; Treisman, 1963).

O relógio interno é originalmente composto de uma estrutura que considera tanto a percepção quanto a produção do tempo. Nele, um marca-passo (pacemaker) gera pulsos regularmente e quando um sinal de tempo externo é percebido, um interruptor (switch) permite que os pulsos passem até um acumulador (accumulator). O número total de pulsos que determinará a duração percebida é então transferido para a memória de trabalho, que faz a comparação com o conteúdo da memória de referência que armazena um número aproximado de pulsos acumulado em experiências anteriores. Quando os dois valores são correspondentes o bastante, uma estimativa do tempo é realizada, entretanto, a vivência do tempo pode ser dilatada ou comprimida pela memória de trabalho, por componentes atencionais e por processos decisionais (Church, 1984; Gibbon \& Church, 1984; Gibbon et al., 1984; Treisman, 1963).

Segundo Meck (1984), o número de pulsos acumulados é dependente do grau de atenção atribuído a duração, assim, em tarefas que apresentam características temporais e não temporais a atenção é compartilhada e a tendência é que a estimação da duração seja considerada como mais curta do que realmente é, presumivelmente devido à atenção ter sido desviada do componente temporal. Para Allman, Teki, Griffiths e Meck (2014), o funcionamento do relógio interno pode ser influenciado por fatores sensoriais, psicológicos e fisiológicos. 
Estes circuitos envolvidos na contagem do tempo compreendem não somente aqueles compreendidos na acumulação de pulsos, mas também naqueles implicados com a manutenção da atenção e recursos de memória para o tempo, e também, para o monitoramento e reatribuição destes recursos entre tarefas (Allman et al., 2014; Buhusi \& Meck, 2009; Rijn, Kononowicz, Meck, Ng, \& Penney, 2011). Estudos de neuroimagem em humanos sugerem que tarefas de contagem do tempo envolvem circuitos cerebrais tipicamente atuantes em processos de atenção e memória de trabalho (Coull \& Nobre, 2008; Coull, Nazarian, \& Vidal, 2008; Livesey, Wall, \& Smith, 2007; Lustig, Matell, \& Meck, 2005).

Quanto aos modelos de processamento cognitivo, eles consideram que fatores psicológicos associados à quantidade de informação, conteúdo mental e mudanças contextuais presentes nos estímulos estejam envolvidos no processo de estimação temporal, desta maneira, existiria uma relação direta entre o tempo estimado e os processos de memória e atenção (Block \& Zakay, 1996). Os principais modelos são:

(1) O Modelo da Atenção (Block \& Zakay, 1997; Thomas \& Brown, 1974; Thomas \& Weaver, 1975; Underwood, 1975; Vroon, 1970) que propõem que a percepção do tempo está relacionada com o grau de atenção que uma tarefa demanda, de maneira que a atenção é dividida entre o processamento de informações temporais e não temporais. Assim, se maior é a exigência para os componentes não temporais da tarefa, menos atenção é atribuída ao componente temporal e o tempo será julgado como menor do que realmente é. Explicações teóricas para estes efeitos enfatizam a limitada capacidade atencional, várias tarefas realizadas ao mesmo tempo e a alocação de recursos de processamento cognitivo (Brown, 1997; Zakay \& Block, 2004).

(2) O modelo do armazenamento (Ornstein, 1969) propõe que o julgamento do tempo é uma função da quantidade de espaço armazenado na memória de um evento que ocorreu durante um intervalo, isto é, a estimação temporal está diretamente relacionada com o esforço para armazenamento na memória; este, por sua vez, está diretamente relacionado com o número e complexidade da informação apresentada em um intervalo de tempo, deste modo, o julgamento temporal será superestimado se o conteúdo da informação for mais complexo.

(3) O modelo da Mudança Contextual (Block, 1985, 1990; Block \& Reed, 1978) afirma que a duração estimada é uma construção cognitiva influenciada por mudanças contextuais do organismo, como mudanças emocionais, ou da situação do ambiente e outros elementos contextuais, que são codificadas na memória durante um período de tempo. Deste modo, se 
mais mudanças contextuais são resgatadas na memória, a duração lembrada será superestimada.

(4) O modelo de Expectativa (Boltz, 1989; Jones \& Boltz, 1989) considera que a duração estimada é determinada pela estrutura do evento a ser julgado. Eventos altamente coerentes que apresentam características do intervalo de tempo marcado por um início e fim não arbitrário, e que os vários níveis de estrutura se entrelaçam e se interrelacionam de modo previsível, como por exemplo, uma melodia, cujo conteúdo é altamente organizado e o fluxo é ininterrupto, são julgados em termos de se seu fim confirma ou viola as expectativas. Entretanto, eventos menos coerentes que se desenrolam de modo mais arbitrário e sem previsibilidade em seu arranjo estrutural, que pode ser exemplificado por uma leitura desorganizada e frequentemente interrompida, são julgados a partir de estratégias mnemônicas que promovem uma organização e integração dos eventos dentro de um intervalo de tempo particular (Ver também o Modelo da Fração de Desenvolvimento Esperado de Firmino e Bueno, 2008, 2016).

Assim, considerando os diferentes paradigmas, os vários métodos de mensuração das estimativas temporais e os distintos modelos de percepção do tempo, vários estudos foram realizados utilizando de diferentes recursos, tais como sinais sonoros (Thomas \& Brown, 1974), visuais (Brown, 1995; Thomas \& Weaver, 1975) e tarefas com distintos níveis de demandas cognitivas (Block \& Reed, 1978; Brown, 1985, 1997) para investigar a questão de como o tempo é percebido pelos indivíduos.

Há também trabalhos que buscam compreender a influência da apreciação artística sobre a experiência temporal, para tanto, utilizaram obras de arte como, por exemplo, música (Bueno \& Ramos, 2007; Cocenas-Silva, Bueno, Molin, \& Bigand, 2011; Droit-Volet, Ramos, Bueno, \& Bigand, 2013; Firmino \& Bueno, 2008, 2016), imagens de pinturas e esculturas (Nather \& Bueno, 2006a; Nather, Bueno \& Bigand, 2013). Estes estudos fazem parte de um campo de pesquisa denominado de Nova Estética Experimental (Berlyne, 1974), que será discutido a seguir. 


\subsection{ESTÉTICA EXPERIMENTAL E A PERCEPÇÃO DE TEMPO}

Fenômenos estéticos se fazem presentes nos mais variados contextos, podem se estender da matemática ao trabalho doméstico. Tudo na vida tem seu lado estético, no entanto, neste contexto, as obras de arte ganham destaque especial e são amplamente estudadas com a finalidade de se compreender a questão da percepção estética do observador em contato com a obra, contato este que gera respostas que podem ser analisadas (Berlyne, 1974; Bueno, 1985; Fraisse, 1984), deste modo, duas são as linhas de pesquisas principais que se propõem a explicar o fenômeno estético, são elas: a Estética Especulativa e a Estética Empírica (Berlyne, 1974).

A Estética Especulativa depende fortemente da dedução e visa principalmente à definição de conceitos, princípios e proposições que são elaborados a partir do exame interpretativo de textos e amostras de arte. Já a Estética Empírica, que é de particular importância para o escopo deste trabalho, se utiliza de métodos controlados, que implica na observação sob determinadas circunstâncias para verificar efeitos sobre formas de comportamento que se centram em fenômenos estéticos (Berlyne, 1974).

Segundo Berlyne (1974), um ramo proeminente da Estética Empírica é a Estética Psicobiológica, que partindo de um ponto de vista biológico, aplica os métodos das ciências empíricas (procedimentos de amostragem, projeto de pesquisa e análise estatística de dados) à investigação de condições observáveis que possam influenciar o comportamento, para deste modo, chegar a novos conhecimentos sobre os processos psicológicos envolvidos na criação e apreciação de obras de arte.

Uma parte da Estética Psicobiológica é a Estética Experimental, que foi fundada por Gustav Fechner em 1876 e após sua revigoração com novas abordagens, técnicas, objetivos e novas idéias oriundas de variadas fontes, foi apropriadamente denominada de Nova Estética Experimental, que de acordo com Berlyne (1974), estuda obras de arte ou outros fenômenos estéticos através de experiências, na qual um experimentador sistematicamente manipula fatores causais, visando verificar quais seus efeitos sobre algum aspecto do comportamento do indivíduo.

Por consequência, sua característica é a análise das relações entre variáveis independentes (trechos de músicas, pinturas, esculturas, etc.) e variáveis dependentes (relatos verbais, medidas psicofísicas e comportamentais, etc.), de maneira que os experimentos podem ser feitos através de duas abordagens: a abordagem analítica, que estuda as reações 
frente a obras de arte autênticas (originais) ou reproduções dos mesmos, como o uso de uma pintura, e a abordagem sintética, que seleciona e manipula fatores particulares da obra que podem influir na apreciação artística, como as cores (matriz predominante) e traços presentes numa imagem (Berlyne, 1974).

Com tais características, a Estética Experimental entende que uma obra de arte pode ser considerada como um estímulo padrão e analisada nos termos de seu conteúdo de informação implícito, sendo descrita em relação a sua expressividade, cultura, sintática e semântica, e considera que a obra possui propriedades colativas que se referem a atributos estruturais em torno de dimensões como, por exemplo, familiar-estranho e simples-complexo, deste modo, leva-se em conta o que a obra representa e o que está para além dela (Berlyne, 1974).

CupChik e Berlyne (1979) referem que o termo "propriedades colativas" tem a função de descrever os efeitos das comparações entre elementos que são apresentados simultaneamente ou em sequência, e ilustram trazendo o seguinte exemplo: quanto maior o nível de incongruência de estímulos apresentados de modo sucessivo, maior a quantidade de informação contida, o que pode aumentar o estado de excitação do indivíduo e contribuir para que o mesmo seja percebido como novidade ou surpreendente.

Uma maneira de realizar a análise das propriedades estruturais dos estímulos é através do uso de escalas de diferencial semântico, que possibilitam o julgamento dos objetos artísticos e permitem ressaltar quais são os atributos mais relevantes e evidentes no encontro da obra de arte com o observador, assim, o estudo da relação entre as diferentes propriedades presentes em um trabalho artístico pode auxiliar a isolar os predicados mais significativos e determinar dimensões de análise (Nather \& Bueno, 2006b).

Neste sentido, de acordo com Berlyne (1974) três fatores podem ser estudados: colativos, valor hedônico (prazer) e potencial de excitação (arousal). O primeiro, referindo-se a propriedades que influenciam na compreensão da obra; o segundo relacionado à apreciação do trabalho artístico; e o terceiro associado a alterações internas provocadas nos indivíduos a partir do contato com o estímulo.

Em estudos da estética experimental Berlyne e colaboradores realizaram uma série de pesquisas (Berlyne, 1957, 1958, 1961, 1963, 1973; Berlyne, Craw, Salapatek, \& Lewis, 1963; Berlyne \& Crozier, 1971; Berlyne, Ogilvie, \& Parham, 1968; Berlyne \& Peckham, 1966; CupChik \& Berlyne, 1979) utilizando diferentes escalas de diferencial semântico, estabelecendo critérios controlados de experimentação, nos quais, se coletou julgamentos ou relatos verbais e não verbais referentes às impressões dos participantes expostos a obras de 
arte (pinturas, principalmente), de maneira que, seus trabalhos enfatizaram o tempo despendido para observação dos estímulos através da análise do tempo de exploração e da escolha exploratória. Sendo que o primeiro consistia em permitir ao indivíduo observar um estímulo pelo tempo que desejasse. E o segundo, se referia a escolher um entre dois estímulos apresentados simultaneamente para que pudesse observá-lo novamente.

Os métodos experimentais utilizados por Berlyne e seus colaboradores, contribuíram para esclarecimentos a respeito da percepção estética e revelaram que propriedades colativas como incongruência, novidade e entropia aumentam a curiosidade exploratória e podem alterar o nível de excitação (arousal) do organismo (Berlyne, 1957, 1961). Mostraram também que o maior nível de complexidade presente em uma imagem acarreta em maior tempo de observação e numa tendência para considerá-la mais interessante, entretanto, como despertando menos prazer (Berlyne, 1958, 1963; Berlyne \& Crozier, 1971; Berlyne et at., 1968). E segundo Berlyne (1963) a complexidade da obra seria o atributo mais evidente no encontro com o trabalho artístico e seria processado no início da interação obra-observador, produzindo um efeito sobre o fator hedônico.

Além disto, Berlyne (1963) encontrou que no contato com a obra, inicialmente o indivíduo é dirigido pela curiosidade, buscando explorá-la para reunir informação e diminuir a incerteza podendo, posteriormente, analisar mais detalhes, optando por moderadas quantidades de estimulação e, de modo geral, haveria uma preferência por aqueles trabalhos artísticos considerados com maior nível de agradabilidade, porque estes poderiam ser melhor organizados perceptualmente, resultando em uma prazerosa atividade de percepção.

E ainda investigando como se processa a interação expectador-obra de arte, CupChik e Berlyne (1979), utilizando das abordagens analítica e sintética, analisaram a percepção de participantes frente às propriedades colativas de imagens de pinturas incluídas na coleção da Galeria de Arte de Ontário. Nos experimentos foram apresentados, por durações que variavam de 50 a 5.000 milissegundos, pares de pinturas e reproduções padrões artificiais para que os participantes fizessem julgamentos verbais, que eram avaliados segundo escalas. Logo, as escalas de diferencial semântico adotadas pertenciam a três fatores: colativos (simplescomplexo e desordenado-ordenado), afetivas de estado interno (sonolento-alerta e relaxadotenso) e valor hedônico (prazeroso-não prazeroso). O procedimento permitiu verificar como o tempo de visualização de propriedades comuns das pinturas influencia no impacto estético das imagens.

Com relação a isto, CupChik e Gebotyes (1988) ressaltam que a percepção do fenômeno estético mudaria na mente do indivíduo durante o curso do contato com a obra de 
arte, de maneira que a agradabilidade (prazer) estaria diretamente implicada na compreensão do estímulo apresentado e a duração do episódio estético determinaria o tempo empregado em atividades cognitivas.

A experiência de tempo no contexto de fenômenos estéticos tem se constituído em um vasto campo de pesquisa na busca por esclarecer como a interação com a obra de arte pode repercutir sobre a percepção subjetiva do tempo. Nesta linha, se encontram trabalhos como o de Bueno (1985; ver também, Bueno \& Engelmann, 1976; Bueno, Firmino, \& Engelmann, 2002) que foi o primeiro no Brasil a abordar a questão do tempo em uma perspectiva psicológica.

O Centro de Estética Experimental da Universidade de São Paulo, em Ribeirão Preto, tem desenvolvido um programa de pesquisas utilizando como estímulos obras de arte para tratar a questão do tempo subjetivo. Os eixos de pesquisa neste centro envolvem, até o momento, música e artes visuais.

Na área da música, Firmino e Bueno $(2008,2016)$ desenvolveram o Modelo da Fração de Desenvolvimento Esperado (FDE), que prevê estimações temporais para quaisquer durações preenchidas por quaisquer modulações tonais e explica porque estas eliciam subestimações do tempo em função inversa do aumento da distância intertonal, com impacto maior para modulações súbitas (Ver também, Firmino, Bueno, \& Bigand, 2009).

Na mesma área, Ramos e Bueno (2012a; 2012b) realizaram estudos nos quais trechos musicais do repertório erudito ocidental foram utilizados como estímulos, no intuito de verificar associações com categorias emocionais (Alegria, Tristeza, Serenidade ou Medo/Raiva) e se a percepção subjetiva do tempo de músicos e não músicos seria afetada por algum componente emocional presente durante a escuta musical. Verificaram que as associações dos trechos musicais com as categorias de emoções foram semelhantes entre os grupos, embora as respostas dos músicos tenham sido mais consistentes (Ramos e Bueno, 2012a) e que enquanto os não músicos apresentaram subestimações temporais associadas à pelo menos um trecho musical de cada uma das categorias emocionais, os músicos subestimaram todos os trechos musicais tristes (Ramos e Bueno, 2012b. Ver também DroitVolet, Bigand, Ramos, \& Bueno, 2010; Droit-Volet, Ramos, Bueno, \& Bigand, 2013).

Ainda na área da música, Cocena-Silva, Bueno, Bigand, \& Molin (2009) e CocenasSilva, Bueno, Molin, \& Bigand, (2011) investigaram a percepção subjetiva do tempo durante a apreciação de música erudita ocidental dos repertórios barroco, clássico, romântico e moderno através de uma análise multidimensional, visando identificar fatores psico-musicais que governam a avaliação temporal. Encontraram que os trechos musicais com alto nível de 
excitação (arousal) levaram os participantes a superestimar o tempo, e a valência afetiva não apresentou influência na percepção temporal. A duração foi também superestimada pelos participantes quando o tempo e sonoridade foram maior. A tensão musical apresentou pouca influência.

$\mathrm{Na}$ área das artes visuais, Nather e Bueno (2006a, 2006b, 2011, 2012a, 2012b) realizaram uma série de estudos com a finalidade de examinar como imagens fotográficas de pinturas e esculturas com diferentes representações de movimento afetavam a percepção do tempo e concluíram que a sugestão de movimento numa imagem estática alonga a experiência temporal (Ver também Nather, Bueno, \& Bigand, 2013; Nather, Bueno, Bigand, \& DroitVolet, 2011; Nather, Fernandes, \& Bueno, 2014; Nather, Mecca, \& Bueno, 2013).

Nather e Bueno (2006a) utilizaram fotografias de dois objetos artísticos tridimensionais, visando verificar se o maior ou o menor movimento representado em uma imagem estática afetaria a estimação subjetiva do tempo. As imagens fotográficas dos objetos tridimensionais utilizados foram feitas em ângulos com maior ou menor sugestão de movimento. Cada um dos estímulos foi apresentado ao participante por um tempo de 36 segundos, sendo que ao final do mesmo, o participante deveria reproduzir a duração temporal que considerava ser igual àquela da apresentação da imagem, para tanto deveria utilizar o teclado de um computador posicionado sobre a mesa a sua frente. Ao término da tarefa o participante realizava a estimação verbal do tempo de duração da apresentação dos estímulos. Os resultados encontrados mostraram que a sugestão de movimento numa imagem estática altera a percepção subjetiva de tempo. Nas reproduções temporais a duração da apresentação do estímulo com menor sugestão de movimento foi subestimada quando comparada ao tempo de exposição do estímulo com maior sugestão de movimento. Os julgamentos verbais apontaram resultados semelhantes, indicando uma tendência de os participantes subestimarem temporalmente o estímulo sem sugestão de movimento em relação ao estímulo com sugestão de movimento.

Diferentes estudos na área da estética experimental utilizam obras de arte genuínas (Bueno \& Ramos, 2007; Cocenas-Silva et al., 2011; Droit-Volet et al., 2013; Firmino \& Bueno, 2016; Firmino et al, 2009; Nather \& Bueno, 2006a; Nather, Bueno, \& Bigand, 2013; Nather et al., 2014; Nather, Mecca, \& Bueno, 2013). Berlyne (1974) enfatiza a importância para o desenvolvimento da estética experimental de estudos com abordagem analítica, que preservam as características genuínas da criação artística. Estes estudos têm apontado importantes aspectos de como se processa o encontro de um indivíduo com obras de artes e têm concordado que determinados fatores ou características das obras artísticas possuem 
atributos que podem ser identificados e processados de maneira semelhante. Estes trabalhos vêm revelando mecanismos internos de apreciação estética e os processos psicológicos subjacentes a estes episódios, incluindo a percepção temporal. No entanto, estas pesquisas acabam por permanecer na área da música e nas artes visuais bidimensionais e não levam em conta o caráter tridimensional das artes plásticas e possibilitar o contato direto com a mesma, como é o caso de se poder manipular um trabalho artístico. Nesta interação direta com a obra,os componentes temporais podem exercer algum nível de influência.

Davidson, Abbott e Gershenfeld (1974) realizaram uma pesquisa na qual os participantes deveriam explorar esculturas padrões, através do manuseio e da visão, e compará-las com esculturas correspondentes, e observaram que o aumento do tempo de exploração das esculturas melhorava a comparação entre elas. Contudo, nesta pesquisa a ênfase estava na precisão de julgamento e nos diferentes movimentos utilizados pela mão para explorar uma obra tridimensional durante um determinado tempo, e assim, não se considerou a percepção do tempo durante a manipulação do estímulo, e a partir disto, questiona-se como a possibilidade de manipular uma obra tridimensional afetaria a percepção subjetiva do tempo.

No que tange a interação público-obra de arte, a artista brasileira Lygia Clark,que integrou o movimento neoconcreto que surgiu no Brasil por volta da década de 60, apresenta um repertório de trabalhos que traz como proposta fundamental o convite para que o observador deixe a condição passiva de expectador e assuma a postura ativa de agir na e sobre a obra. Este assunto será mais discutido na seção seguinte. 


\subsection{ESCULTURA COMO UM CONVITE A AÇÃO}

O movimento artístico neoconcreto, que se destacou no Brasil por volta de 1957, surgiu como uma crítica e oposição ao caráter racional da arte concreta como um projeto de vanguarda cultural brasileira. Os artistas neoconcretos estavam voltados para uma maior liberdade de ação por parte dos artistas e nas diversas propostas construtivas que essa posição possibilitaria (Brito, 1999). Assim, enfatizavam a arte enquanto campo aberto à experimentação (Medeiros \& Soares, 2009).

Neste sentido, a produção artística foi marcada pelo desafio de diminuir as distâncias entre a criação e sua recepção, pelo desenvolvimento de uma arte que modificasse a relação entre o público e a obra, alterando o papel do espectador, estabelecendo sua transição da mera contemplação à participação ativa (Valdivieso \& Freitas, 2012).

De acordo com Medeiros e Soares (2009), a neovanguarda brasileira apresentava um novo conceito de arte vinculado à cultura e vida cotidiana brasileiras, estabelecendo uma ação cultural capaz de instaurar um envolvimento entre artista, obra e público.

Isto condizia com a teoria do não-objeto, proposta por Ferreira Gullar, um dos expoentes do movimento neoconcreto. Segundo Valdivieso e Freitas (2012), o não-objeto era definido como uma não-representação, cujo significado estaria em si mesmo, sendo marcado por convocar o espectador à ação, retirando-o do papel de testemunha passiva, "sem ele, a obra existe apenas em potência, à espera do gesto humano que a atualize" (Valdivieso \& Freitas, 2012, p. 32).

Assim, colocando em primeiro plano a significação da obra por meio da experiência no espaço circundante e da participação do espectador, o grupo neoconcreto era composto por um conjunto heterogêneo de artistas como Hélio Oiticica, Lygia Pape, Franz Weissmann, Wyllis de Castro, Amílcar de Castro e Lygia Clark (Carvalho, 2011; Salzstein, 2011). Lygia Clark (1920-1988), através de seu ideal e obras, teve um papel fundamental no movimento neoconcretista. Ela iniciou como pintora na década de 50, produzindo pinturas/relevos monocromáticos, a partir de então, seguiu uma tendência própria de esculturas. A evolução do seu trabalho apresentou-se como uma jornada que foi além da relação tradicional entre artista e espectador, na qual tradicionalmente, o artista oferece uma mensagem por meio da obra de arte, e o espectador a acolhe, de modo que o objeto artístico é expressamente construído para ser apreendido pela percepção visual, isolando outros sentidos, e independente do corpo como um todo (Brett, 1994). 
A artista considerava que a obra de arte não era a codificação da expressividade do próprio artista dirigido ao outro como espectador, mas que ela oferecia alguns significados para que o outro se tornasse consciente de sua própria expressividade, em um papel de participante. Assim, os objetos só teriam significado na relação com o participante (não mais espectador) através da manipulação no aqui e agora, tornando a experiência multissensorial (Brett, 1994). Deste modo, em 1959, Lygia cria os "Bichos", apresentando-os ao público em 1960.

A obra os "Bichos", é o nome que a artista deu a placas geométricas, de alumínio anodizado, unidas por dobradiças que possibilitam deslocamentos no espaço criando diferentes formas acionadas pela ação do espectador-participante (Carvalho, 2011). Suas partes são funcionalmente associadas entre si e seus movimentos são interrelacionados (Brett, 1994).

As placas que compõem a obra podem ser de três tipos: triangulares, quadradas e circulares. Cada uma atribuindo particularidades às esculturas. As duas primeiras formas, pontiagudas, denotam ofensividade, perigo, algo de selvagem; já as circulares, bem delineadas, suscitam a um toque harmonioso e aconchegante (Scovino, 2003). Logo, os "Bichos" são exatamente o equilíbrio entre a esquematização racional da geometria e o pulso da vida e natureza. Eles incitam a ação do espectador, de modo que o participante pode pegar o objeto e brincar com ele ou mover as partes metálicas articuladas entre si da estrutura. Portanto, não são restritas ao olhar, podem ser exploradas manualmente (Brett, 1994).

Na concepção da própria artista, a obra os "Bichos" se trata de uma obra viva, um trabalho essencialmente ativo, cuja estrutura permite novos aspectos quando é manipulada. Portanto, o entrelaçamento da ação do participante com a resposta imediata do "Bicho" possibilita um relacionamento (Butler \& Pérez-Oramas, 2014).

Conforme Barbieri (2008), com a série "Bichos", Lygia inicia uma subversão da arte, pois (1) propõe que a obra não seja apenas vista, mas também tocada; (2) insere outros sentidos na experiência estética; e (3) concebe o público-observador como participante coautor da obra.

Segundo Scovino (2003), os "Bichos" são ponto de chegada de uma arte participativa, elevando a natureza da atividade corporal, transformando-a em um novo estado perceptivo. Há uma ampliação da participação e da sensorialidade. Não há passividade. E conforme Carvalho (2011), eles são considerados obras emblemáticas do movimento neoconcreto, expressando as principais ideias do Manifesto Neoconcreto (1959) e da Teoria do Não-Objeto (1960), de Ferreira Gullar. 
Compreendendo que Lygia Clark apresenta uma trajetória artística singular, o seu trabalho se mostra resultado de um longo processo de maturação, onde arte e vida se mesclam, e onde ao longo de seu percurso abandona o objeto arte, dado ao espectador para decifrá-lo, e elege o corpo como o lugar privilegiado para suas proposições. Mediante isto, Carvalho (2011, p. 132) afirma que "a artista subverte a própria arte onde o corpo do espectador passa a ser o suporte de suas proposições, o que leva alguns historiadores a denominarem essas manifestações da artista de 'antiarte ou arte-terapia"'. Por conseguinte, o desenvolvimento do seu trabalho começa com pinturas e segue um continuum que termina na prática de uma forma de psicoterapia (Brett, 1994).

À vista disso, os trabalhos de Clark passam a desconstrução do objeto, e vão pouco a pouco criando uma vasta multiplicidade de proposições sensoriais, nas quais o corpo é o receptáculo e o público atua como criador, "e o próprio ato de criar é o ato de criar a si mesmo, de estar em si, no outro, no coletivo, no mundo..." (Carvalho, 2001, p. 136). E nesta jornada, além dos “Bichos", Lygia cria, dentre outras, obras como Caminhando (1964), Pedra e ar (1966), Eu e o tu: série roupa-corpo-roupa (1967), A casa é o corpo: penetração, ovulação, germinação, expulsão (1968), Baba Antropofágica (1973), e a série Estruturação do self (1976-84).

A partir da passagem do objeto artístico para elemento integrante de uma relação no contato com o outro, a dimensão temporal pode assumir um papel importante, de maneira que pontos de contato podem ser levantados entre a obra de Lygia Clark e aspectos que extravasam a sensorialidade, dessa forma, alcançando o espaço-tempo. E nesta perspectiva, na qual o ato assume o valor de obra, a interação com o objeto artístico pode exercer influência sobre a vivência do tempo, como aquelas observadas no trabalho de Nather e Bueno (2012a), no qual o encontro, com esculturas de bailarinas, produzidas por Edgar Degas, as quais sugerem distintos passos de dança, revela componentes de uma percepção do tempo que se apresenta subjetiva.

Em vista disto, ao se resgatar investigações que buscam identificar fatores que afetam a experiência subjetiva de tempo, além de trabalhos relacionados à apreciação estética, há uma preocupação com como é processada a informação temporal por diferentes indivíduos em diferentes estágios da vida (Bherer, Desjardins, \& Fortin, 2007; Droit-Volet, Meck, \& Penney, 2007; Espinosa-Fernández, Miró, Cano, \& Buela-Casal, 2003; Ferreira, Paiva, Prando, Graça, \& Kouyoumdjian, 2016), em diferentes contextos (Berlyne, 1976; Coulangeon, Ravet, \& Roharik, 2005), em distintos estados emocionais (Angrilli, Cherubini, Pavese, \& Manfredini, 1997; Droit-Volet \& Meck, 2007) e em variadas condições de saúde 
(Allman \& Meck, 2012; Barkley, Koplowitz, Anderson, \& McMurray, 1997; Blewett, 1992; Carroll, Boggs, O’Donnell, Shekhar, \& Hetrick, 2008; Foss-Feig et al., 2010; Harrington et al., 2011). Dentre estas pesquisas, se encontram estudos que buscam compreender como pessoas que apresentam diagnóstico de Doença de Parkinson (DP) percebem a passagem do tempo, sendo este um assunto que será discutido na sequência. 


\subsection{DOENÇA DE PARKINSON E PERCEPÇÃO DO TEMPO}

A Doença de Parkinson foi inicialmente denominada como "Paralisia agitante", por James Parkinson, em 1817. No século XIX Charcot dá crédito a J. Parkinson e passa a denominá-la Doença de Parkinson (DP) (Jankovic, 2008).

A DP é uma patologia do sistema nervoso central, crônica e progressiva, que acomete principalmente o sistema motor (Barbosa \& Sallem, 2005; Sveinbjornsdottir, 2016). Ela é a segunda doença neurodegenerativa mais comum no mundo, com incidência e prevalência aumentando juntamente com mudanças demográficas da população. A sua prevalência em países industrializados é de cerca de $1 \%$ em pessoas com mais de 60 anos de idade (Sveinbjornsdottir, 2016).

A DP é especialmente caracterizada por quatro sinais clínicos: tremor de repouso, rigidez, bradicinesia e instabilidade postural (Jankovic, 2008). Porém manifestações não motoras como distúrbios do sistema nervoso autônomo, alterações do sono, cognitiva e psiquiátrica e sintomas sensoriais também podem estar presentes (Barbosa \& Sallem, 2005; Sveinbjornsdottir, 2016).

O início da doença ocorre frequentemente próximo aos 60 anos de idade, acomete pessoas de diferentes raças e apresenta incidência igual em ambos os sexos. Casos da doença antes dos 40 anos são denominados como parkinsonismo de início precoce (Barbosa \& Sallem, 2005).

A etiologia da doença ainda é obscura, no entanto, supõe-se a participação de vários mecanismos etiopatogênicos como: fatores genéticos, neurotoxinas ambientais, estresse oxidativo, anormalidades mitocondriais, excitotoxidade e outros mecanismos patogênicos que têm sido identificados como fatores que contribuem para a morte de células dopaminérgicas e não dopaminérgicas no cérebro de pacientes com DP (Barbosa \& Salem, 2005; Jankovic, 2008).

A DP apresenta distintas alterações cerebrais neuropatológicas, ocorre a formação de corpos esféricos protéicos anormais denominados de corpos de Lewy, e uma espécie de haste se ramifica do soma das células nervosas envolvidas, começando em locais de indução definidos e avançando em uma sequência topograficamente previsível no interior do sistema nervoso (Sveinbjornsdottir, 2016).

Braak et al. (2003; Braak, Ghebremedhin, Rüb, Bratzke, \& Tredici, 2004) descreve seis estágios neuropatológicos da DP. Nos estágios um e dois (pré-sintomático) ocorre à 
inclusão de corpos de Lewy, que se limita a medula oblonga/tegmento pontino e bulbo olfatório/núcleo olfatório anterior. Nos estágios três e quatro, com a progressão da doença, a substância negra e outros núcleos do mesencéfalo e prosencéfalo são afetados e os sintomas clínicos começam a aparecer. E nos estágios cinco e seis, o processo atinge o neocórtex repercutindo em uma ampla variedade de manifestações clínicas.

A DP apresenta uma perda progressiva de neurônios da parte compacta da substância negra, situada no mesencéfalo. A degeneração destas células é irreversível e tem como consequência a diminuição da produção de dopamina, um neurotransmissor fundamental para o controle dos movimentos. O resultado da deficiência dopaminérgica são alterações funcionais no circuito dos gânglios da base, levando ao aparecimento dos principais sinais e sintomas da doença (Barbosa \& Salem, 2005).

Por apresentar disfunção do sistema dopaminérgico, que é considerado intimamente relacionado com os aspectos internos do tempo, a DP ganha um interesse especial em estudos acerca da percepção temporal, pois indica o mecanismo neural envolvido na percepção do temporal (Allman \& Meck, 2012; Cope et al., 2014; Dušek et al., 2012; Jones, Malone, Dirnberger, Edwards, \& Jahanshani, 2008; Merchant et al., 2008; Perbal et al., 2005; Smith, Harper, Gittings, \& Abernethy, 2007; Wild-Wall, Willemssen, Falkenstein, \& Beste, 2008). Com relação aos mecanismos neurais, evidências apontam que o gânglio basal e sua via tálamo-cortical dependente de dopamina parece desempenhar um papel importante no controle de processos que governam o timing motor e o processamento do tempo (Harrington, Haaland, \& Hermanowicz, 1998), de modo que a sinalização dopaminérgica apresenta um papel importante na acurácia e precisão em tarefas de intervalo de tempo (para uma revisão recente ver Agostino \& Cheng, 2016).

De acordo com Grondin (2010), existem várias estruturas cerebrais subcorticais envolvidas no processamento da informação temporal. O gânglio basal estaria envolvido nos estágios precoces de codificação de intervalos de tempo. Portanto, os núcleos caudado e putâmen seriam ativados por tarefas de tempo. O circuito fronto-estriatal também estaria envolvido, sendo que a hipótese é que as células estriatais receberiam impulsos de neurônios corticais quando um sinal de disparo temporal fosse dado. Quando a atividade de registrar o tempo cessasse após um intervalo de tempo específico, uma mensagem seria enviada da substância negra ao estriato, então, o padrão de ativação no momento seria registrado via liberação (burst) de dopamina e serviria para identificar a duração específica do intervalo.

Buscando identificar os sistemas neurais relacionados com o processamento temporal, Harrington et al. (2011), utilizando de imagem por ressonância magnética funcional (fMRI), 
submeteram indivíduos com DP sob efeitos de medicação (condição ON) e na ausência de efeitos da medicação (condição OFF) a tarefas de percepção do tempo. Nesta tarefa, foram apresentados sucessivamente pares de estímulos visuais e auditivos, e então os participantes deveriam julgar se o segundo estímulo era mais curto ou mais longo do que o primeiro. As durações variaram de $1200 \mathrm{~ms}$ a $1800 \mathrm{~ms}$. Os resultados encontrados revelaram os mecanismos neurocomportamentais de déficits na percepção do tempo apresentados por indivíduos com DP e sua resposta mediante a terapia medicamentosa. Prejuízos na percepção temporal na condição OFF foram associados com ativação anormal no estriato, regiões corticais (área pré-motora, área motora suplementar, giro cingulado, giro pré e pós central, insula, córtex frontal-médio e parietal-inferior e giro parahipocampal) e o cerebelo (lóbulos e vermis). A disfunção neuronal mostrou em alguns momentos uma dinâmica temporal anormal, na qual respostas hemodinâmicas do estriato foram tipicamente atenuadas, mas também temporalmente atrasadas e, algumas vezes, prolongadas. A disfunção estriatal foi consistente com o papel da dopamina em operações de "timekeeping". Identificou-se também atividade prolongada em uma rede da memória de trabalho (córtex frontal-médio e parietal inferior e cerebelar lateral). A terapia medicamentosa não amenizou os déficits na percepção do tempo, apesar de demonstrar benefícios para o sistema motor.

No que se refere às durações percebidas pelos indivíduos, existem indícios de que as áreas neurais ativadas durante o processamento de intervalos de sub-segundos e suprasegundos não são idênticas (Lewis \& Miall, 2003). Enquanto os intervalos de sub-segundos parecem ser processados por um circuito motor, envolvendo o córtex sensório-motor, área motora suplementar e zona intermédia do cerebelo, os intervalos de supra-segundos provavelmente ativam as áreas de processamento cognitivo ou perceptivo como os córtices pré-frontal dorsolateral direito, insular e parietal e hemisfério cerebelar lateral (Lewis \& Miall, 2003; Middleton \& Strick, 1994).

De modo semelhante, investigações sobre os mecanismos neurais de processamento temporal apontam resultados convergentes de estudos em animais e humanos que indicam que a percepção do tempo depende da ativação do circuito cortico-tálamo-estriato-cortical (Matell \& Meck, 2000, 2004; Matell, Meck, \& Nicolelis, 2003; Nenadic et al., 2003), rede neural que também compreenderia o mecanismo relacionado com a ação voluntária (Harrington \& Jahanshahi, 2016). Mediante isto, torna-se importante ressaltar que o tempo é uma faceta básica da representação da ação, uma vez que entra em jogo quando antecipa e guia o timing dos movimentos (Harrington \& Jahanshahi, 2016). 
Entretanto, Harrington e Jahanshahi (2016) afirmam que podem ocorrer distorções da experiência temporal, as quais estariam relacionadas com a interação do circuito corticotálamo-estriato-cortical com vários centros neurais dependendo da situação: estado interno do organismo, experiências passadas, propriedades dos estímulos, controle cognitivo, nível de atenção, emoção e processamento sensorial. Vários estudos relacionando a percepção do tempo a condições contextuais foram realizados (Angrilli et al., 1997; Berry, Li, Lin, \& Lustig, 2014; Eagleman, 2008; Mella, Conty, \& Pouthas, 2011) e apresentam resultados importantes que destacam o processamento temporal como dependente do contexto, e por sua vez também influenciando na ação voluntária (Debaere, Wenderoth, Sunaert, Hecke, \& Swinnen, 2003).

Relacionando percepção do tempo com atividade motora, Torta et al. (2010) realizaram um estudo de abordagem prospectiva, questionando se indivíduos com DP apresentariam alterações em suas habilidades de reproduzir durações de seus próprios atos motores. Os participantes foram agrupados em condições específicas de tratamento: com estimulação cerebral profunda (ECP)/Sem medicação, sem ECP/sem medicação e sem ECP/com medicação.O procedimento proposto consistiu de dois experimentos: no experimento 1 os participantes foram solicitados a julgar a duração de seus próprios desempenhos motores em uma tarefa de reprodução motora. Os participantes sentados em frente a um instrumento, composto de dois parafusos apoiados em um suporte de madeira, deveriam desrosquear uma porca do comprimento total do parafuso localizado a direita do suporte utilizando a mão dominante. Depois, os participantes eram instruídos a realizar um primeiro toque (tap) com a mão sobre a mesa para iniciar a reprodução do intervalo e um segundo toque quando consideravam ter passado o intervalo correto de tempo que levaram para realizar a tarefa motora. $\mathrm{O}$ procedimento foi elaborado para mensurar a precisão do intervalo de tempo de reprodução baseado na própria ação motora prévia. Assim, calculou-se a razão entre o tempo estimado e o tempo real, sendo o resultado designado como precisão de reprodução motora (PRM). A duração real da ação e o tempo estimado foram contabilizados com um cronômetro pelo experimentador. $\mathrm{O}$ experimento 2 consistiu de uma tarefa de reprodução de intervalo, na qual o examinador produzia um intervalo de tempo, tocando (tap) com a mão por duas vezes na mesa e o participante deveria reproduzido o intervalo entre os toques usando o mesmo procedimento. Portanto, o participante tocava com a mão uma vez sobre a mesa para iniciar a reprodução e uma segunda vez para denotar o seu término. $\mathrm{O}$ tempo proposto pelo experimentador foi o mesmo que o participante havia previamente utilizado para desrosquear o parafuso. Assim, calculou-se a razão entre o tempo reproduzido e 
o tempo proposto pelo experimentador, valor denominado de precisão de reprodução de intervalo (PRI). Os resultados encontrados para PRM evidenciaram que o tratamento teve efeito relevante no desempenho dos participantes, pois os participantes foram significativamente mais precisos nas condições com ECP/sem medicação e sem ECP/com medicação quando comparados com a condição sem ECP/sem medicação. No entanto, todos tenderam a subreproduzir a duração da tarefa de reprodução motora. Nenhuma diferença foi evidenciada entre as diferentes condições de tratamento na PRI, referente à tarefa de reprodução de intervalo.

Outros estudos investigando a percepção do tempo em indivíduos com DP têm sido relatados, nos quais se realiza a estimação de durações de estímulos sonoros (Wearden et al., 2008), de estímulos visuais (Pastor, Artieda, Jahanshahi, \& Obeso, 1992) e tarefas de tapping (Riesen e Schnider, 2001), e levantam a possibilidade de que os resultados encontrados poderiam estar relacionados com a atividade motora dos participantes (Malapani, Deweer, \& Gibbon, 2002; Malapani et al., 1998; Riesen \& Schnider, 2001).

Pesquisas sobre a execução de movimentos dos membros superiores ressaltam que tarefas motoras envolvem a implementação de movimentos sequenciais, de modo que alcançar um objeto é frequentemente seguido de apreendê-lo e deslocá-lo para uma posição diferente. A própria preensão de um objeto abrange a manifestação da ativação simultânea e coordenação temporal de dois componentes: (1) alcance (transporte), referente ao movimento do braço e (2) preensão propriamente dita (manipulação), relacionada ao movimento da mão. O mecanismo de ação destes dois componentes é dependente de propriedades intrínsecas e extrínsecas do alvo, da distância do alcance e do nível de complexidade da tarefa (Castiello, Stelmach, \& Lieberman, 1993; Castiello, Bennett, \& Paulignan, 1992; Gentilucci \& Negrotti, 1999a).

De fato, a velocidade do componente de alcance tem demonstrado ser afetada pelo movimento de preensão da mão, que dentre outros fatores, pode estar associado ao tamanho do objeto-alvo; no caso de um objeto com diâmetro pequeno, naturalmente se adota a preensão fina, que é caracterizada pela oposição entre o dedo indicador e o polegar; para objetos com diâmetro largo, naturalmente se usa a preensão grossa, que utiliza a flexão de todos os dedos ao redor do objeto (Castiello et al., 1993; Castiello et al., 1992).

Com relação ao movimento dos membros superiores de indivíduos com DP, existem evidências que apontam que a coordenação temporal entre os componentes da preensão é prejudicada nestes participantes, de maneira que, a solicitação de movimentos mais precisos e a implementação de parâmetros de movimentos relacionados à tarefa, como por exemplo, 
produzir movimentos rápidos ou acurados, são particularmente difíceis para esta população (Alberts, Saling, Adler, \& Stelmach, 2000; Castiello et al., 1993).

Mediante o que já foi apresentado, é possível considerar estudos que abordam a questão do tempo sobre uma perspectiva teórica e experimental, relacionando-a à investigação com fatores específicos como a percepção do tempo mediante a experiência de apreciação artística, ou quando um indivíduo é acometido por uma patologia, como é o caso da DP. E ainda, distintas associações em torno do aspecto temporal são observadas, como a relação entre manipulação de objetos, estimação do tempo e DP. No entanto, não se encontrou na literatura pesquisada a relação entre percepção subjetiva do tempo, manipulação de obra de arte e DP, de maneira que se questiona quais seriam os efeitos da manipulação de uma obra de arte na estimação temporal realizadas por estes participantes. 


\section{JUSTIFICATIVA E OBJETIVO}

Existem estudos que apontam que a percepção do tempo pode sofrer a influência de diferentes fatores (Eagleman, 2008), entre eles a apreciação de trabalhos artísticos, como a escuta musical (Bueno \& Engelmann, 1976; Bueno, Firmino, \& Engelmann, 2002; Bueno \& Ramos, 2007; Cocenas-Silva, Bueno, Molin, \& Bigand, 2011; Droit-Volet, Bigand, Ramos, \& Bueno, 2010; Droit-Volet, Ramos, Bueno, \& Bigand, 2013; Firmino \& Bueno, 2008, 2016; Firmino, Bueno, \& Bigand, 2009; Ramos \& Bueno, 2012a, 2012b) e a observação de imagens de pinturas e esculturas (Nather \& Bueno, 2006a, 2006b, 2011, 2012a, 2012b; Nather, Bueno, \& Bigand, 2013; Nather, Bueno, Bigand, \& Droit-Volet, 2011; Nather, Fernandes, \& Bueno, 2012, 2014; Nather, Mecca, \& Bueno, 2013). Entretanto, na literatura pesquisada encontrouse apenas o estudo de Davidson, Abbott e Gershenfeld (1974) que trata da questão da apreciação de obras de arte tridimensionais, a saber, esculturas, mas sem que os pesquisadores investigassem o processo de manuseio destas obras pelos participantes, sem relacionar a tarefa com a questão da vivência temporal.

Levando em conta que o tempo é uma faceta básica da representação da ação, uma vez que entra em jogo quando antecipa e guia o timing dos movimentos (Harrington \& Jahanshahi, 2016) e que trabalhos apontam que o processamento temporal influenciaria a ação voluntária (Debaere, Wenderoth, Sunaert, Hecke, \& Seinnen, 2003), pesquisas realizadas com pessoas com Doença de Parkinson (Malapani, Deweer \& Gibbon, 2002; Malapani et al., 1998; Pastor et al., 1992; 2001; Torta et al., 2010; Wearden et al., 2008) evidenciaram que a atividade motora pode afetar a percepção temporal.

Embora vários estudos tenham sido realizados buscando revelar como o tempo é percebido por pessoas com diagnóstico de Doença de Parkinson (Allman \& Meck, 2012; Cope et al., 2014; Dušek et al., 2012; Harrington, Haaland, \& Germanowicz, 1998; Harrington et al., 2011; Jones et al., 2008; Merchant et al., 2008; Perbal et al., 2005; Smith et al., 2007; Wild-Wall et al., 2008), não se encontrou na literatura consultada estudos que relacionassem a percepção do tempo destes indivíduos com a manipulação de esculturas.

Numa perspectiva ecológica, no cotidiano de um indivíduo, este se encontra constantemente interagindo com o meio no qual vive através do manuseio de distintos objetos; a atividade exploratória do seu ambiente pode ser refletida na manipulação de uma obra de arte. 
O presente projeto de pesquisa teve como objetivo examinar o efeito da manipulação de uma obra de arte sobre o tempo subjetivo em indivíduos que apresentam DP. Para tanto foram utilizadas como estímulos duas obras de arte apresentando níveis diferentes de complexidade, que a partir da manipulação resultam em diferentes configurações. 


\section{EXPERIMENTO 1}

Entende-se que a apreciação de uma obra de arte é um processo complexo no qual o público busca perceber, organizar e compreender o trabalho artístico com a finalidade de lhe atribuir significado estético. Neste processo, além de outros fatores, podem estar envolvidos aspectos de ordem subjetiva, cultural, tendências estilísticas, da própria história da arte, além da intenção do artista ao criar a obra (CupChik, 1986).

No entanto, cabe ressaltar que a proposta deste estudo não é analisar uma obra com a finalidade de avaliar seu conteúdo ou de tecer críticas, muito menos se pretende reduzi-la a materiais meramente físicos, ou mesmo tem-se a pretensão de identificar o significado estético individual atribuído a ela.

E, ainda que reconhecendo a abrangência envolvida na apreciação estética, para fins desta pesquisa, um recorte será realizado com a intenção de destacar determinados atributos da obra, partindo do pressuposto que o impacto do objeto artístico é alcançado através da estruturação complexa de elementos, que no encontro público-obra estão presentes esquemas perceptuais, e que o processo de apreciação assume certas generalidades, isto é, grupos de participantes possibilitam levar em conta processos subjacentes gerais, em detrimento de variações individuais (CupChik, 1986). Assim, afirma CupChik (1986), as decisões, ações e preferências de experts e leigos em matéria de arte são tratadas como variações de processos básicos.

Portanto, da experiência de apreciação de uma obra de arte, algumas propriedades colativas foram evidenciadas não para reduzir o impacto que emerge do contato com o trabalho artístico, mas para buscar compreender esquemas perceptuais fundamentais, pois de acordo com Berlyne (1963), as propriedades colativas percebidas refletem uma tentativa do indivíduo de encontrar significado na obra e não deixa de ser um modo de envolvimento no encontro com a mesma.

Neste sentido, o objetivo deste experimento foi identificar como participantes julgam as propriedades colativas de modelos produzidos a partir da obra intitulada "Caranguejo", que compõe a série "Bichos" de Lygia Clark. 


\subsection{PARTICIPANTES}

Participaram do estudo 13 estudantes de pós-graduação do Programa de Psicobiologia, 9 homens e 4 mulheres, não treinados em cursos regulares de atividade artística,com idades entre 25 e 33 anos.

\subsection{ESTÍMULOS}

A partir da obra "Caranguejo" da série "Bichos" de Lygia Clark, foram construídos cinco estímulos, utilizando como material papel acartonado. Três eram compostos de peças planas (denominadas faces), com a forma geométrica de um triângulo escaleno, com as dimensões $26 \times 17 \times 14.5 \mathrm{~cm}$. As faces foram ligadas uma a outra pelos lados de menor dimensão por fita adesiva branca, formando um objeto de sequência de faces móveis. Os estímulos continham números diferentes de um mesmo elemento, que eram as faces: um estímulo tinha 6 faces, outro estímulo tinha 8 faces e o terceiro foi composto de 10 faces. Eles foram denominados de estímulos 6, 8 e 10, correspondendo ao número de faces.

Os outros dois estímulos, originários dos "Bichos" de Lygia Clark apresentavam padrões estruturais diferentes (número, tamanho e sequências diferentes de faces). Um era formado de faces planas, com a forma geométrica de um triângulo isósceles, com as dimensões $17 \times 12 \times 12 \mathrm{~cm}$. Ele foi chamado de estímulo Q. O outro estímulo, também foi formado de faces planas, com a forma geométrica de um triângulo escaleno, com as dimensões $25 \times 23 \times 10 \mathrm{~cm}$ e foi denominado de estímulo Q-. Ambos tiveram suas faces ligadas uma a outra pelos lados de menor dimensão por fita adesiva branca (Figura 1). 


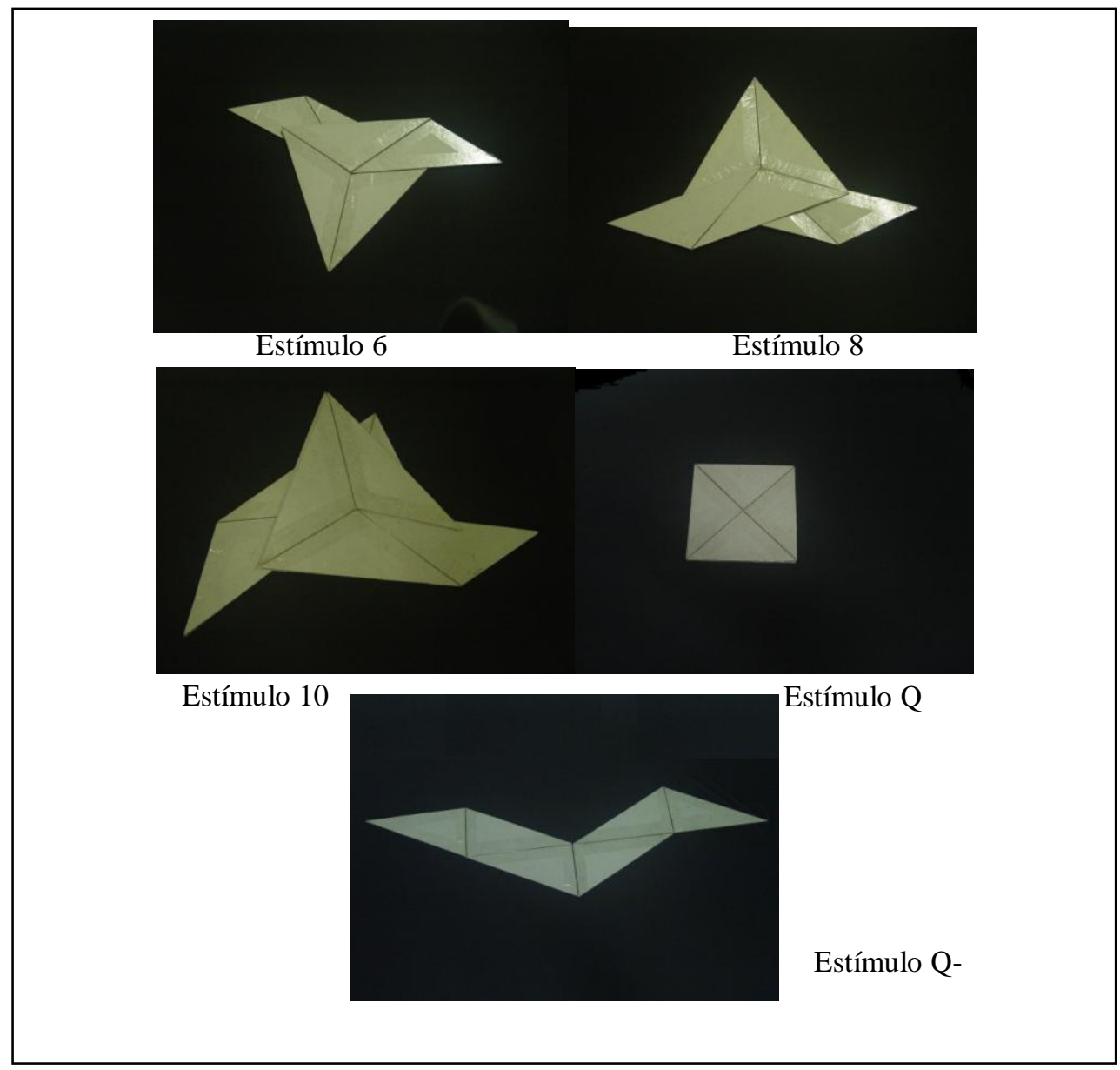

Figura 1. Modelos baseados na série "Bichos" de Lygia Clark que foram utilizados como estímulos no experimento 1. Estímulo 6: Acima, à esquerda; Estímulo 8: Acima, à direita; Estímulo 10: No meio, à esquerda; Estímulo Q: No meio, à direita e Estímulo Q-: Abaixo.

\subsection{EQUIPAMENTO E MATERIAL}

O experimento foi realizado em um campus universitário da cidade de Ribeirão Preto (São Paulo), numa sala experimental, durante o período diurno. Havia na sala uma mesa e uma cadeira para os participantes. Atrás da cadeira do participante estava posicionada a cadeira da experimentadora. Sobre a mesa eram dispostos, aleatoriamente, os estímulos.

Foi utilizada uma Escala de Diferencial Semântico (tipo Likert de 7 pontos) das locuções Complexidade (Simples/Complexa), Regularidade (Regular/Irregular), Quantidade de material (Pouco/Muito), Interesse (Interessante/Desinteressante) e Agradabilidade (Agradável/Desagradável) (Apêndice A). 


\subsection{PROCEDIMENTO}

Cada participante foi individualmente conduzido à sala experimental e convidado a sentar na sua cadeira. Em seguida explicou-se verbalmente a tarefa que deveria ser realizada: "Você vai apreciar modelos de obras de arte da artista Lygia Clark. As obras podem ser manipuladas. Deste modo, você terá a sua frente três modelos destas obras. Você poderá manipular cada obra pelo tempo que desejar. Após manipular cada modelo, você receberá uma escala para avaliação. Somente após ter respondido a escala você deverá escolher outra obra para manipular. Em seguida, você receberá mais três modelos pra realizar a mesma tarefa".

Assim, primeiramente foram expostos, de modo aleatório, os estímulos 8, Q e Q-, para que fosse possível verificar, através das respostas dos participantes, como são julgados estímulos que apresentam padrões estruturais diferentes (número, tamanho e sequências diferentes de faces). Depois, foram apresentados, também aleatoriamente, os estímulos 6,8 e 10, visando averiguar, através das respostas dos participantes, como são avaliados estímulos que apresentam padrões estruturais semelhantes, mas com número de faces diferentes.

Após a manipulação de cada estímulo o participante foi orientado a preencher a Escala de Diferencial Semântico (Apêndice A). Antes do começo das tarefas, possíveis dúvidas para a realização do experimento foram esclarecidas.

\subsection{ANÁLISE DOS DADOS}

Todos os dados foram submetidos a análises de normalidade segundo o teste de Shapiro-Wilk. Verificada a normalidade das respostas dos participantes para nível de irregularidade dos estímulos, elas foram submetidas à análise de variância (ANOVA). Para as respostas dos participantes para as propriedades colativas investigadas não foram encontradas normalidades, e os dados foram submetidos ao teste de Kruskal-Wallis. 


\subsection{RESULTADOS}

A análise estatística, através do teste ANOVA, mostrou diferença para as respostas dos participantes ao critério de julgamento de nível de irregularidade (p=.000, gl=72,5) e o teste de Kruskal-Wallis apresentou diferença para o julgamento de nível de complexidade ( $\mathrm{p}=.000$, $\mathrm{gl}=75,2)$. Para as demais respostas, quantidade de material, interesse e agradabilidade não foram encontradas diferenças estatísticas.

Considerando as diferenças estatísticas apresentadas pelos testes acima mencionados, a análise das respostas dos participantes aos critérios de julgamento de nível de complexidade e nível de irregularidade para a exposição simultânea dos estímulos 8 , Q e Q- foi realizada, e encontrou-se que as respostas para o nível de complexidade para o estímulo 8 foram estatisticamente diferente das respostas para o estímulo Q- (Tukey, p=.000, gl $(12,2)$ ), mas não para as respostas para o estímulo Q (Tukey, p=.377, gl (12,2)). Este resultado revela que as respostas dos participantes apontam para um maior nível de complexidade para o estímulo 8 quando este é comparado às respostas para o estímulo Q-, mas não quando ele é comparado às respostas para o estímulo Q (Figura 2).

A análise das respostas dos participantes ao critério de julgamento de nível de irregularidade para a exposição simultânea dos mesmos estímulos (Q-, 8 e Q), mostrou que as respostas para o estímulo 8 apresentavam diferença estatística com relação aos demais estímulos (Q Tukey, $\mathrm{p}=.002$, gl (12,2); Q-Tukey, $\mathrm{p}=.004$, $\mathrm{gl}(12,2)$ ). Tais dados indicam que o estímulo 8 retrata maior nível de irregularidade quando comparado aos estímulos Q- e Q (Figura 3). 


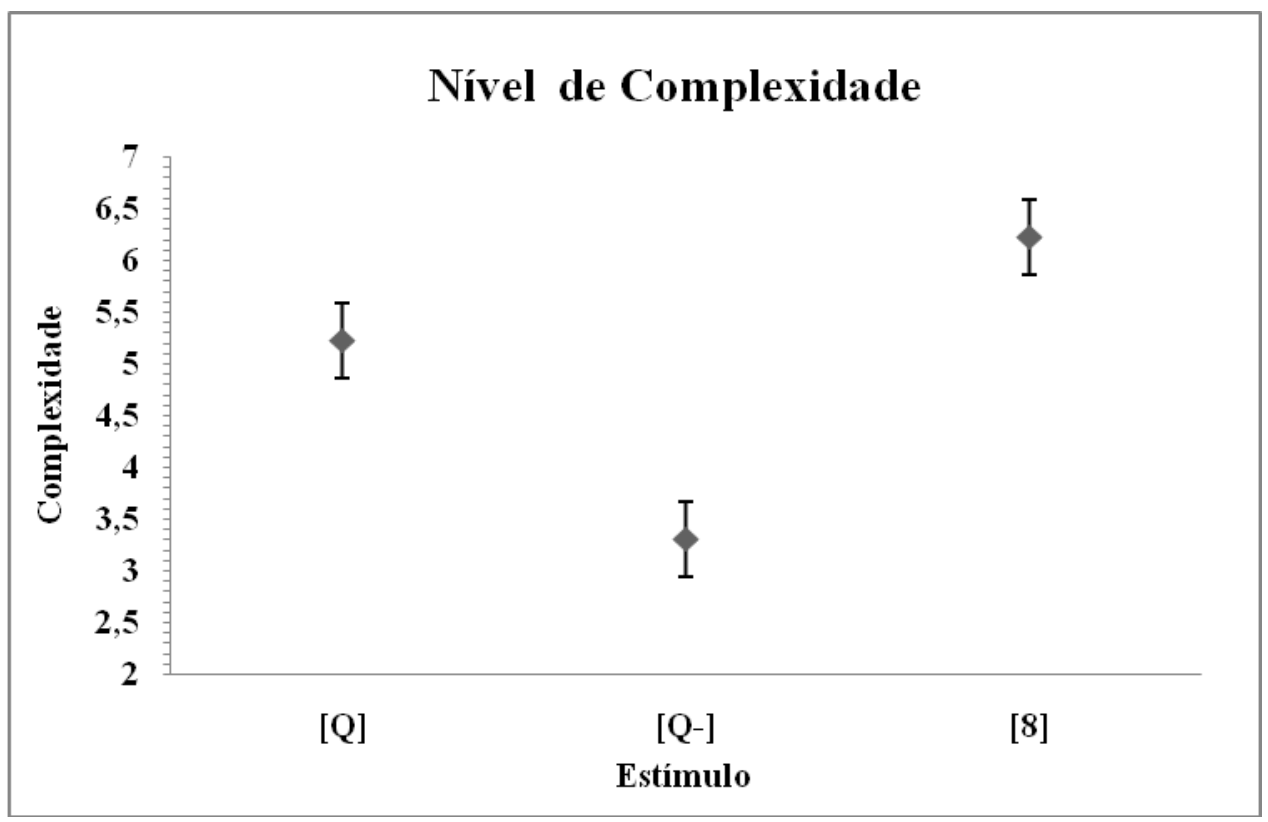

Figura 2. Gráfico representando as pontuações médias e erros padrão das respostas dos participantes a critério de julgamento de Nivel de complexidade dos estímulos $Q, Q-e 8$.

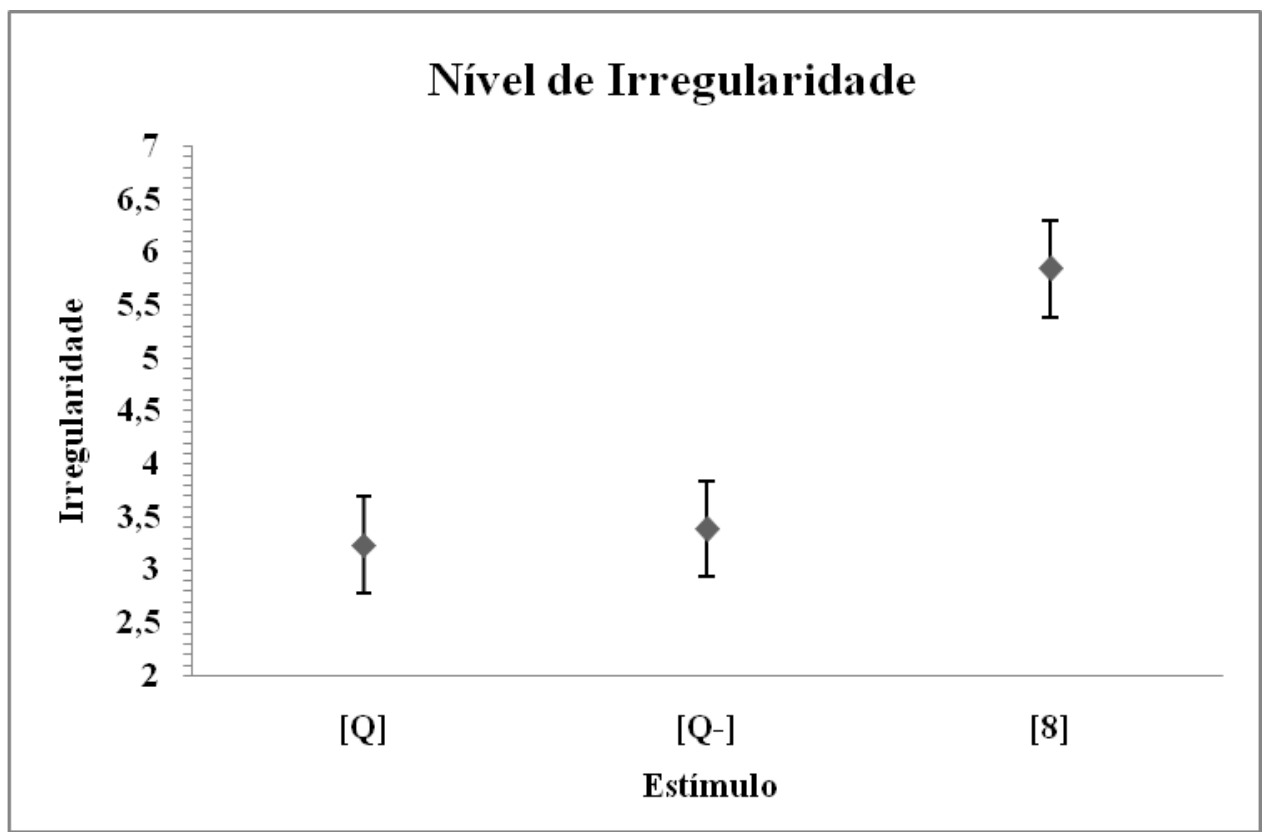

Figura 3. Gráfico representando as pontuações médias e erros padrão das respostas dos participantes ao critério de julgamento de Nível de irregularidade dos estímulos $Q, Q-e 8$.

As médias das respostas para quantidade de material, interesse e agradabilidade para os estímulo Q, Q- e 8, mostraram que o estímulo Q- foi considerado com menor quantidade de material e menos interessante quando comparado aos outros dois estímulos; o estímulo avaliado como mais interessante foi o estímulo 8, que juntamente com o estímulo Q, apresentou maior quantidade de material; o estímulo julgado como mais agradável foi o estímulo Q quando comparado aos outros dois estímulos (Figura 4). 


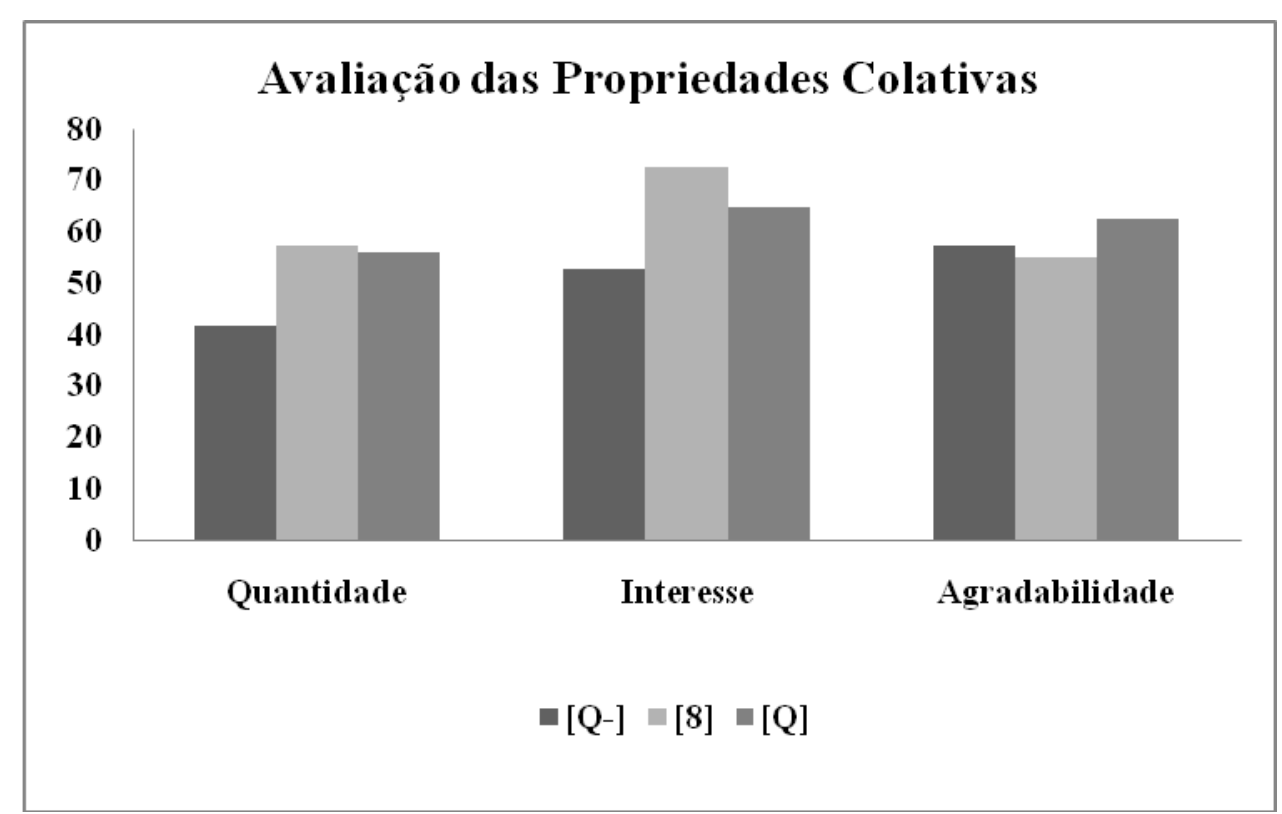

Figura 4. Gráfico representando as médias da porcentagem das respostas dos participantes para os critérios de julgamento para Quantidade de material, Nível de interesse e Nível de agradabilidade dos estímulos $Q-, 8$ e $Q$.

Para verificar se o número de faces dos estímulos tinha relação com o nível de complexidade, compararam-se as respostas dos participantes para este critério de julgamento para os estímulos 6, 8 e 10 e encontrou-se que as respostas para o estímulo com menor número de faces apresentavam-se estatisticamente diferente das respostas dos outros dois estímulos (Estímulo 8: Tukey p=.001, gl=12,2; Estímulo 10: Tukey p=.000, gl=12,2), o que indica que o estímulo 6 foi considerado com o menor nível de complexidade quando comparado aos estímulos 8 e 10. Não foi encontrada diferença estatística entre as respostas de julgamento para os estímulos 8 e 10 (Tukey $\mathrm{p}=.833$, gl=12,2).

Ainda para analisar se o número de faces tinha relação com o nível de complexidade e também com o nível de irregularidade, realizou-se o cálculo das pontuações médias e erros padrão das respostas dos participantes para estes dois critérios de julgamento para os estímulos 6,8 e 10, e encontrou-se que os menores valores das pontuações médias para as respostas correspondiam ao estímulo de menor número de faces, isto é, ao estímulo 6 (Figura 5 e 6$)$. 


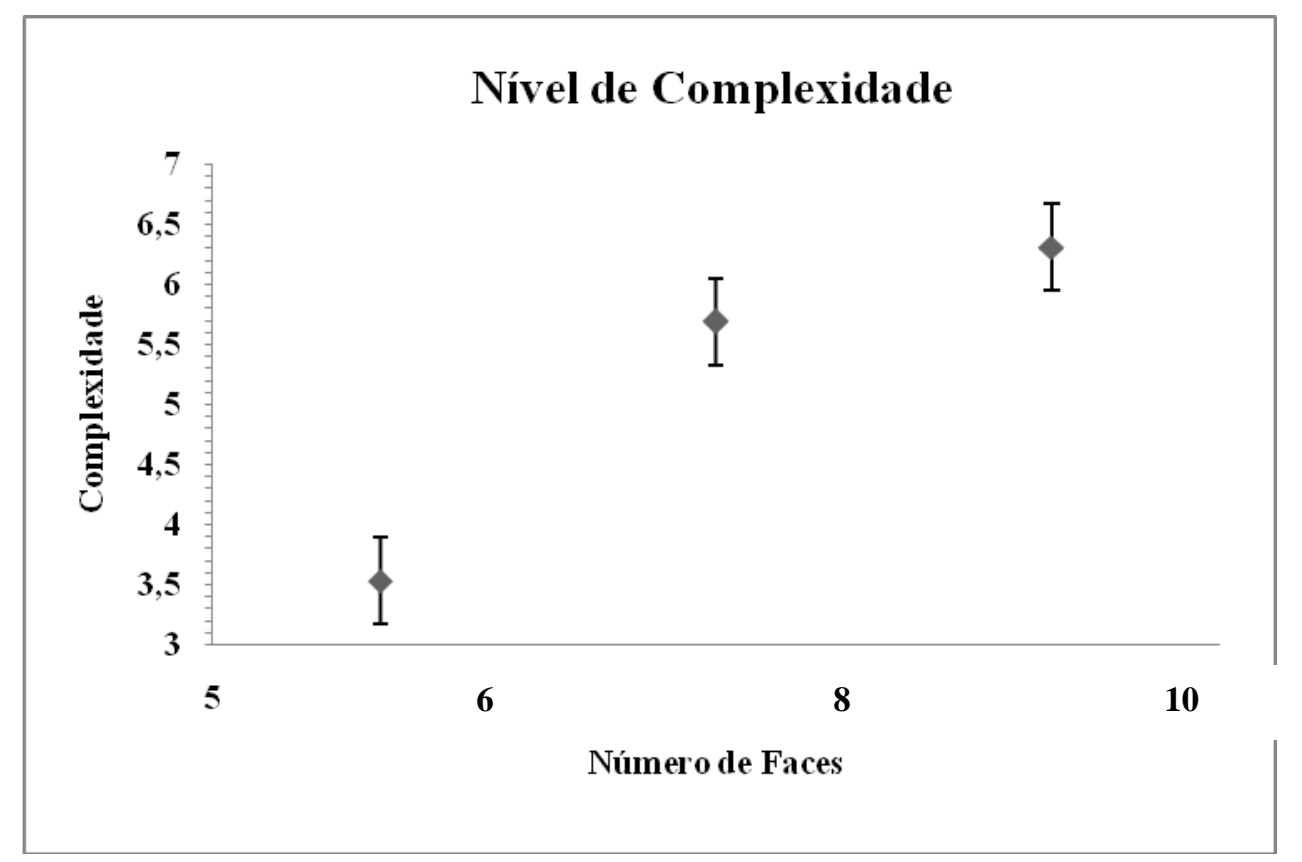

Figura 5. Gráfico representando os valores médios e erro padrão da relação do número de faces com as respostas dos participantes ao critério de julgamento de Nivel de complexidade dos estímulos 6, 8 e 10.

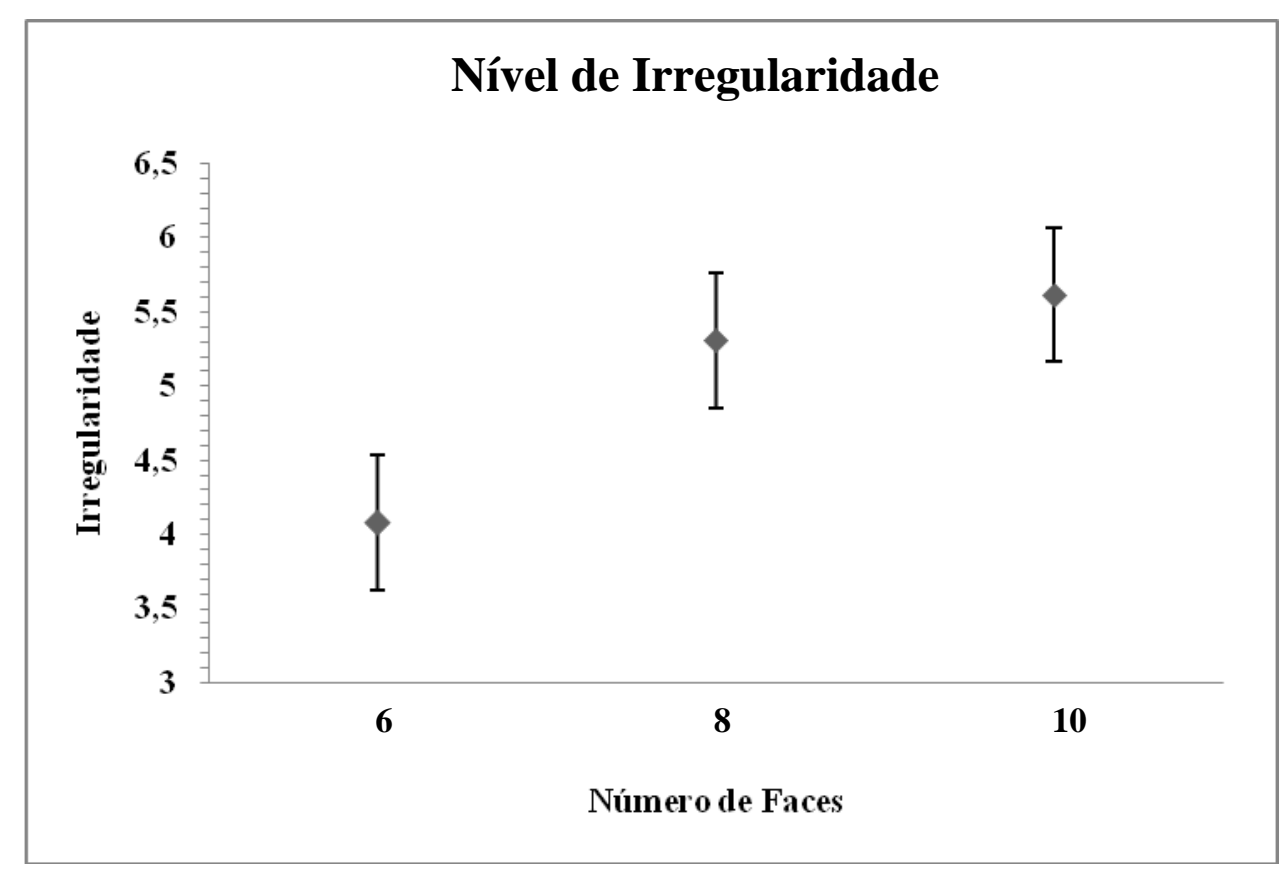

Figura 6. Gráfico representando os valores médios e erro padrão da relação do número de faces com as respostas dos participantes ao critério de julgamento de Nível de irregularidade dos estímulos 6, 8 e 10.

As médias das respostas para quantidade de material, interesse e agradabilidade para os estímulos 6,8 e 10, mostraram que o estímulo 6 foi considerado com menor quantidade de material e menos interessante quando comparado aos outros dois estímulos; o estímulo avaliado como mais interessante foi o estímulo 8, seguido pelo estímulo 10; o estímulo 10 , 
apresentou maior quantidade de material e menor nível de agradabilidade; os estímulos julgados como mais agradáveis foram os estímulos 8 e 6 (Figura 7).

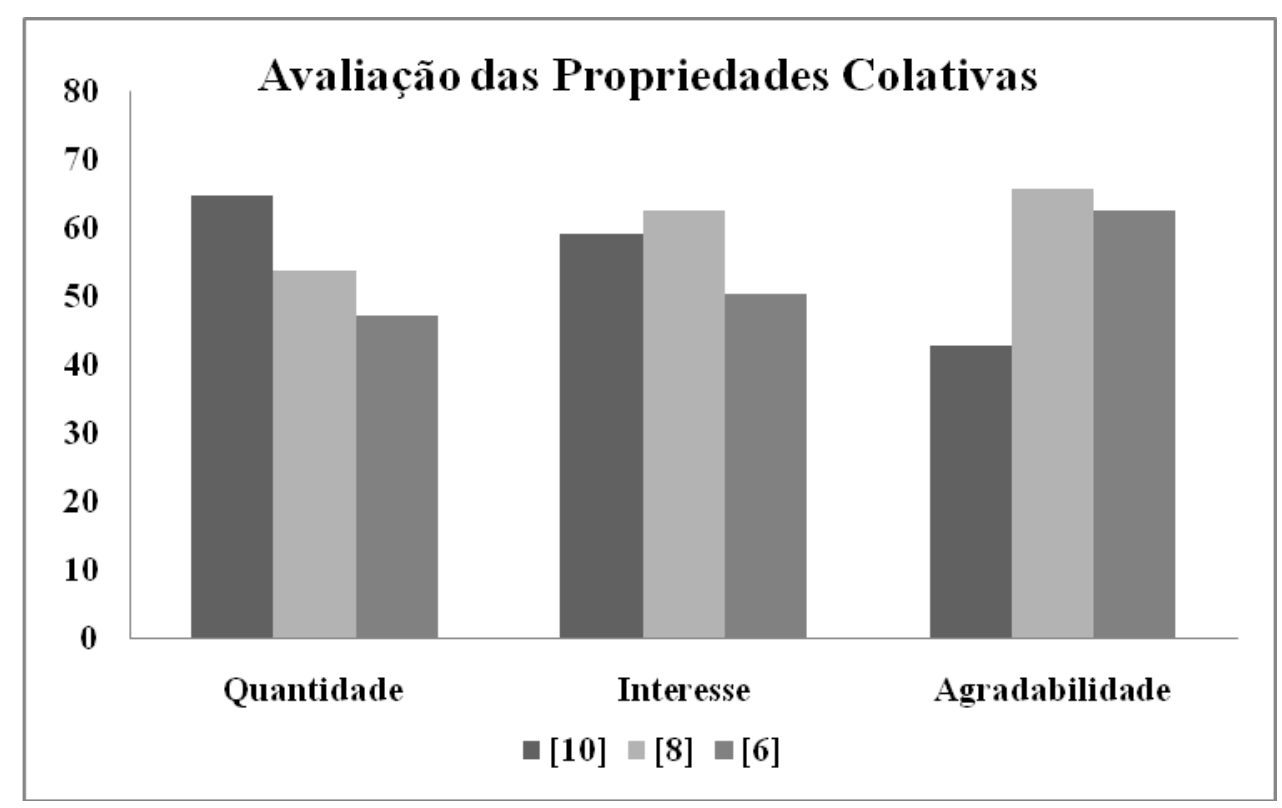

Figura7. Gráfico representando as médias da porcentagem invertida das respostas dos participantes para os critérios de julgamento para Quantidade de material, Nível de interesse e Nivel de agradabilidade dos estímulos 10, 8 e 6.

\subsection{DISCUSSÃO}

Os resultados obtidos no presente experimento possibilitaram identificar como participantes julgam as propriedades colativas de modelos produzidos a partir da obra intitulada "Caranguejo", que compõe a série "Bichos" de Lygia Clark.

Assim, foi possível verificar que dentre as respostas de julgamentos para os estímulos8, Q e Q-, o primeiro foi apontado com o maior nível de complexidade, sendo possível considerar o que aponta Berlyne (1958, 1963; Berlyne, Ogilvie, \& Parham, 1968), ao afirmar que certos atributos dos estímulos, incluindo número de elementos, distinção entre eles e o quanto representam uma unidade, quando examinados juntos,conferem ao mesmo a propriedade de complexidade.

Em estudo para verificar qual era a influência da complexidade retratada em imagens sobre o comportamento exploratório dos indivíduos, Berlyne (1958) utilizando como estímulo pares de figuras que apresentavam diferentes formas de complexidade representadas por diferentes categorias, tais como irregularidade da estrutura, quantidade de material, 
heterogeneidade dos elementos, irregularidade da forma, incongruência e justaposição incongruente, encontrou que, de modo geral, os estímulos considerados com maior nível de complexidade em cada categoria, despertaram mais curiosidade, e assim atraíram mais atenção, o que conduziu o indivíduo a explorar o estímulo por mais tempo quando comparado a um estímulo que configurava menor nível de complexidade.

Neste sentido, pode-se supor que os estímulos Q e Q- por apresentarem formato e padrões geométricos regulares, o que segundo Berlyne $(1958,1961)$ expressa menor nível de complexidade, suscitaram menos curiosidade e, consequentemente, chamaram menos atenção dos participantes, e deste modo, foram julgados como menos interessantes e com menor nível de complexidade. Já o estímulo 8, teria despertado mais atenção e teria sido considerado como mais interessante por refletir maior irregularidade em sua forma e estrutura, e portanto, isto teria influenciado para que fosse avaliado pelos participantes como mais complexo quando comparado aos outros dois estímulos.

O resultado da avaliação atribuindo maior nível de agradabilidade para o estímulo Q também pode ser reflexo do formato e padrão geométrico regular de sua estrutura que pode ter facilitado sua compreensão pelo participante, uma vez que CupChik e Gebotyes (1988) afirmam que a agradabilidade de um objeto está diretamente relacionada com seu nível de compreensão pelo participante.

No que se refere ao resultado encontrado nesta pesquisa, que aponta uma relação direta do nível de complexidade e de irregularidade com a quantidade de faces dos estímulos, há uma compatibilidade com alguns trabalhos de Berlyne (1958; Berlyne, Ogilvie, \& Parham, 1968), que apontam que o julgamento do nível de complexidade de um objeto varia diretamente com o número de elementos que este apresenta e que quanto mais elementos estiverem presentes em um estímulo, maiores serão as possibilidades de variação deste e maior será seu conteúdo de informação e, portanto, mais complexo ele será.

A avaliação do nível de complexidade dos estímulos 6, 8 e 10 também parece estar relacionada com a avaliação do nível de interesse, uma vez que os estímulos 8 e 10 considerados com maior nível de complexidade foram apontados como mais interessantes do que o estímulo 6 considerado com menor nível de complexidade.Neste sentido, uma série de experimentos realizados por Berlyne (1957, 1958, 1961; Berlyne \& Crozier, 1971; Berlyne \& Lawrence, 1964), revelaram que os participantes gastavam mais tempo visualizando estímulos mais complexos, o que evidenciou que existia uma tendência dos indivíduos de demonstrarem maior interesse por um objeto que se mostra mais complexo, por este ser uma fonte rica em 
informação, em detrimento de outro que se apresenta mais simples e, por conseguinte,relativamente mais pobre de conteúdo.

No que tange ao resultado do julgamento do nível de agradabilidade e do nível de interesse de todos os estímulos (Q, Q-, 6, 8 e 10), observou-se uma relação inversa entre eles, na qual os estímulos avaliados com maior nível de complexidade foram apontados como mais interessantes, no entanto, menos agradáveis; e o contrário foi notado com relação aos estímulos com menor nível de complexidade, que foram considerados menos interessantes, contudo, mais agradáveis.

Esta evidência pode ser consequência do fato de que estímulos mais complexos elevam a curiosidade perceptiva (Berlyne, 1957, 1966) e aumentam o nível de excitação do organismo (Berlyne \& Lawrence, 1964), sendo estes aspectos que geram desconforto ao participante, e podem ser prontamente eliminados com a exploração do estímulo (Berlyne, 1963). Já o estímulo mais simples, não teria o mesmo potencial para despertar a curiosidade perceptiva, em vista disto, não suscitaria interesse, logo não geraria desconforto, e assim seria considerado agradável, uma vez que segundo Berlyne (1963), o julgamento de agradabilidade parece refletir processos internos dependentes de propriedades dos estímulos que reduzem ou reprimem o nível de excitação do organismo.

Berlyne (1963), ao analisar o nível de interesse e de agradabilidade despertado por imagens com diferentes níveis de complexidade, constatou que os estímulos com maior nível de complexidade foram avaliados como mais interessantes e menos agradáveis, e os estímulos com menor nível de complexidade foram considerados como menos interessantes, entretanto, mais agradáveis.

No entanto, nesta pesquisa, a ausência de diferença estatística para as respostas dos participantes para o julgamento dos atributos dos estímulos relacionados com quantidade de material, interesse e agradabilidade, demonstrada pelo teste usado, pode ser explicada por uma tendência dos participantes a implicitamente considerarem que devem atribuir maior valor a um estímulo em detrimento de outro, uma vez que os indivíduos são diferentemente expostos a todo tipo de educação e outras influencias que oferecem noções preconcebidas do que deve ser preferido ou valorizado. Tal viés é provável ser mais proeminente quando estudantes de psicologia são usados como participantes, e isto pode ter contribuído para os achados do presente estudo. No entanto, como bem aponta Berlyne (1963), tão logo se torne aparente tal viés, se ele de fato existe, não impede os efeitos das variáveis independentes de emergirem. 
Os dados deste estudo, portanto, mostram que a manipulação de objetos, como obras de arte tais quais os modelos produzidos nesta pesquisa, que foram construídos a partir da obra intitulada "Caranguejo", que compõe a série "Bichos" de Lygia Clark, permite que propriedades colativas sejam identificadas, julgadas e influenciem no comportamento exploratório. Além disso, os dados apontam que atributos como quantidade de material e níveis distintos de irregularidade influenciam nas avaliações do nível de complexidade dos estímulos. 


\section{EXPERIMENTO 2}

Os resultados apresentados no experimento 1 foram utilizados como base para a determinação dos estímulos que seriam empregados no experimento 2. Assim, o principal critério para a seleção dos estímulos foi o nível de complexidade, pois de acordo com Berlyne (1963), a complexidade de uma obra de arte seria o atributo mais evidente no encontro com o trabalho artístico.

Deste modo, os elementos considerados para análise foram: a irregularidade da obra e a quantidade de material, que, segundo Berlyne (1958), implicam em diferentes níveis de complexidade aos estímulos. Esses atributos foram definidos da seguinte forma:

a) Irregularidade da estrutura: estímulos que, expostos simultaneamente, são estruturados com os mesmos elementos, mas arranjados com padrões diferentes de regularidade (Berlyne, 1958).

b) Quantidade de material: cada estímulo apresentado simultaneamente contém uma quantidade de material diferente do outro, de maneira que, um tem mais elementos que o outro, o que implica numa maior possibilidade de variação e, logo, em maior quantidade de informação (Berlyne, 1958).

Portanto, levando em conta que dentre os estímulos Q, Q- e 8, este último foi apontado como apresentando maior nível de irregularidade e maior quantidade de material, considerouse que a estrutura deste estímulo indicava atributos colativos relevantes para a atividade perceptiva a ser proposta no experimento seguinte.

E ao verificar a relação das respostas para os níveis de complexidade e de irregularidade com a quantidade de faces dos estímulos que apresentavam a mesma estrutura do estímulo 8, ou seja, a relação destas propriedades entre os estímulos 6,8 e 10, identificouse que os estímulos 6 e 10 seriam os mais apropriados para serem utilizados no experimento 2, pois evidenciaram em suas estruturas diferentes quantidades de faces que demonstraram conferir a eles distintos níveis de complexidade e de irregularidade.

O experimento 2 teve como objetivos: (1) Examinar os efeitos da manipulação de 2 distintos objetos artísticos (estímulos) representando níveis de complexidade e de irregularidade diferentes na estimação temporal de indivíduos com diagnóstico de Doença de Parkinson. (2) Estabelecer categorias de manipulação dos estímulos para indivíduos com diagnóstico de Doença de Parkinson (DP). Dados da literatura mostram que devido ao alto grau de liberdade dos movimentos das mãos e dedos diversas classificações de preensões 
foram realizadas (Kamakura, Matsuo, Ishii, Mitsuboshi, \& Miura, 1980; Kyota \& Saito, 2012; Lee \& Jung, 2014), no entanto, não foram encontradas categorias de manipulação para pessoas que apresentam diagnóstico de DP.

\subsection{PARTICIPANTES}

Dez participantes com diagnóstico clínico de Doença de Parkinson (DP) e 10 participantes controle (sem a doença) com idade correspondente, de ambos os sexos (Tabela 1). A média de idade foi 57,3 anos ( $\mathrm{SD}=5.33$; variando 49 - 66) para pacientes e 54,4 anos $(\mathrm{SD}=8.36$; variando 39 - 68) para os participantes controle (GC). Todos os pacientes preencheram os critérios da UK Brain Bank para DP idiopática. Os participantes controles não apresentavam doenças neurológicas e, os pacientes não apresentavam doenças neurológicas outras além da DP. Todos os participantes estavam livres de demência, avaliados pelo Mini Exame do Estado Mental (MEEM) $(\leq 21)$, e apenas um participante de cada grupo apresentou escore maior que 5 na Escala de Depressão Geriátrica (EDG), denotando depressão leve. Nenhum dos participantes tinha histórico de traumatismo craniano nos últimos 10 anos, ou incidência de abuso de drogas (incluindo álcool), acidente vascular encefálico ou epilepsia. No momento do teste todos os pacientes estavam na condição ON de medicação. Todos os participantes assinaram o Termo de Consentimento Livre e Esclarecido antes de participar do estudo. O procedimento realizado foi aprovado pelo Comitê de Ética em Pesquisa em Seres Humanos da Faculdade de Filosofia, Ciências e Letras de Ribeirão Preto da Universidade de São Paulo (Apêndice B e C - Termo de Consentimento Livre e Esclarecido). 
Tabela 1.Informações quanto a demografia e dados clínicos do grupo de participantes com Doença de Parkinson e participantes controle sem a doença. UPDRS-MDS: Moviment Disorder Society - Unified Parkinson's Diasease Rating Scale; MEEM: Mini Exame do Estado Mental; EDG: Escala de Depressão Geriátrica

\begin{tabular}{|c|c|c|c|c|c|}
\hline \multicolumn{2}{|c|}{$\begin{array}{c}\text { Participante/ } \\
\text { Gênero }\end{array}$} & \multirow{2}{*}{$\begin{array}{c}\begin{array}{c}\text { Idade/Escolaridade } \\
\text { (anos) }\end{array} \\
66 / 3\end{array}$} & \multirow{2}{*}{$\begin{array}{c}\begin{array}{c}\text { UPDRS-MDS } \\
\text { motor }\end{array} \\
41\end{array}$} & \multirow{2}{*}{$\frac{\text { MEEM }}{26}$} & \multirow{2}{*}{$\frac{\text { EDG }}{4}$} \\
\hline \multirow{10}{*}{ 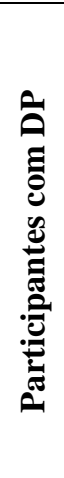 } & $\mathrm{S} 1 / \mathrm{M}$ & & & & \\
\hline & $\mathrm{S} 2 / \mathrm{F}$ & $59 / 7$ & 23 & 25 & 2 \\
\hline & $\mathrm{S} 3 / \mathrm{M}$ & $49 / 11$ & 27 & 28 & 1 \\
\hline & $\mathrm{S} 4 / \mathrm{M}$ & $61 / 11$ & 38 & 29 & 4 \\
\hline & S5/M & $50 / 2$ & 13 & 25 & 3 \\
\hline & S6/M & $58 / 0$ & 11 & 22 & 5 \\
\hline & $S 7 / F$ & $55 / 10$ & 39 & 28 & 2 \\
\hline & S8/M & $56 / 4$ & 14 & 23 & 6 \\
\hline & $\mathrm{S} 9 / \mathrm{M}$ & $63 / 4$ & 41 & 25 & 0 \\
\hline & $\mathrm{S} 10 / \mathrm{F}$ & $56 / 7$ & 49 & 21 & 4 \\
\hline \multirow{10}{*}{ 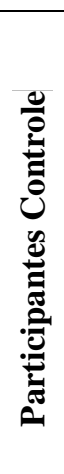 } & $\mathrm{S} 11 / \mathrm{F}$ & $60 / 7$ & - & 26 & 7 \\
\hline & $\mathrm{S} 12 / \mathrm{F}$ & $61 / 8$ & - & 25 & 3 \\
\hline & $\mathrm{S} 13 / \mathrm{F}$ & $60 /+11$ & - & 26 & 2 \\
\hline & $\mathrm{S} 14 / \mathrm{M}$ & $55 / 8$ & - & 24 & 1 \\
\hline & $\mathrm{S} 15 / \mathrm{F}$ & $54 /+11$ & - & 26 & 3 \\
\hline & $\mathrm{S} 16 / \mathrm{M}$ & $47 /+11$ & - & 29 & 0 \\
\hline & $\mathrm{S} 17 / \mathrm{F}$ & $48 / 11$ & - & 26 & 3 \\
\hline & $\mathrm{S} 18 / \mathrm{M}$ & $52 / 11$ & - & 26 & 1 \\
\hline & $\mathrm{S} 19 / \mathrm{F}$ & $39 / 11$ & - & 29 & 1 \\
\hline & $\mathrm{S} 20 / \mathrm{M}$ & $68 / 11$ & - & 25 & 1 \\
\hline
\end{tabular}

\subsection{ESTÍMULOS}

Foram usadas como estímulos reproduções alteradas de uma escultura da série "Bichos" de Lygia Clark. Os estímulos foram compostos de peças planas (denominadas faces) construídas com chapa de alumínio fosco de $2 \mathrm{~mm}$ de espessura, com a forma geométrica de um triângulo escaleno, com as dimensões 26 x 17 x $14.5 \mathrm{~cm}$. As faces foram ligadas uma a outra pelos lados de menor dimensão por dobradiças produzidas com o mesmo material das faces, formando um objeto de sequência de faces móveis.

Os estímulos apresentavam estruturas e elementos iguais, sendo um o estímulo A, que continha 6 faces, e o outro, o estímulo B que era formado por 10 faces; o primeiro representava menor nível de complexidade e menor nível de irregularidade quando comparado ao segundo (Anexo A). 
O estímulo-treino foi composto por uma peça construída com mesmo material e dimensões de uma face dos estímulos A e B, alumínio fosco de $2 \mathrm{~mm}$ de espessura, com a forma geométrica de um triângulo escaleno, com as dimensões 26 x 17 x $14.5 \mathrm{~cm}$, no entanto ela foi dobrada na altura em ângulo de $90^{\circ}$.

\subsection{EQUIPAMENTO E MATERIAL}

O experimento 2 foi realizado em uma sala no Hospital das Clínicas da Faculdade de Medicina de Ribeirão Preto-USP, durante o período diurno. Uma cadeira para o participante foi posicionada em frente a um anteparo giratório (anexo B), colocado sobre uma mesa, construído em MDF $6 \mathrm{~mm}$, pintado de preto fosco, com a base em borracha, contendo três compartimentos, nos quais foram colocados os estímulos, de maneira que em cada compartimento ficava um estímulo (estímulo-treino, estímulo A e estímulo B). Uma cadeira para o experimentador foi posicionada ao lado do anteparo giratório. Uma filmadora Panasonic HDC-HS80 foi posicionada fixamente em uma haste a $55 \mathrm{~cm}$ acima do local da manipulação. O tempo de manipulação foi registrado pelo programa E-prime V2.0 instalado em um computador notebook Positivo V146. Para registrar o tempo de manipulação, havia um botão conectado ao computador e posicionado no lado direito do participante. Um questionário (Apêndice D) referente a dados pessoais e às experiências decorrentes da exploração do estímulo foi utilizado.

\subsection{PROCEDIMENTO}

Para todos os participantes, foi primeiramente apresentado o estímulo-treino e a instrução foi exatamente a mesma que foi dada para a tarefa a ser realizada utilizando os estímulos A e B. Em seguida, os estímulos foram expostos na ordem A e depois B para metade de cada um dos grupos de participantes, e para a outra metade dos participantes os estímulos foram apresentados na ordem B e depois A. O objetivo de tal procedimento foi evitar o efeito de ordem.

Os participantes sentavam-se em uma cadeira posicionada em frente ao anteparo e eram orientados a assumirem uma posição confortável de maneira que suas mãos alcançassem 
o centro do compartimento. A tarefa era explicada verbalmente pelo experimentador aos participantes, da seguinte forma:

-Você irá manusear um objeto pelo tempo que quiser. Quando for começar o manuseio, aperte o botão. Quando terminar, aperte o botão outra vez.

Os participantes manipulavam o estímulo apresentado pelo tempo que desejassem. A tarefa era repetida com o estímulo seguinte. A manipulação dos estímulos foi gravada. Ao final, o questionário foi aplicado, na mesma sala experimental, e as respostas foram anotadas pelo experimentador.

\subsection{ANÁLISE DOS DADOS}

\subsubsection{Análise da estimativa verbal do tempo de manipulação e do tempo real de manipulação dos estímulos}

Devido a variações no tempo de manipulação dos estímulos pelos participantes, considerações metodológicas especiais foram feitas, de modo que realizou-se uma padronização das estimativas temporais verbais utilizando a seguinte fórmula:

$\frac{t_{(r)}-t_{(e)}}{t_{(r)}}=C E T p$

Sendo $t(r)$ o tempo real de manipulação pelo participante, $t(e)$ o tempo verbal estimado de manipulação pelo participante e CETp o coeficiente de estimação temporal ponderado, onde valores negativos foram considerados como superestimação e valores positivos como subestimação.

Os valores do CETp foram submetidos ao teste de Shapiro-Wilk e não mostraram distribuição normal (grupo DP: $p=.017$ e GC: $p=.222$ ). Os valores do CETpe os valores do tempo real de manipulação dos estímulos pelos participantes foram então submetidos a análise pelos Testes de U-Mann-Whitney e Wilcoxon. 


\subsubsection{Análise das filmagens das manipulações e das categorias de manipulação dos estímulos}

As filmagens das manipulações dos estímulos pelos participantes do grupo GC e do grupo DP foram transcritas cursivamente. A partir da análise das transcrições, 28 categorias de manipulações foram identificadas (Tabela 2), segundo a classificação de tipos de preensão de Lee \& Jung (2014), que investigaram os tipos de preensão voluntária comumente usada por estudantes (média de idade 24.7) de acordo com as propriedades dos objetos (i. e., forma, tamanho e direção). A classificação teve como critério o uso da palma da mão e o número de dedos envolvidos.

Tabela 2. As 28 categorias de manipulação definidas a partir das transcrições das filmagens das manipulações dos estímulos realizadas pelos participantes. Os dedos foram abreviados da seguinte forma: P: polegar; I: indicador; M: médio; A: anular e Mi: dedo mínimo.

\begin{tabular}{l|l}
\hline \multicolumn{2}{c}{ Categorias de manipulação } \\
\hline Tocar face & Movimentar face e dobradiças - PI \\
Tocar face - PI & Movimentar face e dobradiças - PIM \\
Tocar face - P lateral do I & Movimentar de face e dobradiças - PIMA \\
Tocar face - PIM & Movimentar face e dobradiças - PIMAMi \\
Tocar face - PIMA & Movimentar face e dobradiças - I adução M \\
Tocar face -PIMAMi & Movimentar face e dobradiças - I adução M \\
Tocar face - I adução M & oposição P \\
Tocar face - duas mãos & Movimentar face e dobradiças - duas mãos \\
Tocar duas faces & Soltar estímulo - uma mão \\
Mão desliza sobre a face & Soltar estímulo - duas mãos \\
Movimentar duas faces - uma mão & Deslocar estímulo - uma mão \\
Movimentar face - P lateral do I & Deslocar estímulo - duas mãos \\
Movimentar face e dobradiças - P lateral dos IM & Elevar o estímulo com perda de contato - duas \\
Movimentar face e dobradiças - PMA & mãos \\
\hline
\end{tabular}

Para os termos empregados na categorização, as seguintes definições foram consideradas:

a) Tocar: toque realizado com a palma da mão e/ou dedos a uma ou mais faces dos estímulos.

b) Movimentar: o movimento somente de faces ou o movimento de faces e dobradiças realizado com a palma da mão e dedos.

c) Soltar: quando o estímulo era depositado sobre a base do anteparo sem qualquer contato de uma ou ambas as mãos. 
d) Deslocar: quando o estímulo era deslocado de um lugar para outra na base do anteparo utilizando uma ou ambas as mãos.

e) Elevar: quando o estímulo era elevado com ou sem perda de contato com a base do anteparo utilizando uma ou ambas as mãos.

As 28 categorias foram reduzidas em 10 categorias, tendo como critério para o agrupamento o grau de semelhança do movimento das mãos e dedos realizado pelo participante no momento da preensão e manipulação dos estímulos; em seguida as 10 categorias foram agrupadas em 4 categorias denominadas: Tocar (T), Movimentar (M), Soltar $(S)$ e Deslocar $(D)$ (suas definições já foram descritas acima). O critério para reunir estas categorias de manipulação teve como base a similaridade dos aspectos funcionais apresentados pelas mesmas a fim de refinar a classificação dos padrões de movimentos produzidos (Tabela 3 ).

Tabela 3. As 10 categorias de manipulação identificadas a partir das filmagens das manipulações dos estímulos realizadas pelos participantes e a reunião das mesmas, resultando em 4 categorias de manipulação.

\begin{tabular}{l|l}
\hline \multicolumn{2}{c}{ Categorias de Manipulação } \\
\hline Tocar face & Tocar estímulo \\
Tocar duas faces & \\
Mão desliza sobre a face & Movimentar estímulo \\
\hline Movimentar face e dobradiças & \\
Movimentar face e dobradiças - duas mãos & Soltar estímulo \\
\hline Soltar estímulo - uma mão & \\
Soltar estímulo - duas mãos & \\
\hline Deslocar estímulo & Deslocar estímulo \\
Elevar o estímulo com perda de contato & \\
Elevar o estímulo sem perda de contato &
\end{tabular}

Após definição das 4 categorias de manipulação dos estímulos, as gravações das manipulações foram analisadas através do programa EthoLog 2.2 (Ottoni, 2000), que é uma ferramenta que auxilia na observação do comportamento, registrando sua sequência, frequência e duração.

Por razões metodológicas que consideraram o tempo variável de manipulação dos estímulos para cada participante, realizou-se uma padronização para análise das categorias de manipulação utilizando as seguintes fórmulas:

$P_{\text {(cat) }}=\frac{t(\text { cat })}{t_{r}}$ 
$F R_{(c a t)}=\frac{F_{a b s}}{t_{r}}$

Sendo $\mathrm{P}($ cat) a proporção para cada categoria, $\mathrm{t}(\mathrm{cat})$ o tempo de manipulação dos estímulos pelo participante para cada categoria, t(r) o tempo real de manipulação dos estímulos pelo participante, FR(cat) a freqüência relativa para cada categoria e Fabs(cat) a freqüência absoluta para cada categoria. As categorias foram denominadas: T: Tocar; M: Movimentar; S: Soltar e; D: Deslocar.

Realizou-se o teste de Shapiro-Wilk para verificar a normalidade dos dados, porém não foi encontrada normalidade, assim, os dados obtidos foram submetidos à análise pelos testes $U$ de Mann-Whitney e Wilcoxon.

\subsection{RESULTADOS}

\subsubsection{Estimação do tempo de manipulação dos estímulos}

As médias dos valores do Coeficiente de Estimação Temporal ponderado (CETp) foram negativas para ambos os grupos e estímulos, o que indica que todos os participantes estimaram com maior duração o tempo de manipulação dos estímulos, entretanto, os participantes com diagnóstico de DP mostraram uma menor estimação do tempo de manipulação dos estímulos quando comparados aos integrantes do GC (DP: -0,42; GC: -0,89; Figura 7).

Quanto à análise dos valores do CETp, não foram verificadas diferenças entre os grupos de participantes $(\mathrm{p}=.194)$. Não foram também verificadas diferenças entre os estímulos para os valores do CETp $(\mathrm{p}=.191)$. Na análise entre os grupos e estímulos encontrou-se diferença estatística do CETp para o GC do estímulo A comparado ao estímulo $\mathrm{B}(\mathrm{p}=.047)$, diferença que não foi encontrada para os participantes do grupo DP $(\mathrm{p}=.799)$. Este resultado mostra que os integrantes do GC estimaram como diferentes o tempo de manipulação dos estímulos A e B (média dos valores do CETp para o Estímulo A = -1,21 e para o Estímulo $\mathrm{B}=-0,56)$, enquanto o mesmo resultado não foi encontrado para os participantes do grupo DP (média dos valores do CETp para o Estímulo A = -0,41 e para o Estímulo B = -0,43; Figura 8). 


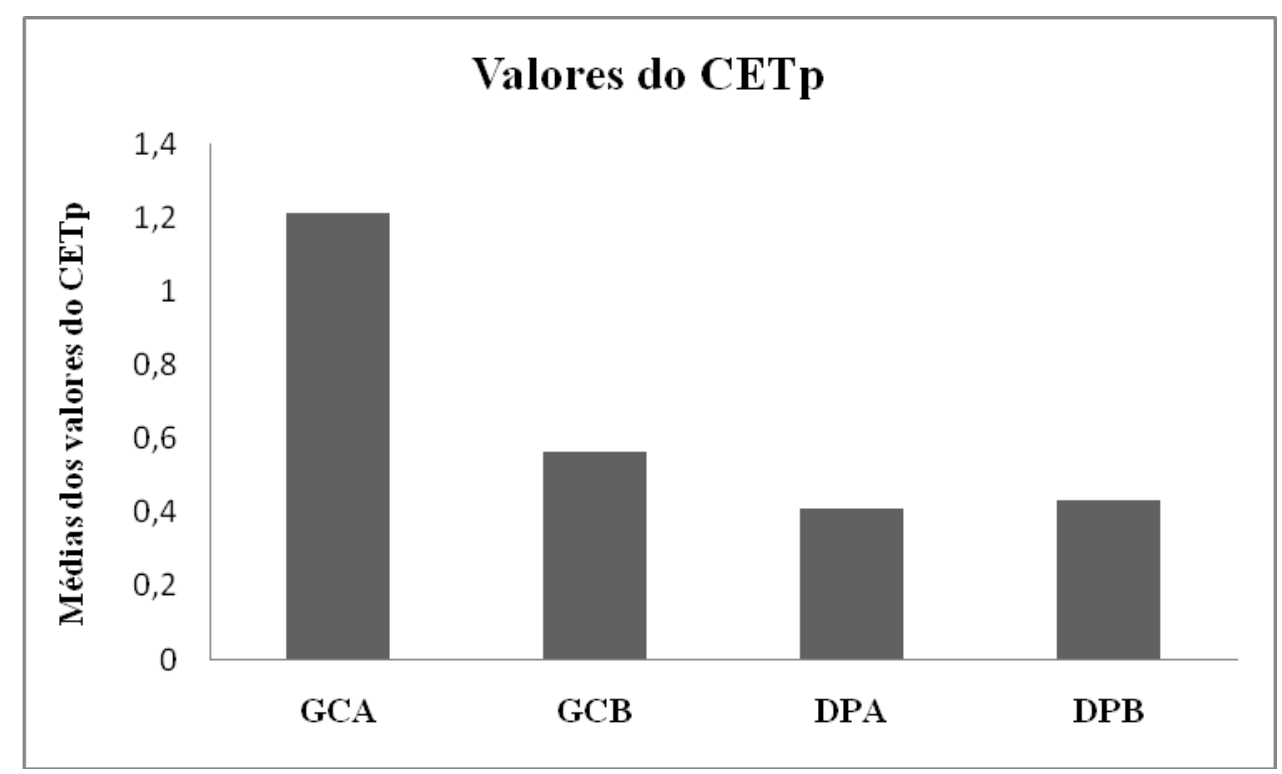

Figura 8. Gráfico representando os valores das médias do CETp das estimativas verbais realizadas pelos participantes do tempo de manipulação dos Estímulos A e B. CETp: coeficiente de estimação temporal ponderado; GCA: média do CETp para o Estímulo A do grupo de participantes controle; GCB: média do CETp para o Estímulo B do grupo de participantes controle. DPA: média do CETp para o Estímulo A do grupo de participantes com diagnóstico de Doença de Parkinson; DPB: média do CETp para o Estímulo B do grupo de participantes com diagnóstico de Doença de Parkinson. Os valores do CETp (GCA: -1,21; GCB: -0,56; DPA: 0,41; DPB: -0,43) foram multiplicados por (-1).

Com relação à análise do tempo real de manipulação( $\left.t_{(r)}\right)$, encontrou-se diferença estatística entre os grupos de participantes $(p=.003)$, e encontrou-se diferenças entre o grupo GC e o grupo DP para o estímulo B $(\mathrm{p}=.015)$, para os demais grupos não encontrou-se diferenças.Este resultado mostra que o $t_{(r)}$ dos estímulos foi menor para os participantes do grupo DP (média 52s) quando comparado ao GC (GC: média 87s); e que o estímulo com maior nível de complexidade (Estímulo B) teve maior $t_{(r)}$ realizado pelo GC (88s) do que pelo grupo DP (52s); no entanto, o $t_{(r)}$ do estímulo com menor nível de complexidade (estímulo A) não apresentou diferença entre os grupos de participantes (GC: 86; DP: 53; Figura 9). 


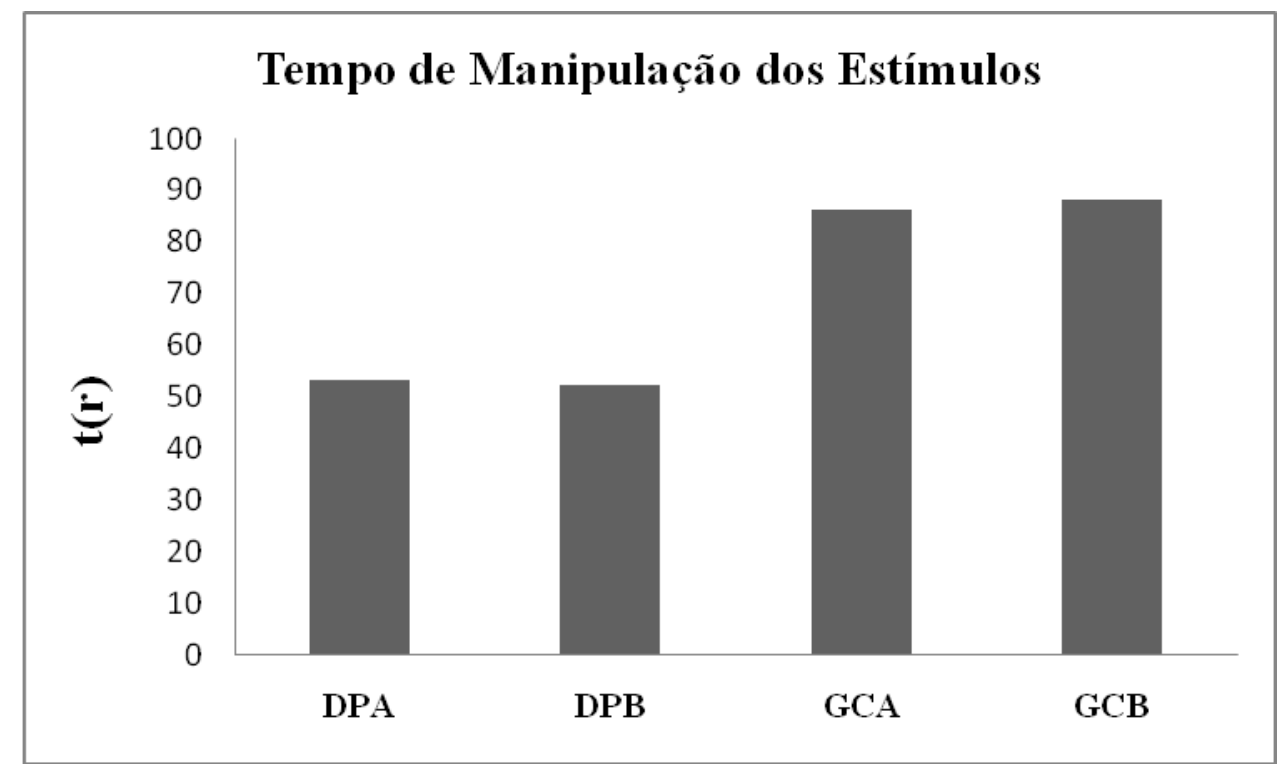

Figura 9. Gráfico representando os valores da média, em segundos, do tempo real de manipulação $(t(r))$ dos estímulos dos grupos de participantes. DPA: representação da média do t(r) do Estímulo A para os participantes com diagnóstico de Doença de Parkinson; DPB: representação da média do t(r) do Estímulo B para os participantes com diagnóstico de Doença de Parkinson; GCA: representação da média do t(r) do Estímulo A para os participantes do GC; GCB:representação da média do t(r) do Estímulo B para os participantes do GC.

\subsubsection{Categorias de manipulação dos estímulos}

A análise dos valores das proporções $\left(P_{\text {(cat) }}\right)$, das frequências $\left(F_{\text {(cat) }}\right)$ e das frequências relativas $\left(F R_{(\text {cat })}\right)$ de cada categoria de manipulação entre os participantes mostrou diferenças entre o grupo de participantes controle (GC) e o grupo DP para Proporção da categoria $\operatorname{Tocar}\left(P_{(T)}: \mathrm{p}=.002\right)$, para Frequência da categoria $\operatorname{Movimentar}\left(F_{(M)}: \mathrm{p}=.004\right)$ e para Frequência relativa da categoria $\operatorname{Tocar}\left(F R_{(T)}: \mathrm{p}=.035\right)$.

A média de toques realizados pelo grupo DP foi de $10,9 \%$ do tempo real de manipulação e para o grupo GC a média de toques foi de 5,1\% do tempo real de manipulação, o que indica que os integrantes do GC apresentaram menor média de toques aos estímulos quando comparada à média de toques dos indivíduos que pertenciam ao grupo DP. Quanto à análise da $P_{(T)}$ entre os grupos de participantes, encontrou-se diferença para o estímulo $\mathrm{B}(\mathrm{p}=$ .017), revelando que a $P_{(T)}$ do estímulo com maior número de faces (estímulo B) apresentou uma média de toques maior para o grupo DP $(13,7 \%)$ quando comparada à média de toques do GC (5,1\%) (Figura 10). 
Para $F R_{(T)}$ encontrou-se que os participantes do grupo DP apresentaram uma maior média de toques/s $(0,02$ toques/s) quando comparados aos participantes do grupo GC $(0,03$ toques/s).

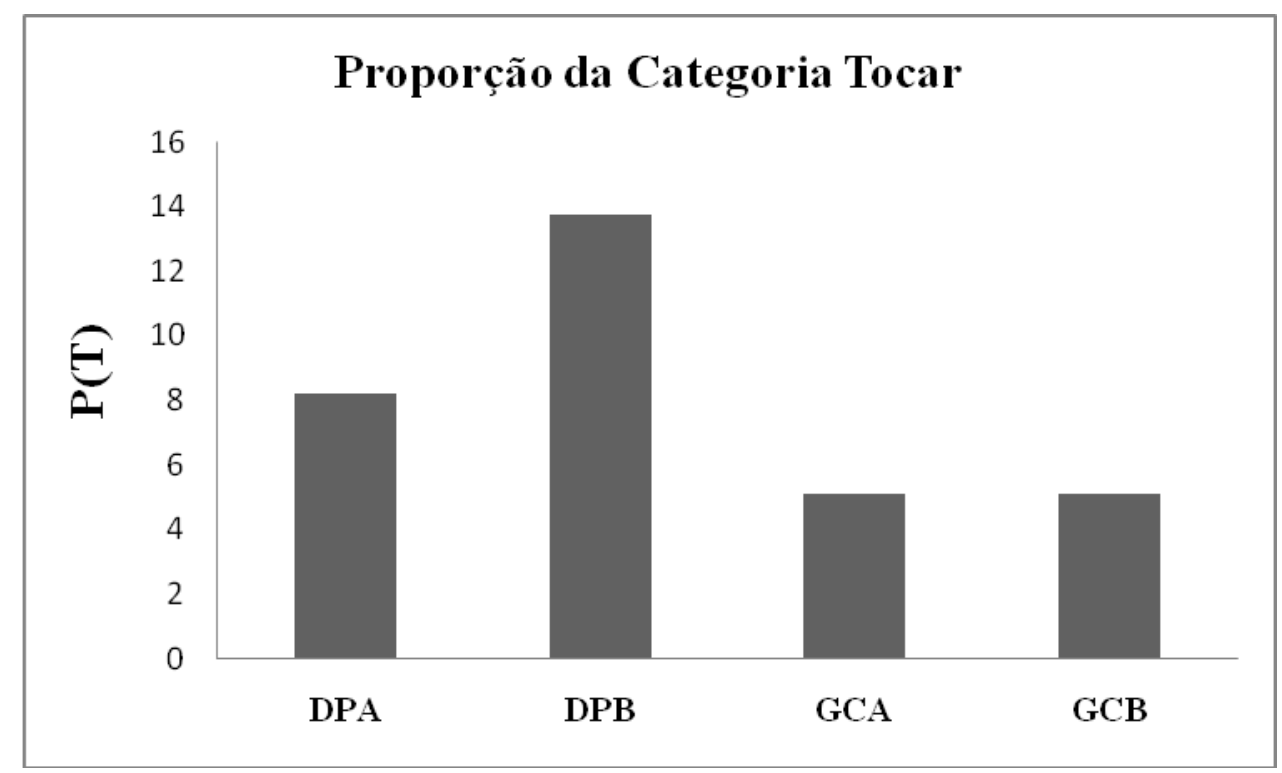

Figura 10. Gráfico representando os valores da média, em porcentagem, da proporção da categoria Tocar $(P(T))$ dos participantes. DPA:representação da média da $P(T)$ do Estímulo A para os participantes com diagnóstico de Doença de Parkinson; DPB: representação da média da $P(T)$ do Estímulo B para os participantes com diagnóstico de Doença de Parkinson; GCA: representação da média da $P(T)$ do Estímulo A para os participantes do grupo controle; GCB:representação da média da $P(T)$ do Estímulo B para os participantes do grupo controle.

$\mathrm{Na}$ análise dos valores da $F_{(M)}$ encontrou-se que os participantes do GC apresentaram maior $F_{(M)}(4,75$ vezes $)$ do que os participantes do grupo DP (1,66 vezes) durante a manipulação dos estímulos (Figura 11).

Ainda com relação à $F_{(M)}$, encontrou-se diferença estatística para o Estímulo A entre os grupos de participantes $(\mathrm{p}=.043)$, indicando que o estímulo com menor nível de complexidade (Estímulo A) apresentou maior $F_{(M)}$ para o GC (5,3 vezes) quando comparado ao grupo DP (1,6 vezes), o que não ocorreu para o estímulo com maior nível de complexidade (Estímulo B; DP: 1,6; GC: 4,2; Figura 11). A análise da $F R_{(M)}$ não revelou diferença entre os grupos de participantes para os estímulos ( $=.133$; Figura 12). 


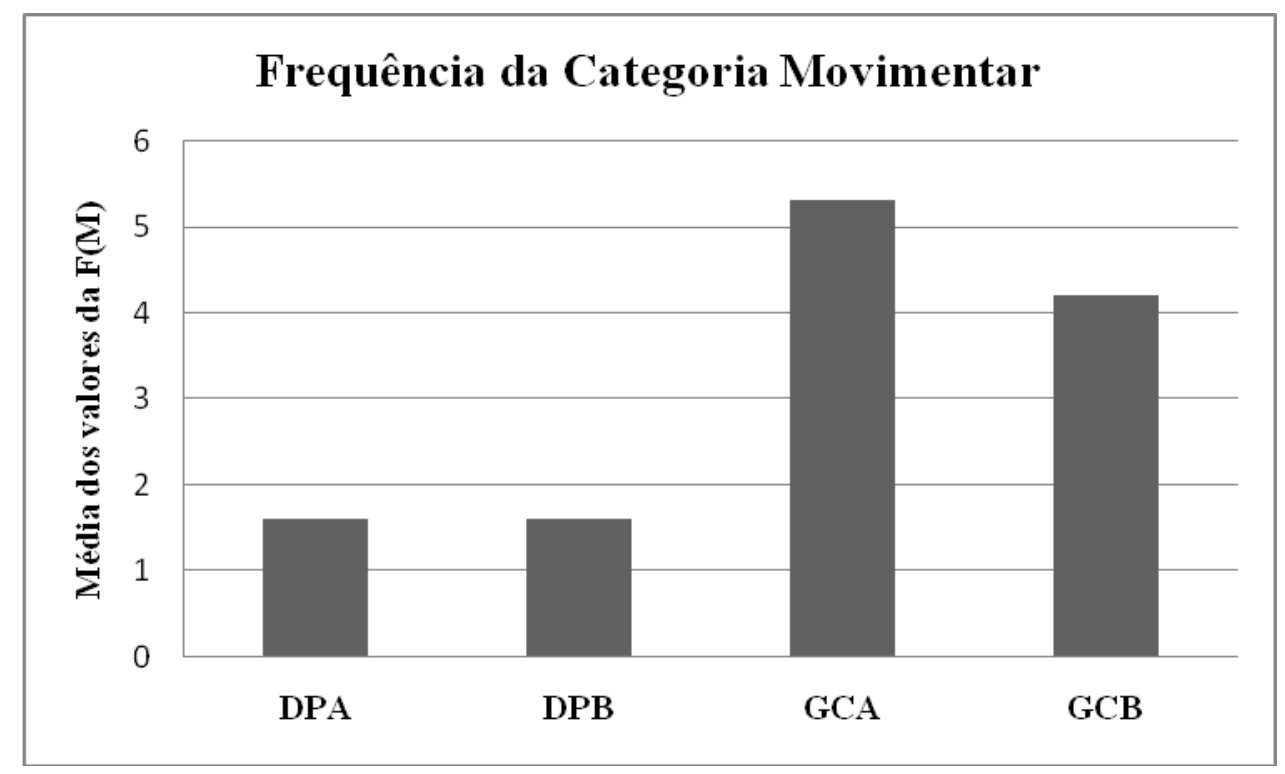

Figura 11. Gráfico representando os valores da média da Frequência da categoria Movimentar $(F(M))$ dos participantes para os estímulos. DPA: representação da $F(M)$ do Estímulo A para os participantes com diagnóstico de Doença de Parkinson; DPB: representação da $F(M)$ do Estímulo $B$ para os participantes com diagnóstico de Doença de Parkinson; GCA: representação da $F(M)$ do Estímulo A para os participantes do grupo controle; GCB: representação da $F(M)$ do Estímulo B para os participantes do grupo controle.

Encontrou-se também diferença para o GC com relação aos estímulos para a Frequência Relativa da categoria Movimentar $\left(F R_{(M)} ; \mathrm{p}=.028\right)$, para a Frequência Relativa da categoria Soltar $\left(F R_{(S)} ; \mathrm{p}=.047\right)$ e para a Frequência Relativa da categoria Deslocar $\left(F R_{(D)} ; \mathrm{p}=.046\right)$, dados que revelam que ocorreu frequência relativa maior para as categorias de manipulação Movimentar, Soltar e Deslocar para o Estímulo A $\left(F R_{(M)}: 0,06 / \mathrm{s}, F R_{(S)}\right.$ : $0,03 / \mathrm{s}$ e $\left.F R_{(D)}: 0,03 / \mathrm{s}\right)$ comparado ao Estímulo B $\left(F R_{(M)}: 0,04 / \mathrm{s}, F R_{(S)}: 0,01 / \mathrm{s}\right.$ e $F R_{(D)}$ : 0,02/s); não foram encontradas diferenças para os participantes do grupo DP (Figura 12). 


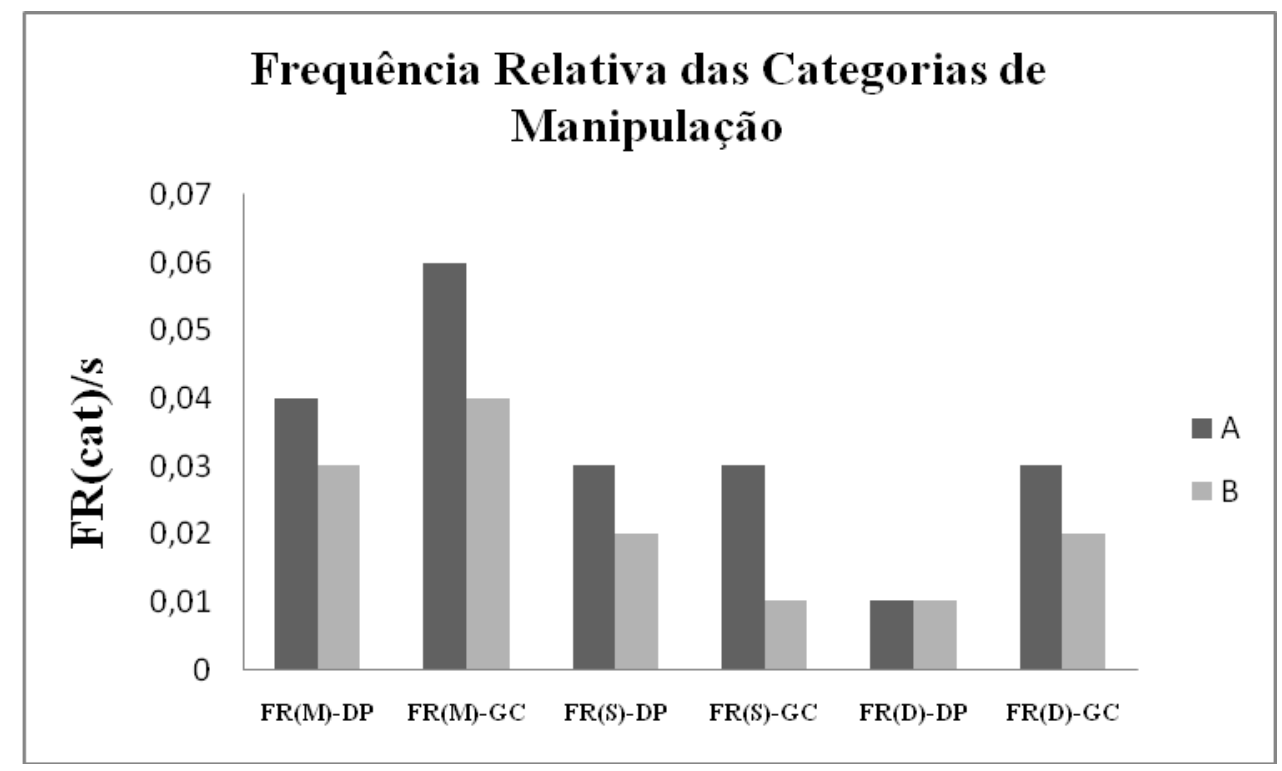

Figura 12. Gráfico representando os valores da média da Frequência Relativa das Categorias de manipulação (FR(cat)) para os participantes. DP: participantes com diagnóstico de Doença de Parkinson; GC: participantes do grupo controle; A: Estímulo A; B: Estímulo B; M: Categoria Movimentar; S: Categoria Soltar; D: Categoria Deslocar.

\subsection{DISCUSSÃO}

Os resultados indicam que a manipulação de obras de arte com níveis diferentes de complexidade gera alteração da percepção do tempo em indivíduos com diagnóstico de DP e indivíduos sem a doença. No presente estudo, todos os participantes superestimaram, ou seja, estimaram os tempos de manipulação como maiores do que os tempos reais. Esta superestimação foi menor para os participantes com DP do que para os participantes sem DP. Block (1978) realizou um estudo no qual investigou o efeito da complexidade de padrões visuais sobre a experiência de duração dos participantes. $\mathrm{O}$ resultado encontrado mostrou que os padrões visuais individuais não tiveram efeito sobre a duração lembrada, e o autor aponta que é possível que o nível de complexidade proporcionado pelos estímulos pode não ter sido suficientemente grande para influenciar o julgamento da duração. No entanto, quando consideradas sequências de padrões visuais, ocorreu o alongamento da duração lembrada conforme aumentou a complexidade da sequência. Estes achados parecem indicar que não é a complexidade do estímulo em si que pode influir na percepção da duração lembrada, mas sim a complexidade da tarefa como um todo.

McClain (1983), utilizando como estímulos listas que apresentavam quantidade variada de palavras que deveriam ser processadas em tarefas que exigiam níveis diferentes de 
complexidade, encontrou que o nível de processamento cognitivo utilizado na execução da tarefa afetou o número de palavras lembradas, de maneira que, em cada lista, quanto mais complexo foi o nível de processamento, mais palavras foram lembradas. E os achados também revelaram que a estimação do tempo, sob o paradigma retrospectivo, seria uma função direta da quantidade de informação apresentada, independente do grau de complexidade do seu processamento; assim, quanto mais palavras foram expostas, maior foi a duração estimada. Estes dados apontam que o tempo julgado aumenta em consonância com o aumento da exigência cognitiva de um evento que ocorreu em um intervalo de tempo.

Entretanto, Hicks, Miller e Kinsbourne (1976) verificaram que o julgamento temporal retrospectivo não ocorria como uma função da quantidade de informação processada. No entanto, os autores argumentam que o julgamento do tempo pode estar relacionado à quantidade de conteúdo recuperado, e destacam que o pobre conteúdo das informações pode ser um fator que conduz à falta de efeito sobre a duração lembrada.

No presente estudo, a superestimação do tempo de manipulação dos estímulos pode estar relacionada à demanda da tarefa, que envolvia, além do processamento visual, o processamento cognitivo do conteúdo informacional dos estímulos, o processamento da ação motora seqüencial - considerada demandar maior atividade cognitiva do que um ato motor simples (Sanes, 1985) -, a coordenação visuo-motora e a integração de todos esses processos. Juntos, estes fatores atribuiriam um alto nível de complexidade à tarefa contribuindo para o alongamento da duração lembrada. Essa suposição pode ser confirmada pelo Modelo do Armazenamento de Ornstein (1969), que propõe que a estimação temporal é afetada pelo nível de complexidade de uma situação que ocorre em um intervalo de tempo.

Essa explicação apresentada para a superestimação do tempo de manipulação das obras de obra parece válida para os participantes com DP e sem a doença, uma vez que ambos os grupos de participantes julgaram o tempo de manuseio dos estímulos como maior do que realmente foi. Contudo, é preciso considerar que os indivíduos com DP apresentaram uma menor superestimação quando comparados aos participantes do GC.

Sanes (1985), visando investigar a capacidade para o processamento da informação durante a seleção e execução de movimentos em pessoas com DP, propôs que estes segurassem uma sonda elétrica (electricprobe) do mesmo modo que segurariam um instrumento de escrita. Durante séries de 20 segundos os participantes deveriam alternar o movimento da sonda, o mais rápido quanto possível, entre alvos pequenos e grandes, separados por espaços que variavam em suas distâncias. Os resultados encontrados, de modo geral, revelaram que o desempenho dos indivíduos com DP piorava com o aumento da 
dificuldade da tarefa, e que estes apresentavam um processamento da informação motora em um ritmo mais lento do que os integrantes do GC. Estes fatores apontam que os pacientes com DP não puderam processar a mesma quantidade de informação por unidade de tempo que os participantes controle, e no que diz respeito ao processamento motor, isto implica que alguns aspectos da programação, recuperação e execução da atividade motora estavam prejudicados nos indivíduos com DP.

Mediante isto, é possível considerar que o alto grau de complexidade da tarefa proposta neste estudo acabou por demandar um alto nível de processamento cognitivo, sendo este um fator que contribuiu para que a estimação temporal fosse superestimada por todos os participantes, e com base nisto, torna-se também possível inferir que prováveis déficits em processar e coordenar as informações referentes à manipulação dos estímulos pode ter contribuído para a menor superestimação apresentada pelos participantes com DP.

Stern, Mayeux, Rosen e Ilson (1983) ressaltam que pacientes com DP apresentam disfunção percepto-motora, especialmente quando executam movimentos voluntários preditivos e sequenciais. Portanto, os autores defendem que o déficit perceptivo-motor dos pacientes com DP pode representar uma inabilidade para coordenar a percepção com certas funções motoras a fim de gerar movimentos baseados em um plano motor. Eles definem percepção como a habilidade para discriminar a informação sensorial externa, como por exemplo, a visual; e descrevem a função motora como uma série de movimentos os quais são sequencialmente executados. Assim, a coordenação dessas duas atividades com a finalidade de desempenhar um plano motor pode representar um nível mais alto de processamento.

E no que se refere à percepção temporal e componente motor, há pesquisas que apontam que o desempenho em atividades motoras pode influenciar a estimação temporal de pessoas com DP (Malapani, Deweer, \& Gibbon, 2002; Malapani et al., 1998; Pastor et al, 1992).

A percepção temporal de pacientes com DP tem sido previamente relatada, revelando que em tarefas de estimação de durações de estímulos sonoros que variavam entre 50$1500 \mathrm{~ms}$, o desempenho de pacientes com DP, em geral, não apresentou déficits quando foram comparados aos do GC, ou quando os pacientes estavam sem medicação comparado com quando estavam medicados (Wearden et al., 2008). Dentre as possíveis explicações para este achado está a ausência de tarefa motora, uma vez que, prejuízos na percepção do tempo poderiam estar relacionados a falhas na atividade motora dos participantes com DP e não estarem diretamente associados a déficits específicos na estimação temporal (Malapani, Deweer, \& Gibbon, 2002; Malapani et al., 1998). Por exemplo, Pastor et al. (1992) relataram prejuízo na estimação verbal e reprodução temporal de intervalos entre 3 e 27 s de pacientes 
com DP. Durante estas durações os participantes foram solicitados a contar internamente, assim, os pacientes teriam sido significativamente mais lentos na contagem interna através de resposta motora subvocal e os resultados seriam devidos à lentidão motora e não decorrentes de um déficit específico da estimação do tempo.

No entanto, o estudo de Riesen e Schnider (2001) não encontrou relação entre atividade motora e estimação temporal. Eles realizaram um experimento que consistia em participantes com DP medicados e participantes controle pressionassem uma "barra de espaço" uma vez por segundo (tapping), para durações de 12, 24 e 48s. O resultado apontou que ambos os grupos conseguiram manter um ritmo de batidas sobre a barra constante nos três intervalos de tempo examinados, embora a frequência dos toques fosse demasiado lenta para todos os participantes. E os pacientes com DP demonstraram estimar os intervalos tão precisamente quanto os controles, embora todos os participantes tenham subestimado as durações. Estes dados indicam que a atividade motora dos pacientes com DP parece não repercutir em déficits da estimação do tempo em pessoas com DP.

Entretanto, o resultado da presente pesquisa pode diferir daquele apresentado por Riesen e Schnider (2001), pelos seguintes fatores: a demanda motora da atividade aqui proposta foi maior: os participantes foram solicitados a manipular obras de arte que apresentavam níveis de complexidade diferentes; o tempo de estimação foi mais alto em nosso experimento, com uma média de 52 s para os participantes com DP e $87 \mathrm{~s}$ para o GC; estas diferenças justificariam as alterações na estimação do tempo encontradas para os participantes com DP.

Outro aspecto que pode ter colaborado com a alteração da percepção temporal apresentada pelos indivíduos com DP é a quantidade de tempo despendida para a realização da tarefa motora proposta. O alto nível de complexidade da tarefa que implicava em alta demanda cognitiva e motora pode ter produzido "desconforto" em decorrência da dificuldade de executar um plano motor (Gentilucci \& Negrotti, 1999b; Horstink, Berger, Spaendonck, Bercken, \& Cools, 1990) e ter implicado em déficits para gerenciar a atenção (Horstink et al., 1990) que levaram os pacientes com DP a manipularem por menos tempo os estímulos. E o menor tempo de manipulação pode ter colaborado para a menor superestimação.

Horstink et al. (1990) afirmam que a realização de tarefas bimanuais implica na execução simultânea de dois programas motores distintos, assim, exigindo o compartilhamento da atenção; pacientes com DP teriam dificuldade para regular a atenção e direcioná-la para a ação (Rowe et al., 2002). No entanto, quando estes pacientes voltam sua atenção para o ato motor, apresentam melhora no desempenho (Behman, Teitelbaum, \& 
Cauraugh, 1998; Canning, 2005). Além disto, os indivíduos com DP apresentam dificuldade para deslocar a atenção repetidamente entre duas orientações espaciais (Brown \& Marsden, 1990).

Ao mesmo tempo que os indivíduos com DP apresentam prejuízos no aspecto atencional, estes mostram, também,disfunção cognitiva em outros componentes, tais como memória, sequenciamento, ordenamento temporal e discriminação de recência, bem como, prejuízo no planejamento auto direcionado de tarefas e no desempenho de tarefas que demandam esforço cognitivo (Brown \& Marsden, 1990).

Todos estes aspectos, quando considerados em conjunto, podem também explicar a similaridade observada entre a estimação temporal da duração de manipulação dos estímulos com diferentes níveis de complexidade apresentada pelo grupo com DP, pois é possível supor que déficits no desempenho cognitivo e motor resultaram em menor tempo de manipulação, que refletiu na menor exploração dos estímulos, o que teria contribuído para que as distinções entre eles não fossem identificadas e, por conseguinte, o tempo de suas manipulações teria sido percebido como de igual extensão. Em vista disto, a maior duração do tempo de manipulação apresentada pelo GC teria repercutido em maior exploração dos estímulos, o que teria possibilitado o reconhecimento de suas peculiaridades, resultando em diferentes percepções de tempo, nas quais o estímulo com maior nível de complexidade foi considerado ter sido manuseado por menor tempo quando comparado ao estímulo com menor nível de complexidade.

A pesquisa de Davidson, Abott e Gershenfeld (1974) confirma que o maior tempo de manipulação permite melhor exploração do estímulo. Neste estudo, os autores realizaram uma pesquisa relacionando percepção visual e tátil, tempo e esculturas. Assim, examinaram como o tempo de exploração das esculturas, através da visão e do tato, poderia afetar a precisão na discriminação das diferentes formas e como o participante fazia uso do tempo de exploração, isto é, como era sua atividade exploratória. Os participantes da pesquisa foram instruídos a explorar esculturas padrões e comparar com esculturas correspondentes. Os períodos de tempo para as comparações eram de $4 \mathrm{~s}$ e $16 \mathrm{~s}$, variando de acordo com as seguintes modalidades: somente exploração tátil, somente exploração visual e exploração tátil-visual. Os participantes foram divididos em grupos segundo cada modalidade. A atividade de exploração de cada participante no grupo de exploração tátil foi gravada, visando categorizar o movimento de exploração das mãos, isto é, o método exploratório usado pelo participante cada vez que ele manipulava o estímulo. Os métodos listados foram: (1) busca global, no qual dedos e polegar eram usados independentemente; (2) busca por detalhes, em que se usavam 
movimentos coordenados dos dedos e polegar; (3) busca palmar, onde a palma da mão pressionava o estímulo; e (4) traçado, referindo-se ao traçado de um caminho com as pontas dos dedos ao redor da escultura. Os resultados encontrados apontaram que o tempo de exploração tátil é um determinante aparentemente importante de precisão. $\mathrm{O}$ aumento do tempo de exploração das formas melhora a comparação entre elas, e por consequência, favorece que estímulos semelhantes sejam identificados. Outro achado da pesquisa é que mudanças no método de manipulação ocorrem paralelamente ao aumento do tempo de exploração tátil refletindo o uso de um maior número de movimentos das mãos para reunir informações do estímulo.

As diferenças no nível de exploração dos estímulos entre o grupo com DP e o GC podem ainda ser reveladas pela análise da manipulação realizada pelos participantes a partir das categorias de manipulação. Esta análise revela que o grupo com DP, comparado ao GC, movimentou e deslocou menos as obras de arte e as tocou e soltou mais, o que indica uma menor exploração dos estímulos. Isto pode ser explicado por déficits na execução de tarefas motoras sequenciais observadas em indivíduos com DP (Castiello et al., 1993; Horne, 1973; Stern et al., 1983).

Gentilucci e Negrotti (1999a, 1999b) realizaram um experimento em indivíduos com DP, no qual buscavam investigar a cinemática de atos motores sucessivos que consistiam em alcançar, pegar e deslocar um objeto. Os resultados encontrados apontaram que os participantes demonstraram planejar a ação motora, entretanto, apresentaram prejuízo na sua execução, e consequentemente, precisavam reprogramar o movimento. As reprogramações ocorreriam em decorrência da complexidade da ação, uma vez que pacientes com DP mostrariam prejuízo em controlar a execução de movimentos complexos (Alberts et al., 2000), e o fato de deslocar o objeto requerer mudanças na amplitude e direção quando relacionado ao ato motor anterior; isto pode ter induzido o participante a realizar os dois atos motores separadamente (Gentilucci e Negrotti, 1999a).

Considerando isto, é possível inferir que as categorias tocar e soltar foram mais realizadas pelos participantes com DP, porque estes devido a prejuízos na execução da ação motora, acabavam por fragmentar os movimentos, precisando constantemente reprogramá-los e reiniciá-los, o que dificultava que as categorias movimentar e deslocar fossem desempenhadas.

Castiello et al. (1993) avaliaram o movimento de alcance e preensão em indivíduos com DP; para tanto, os participantes deveriam alcançar e apreender uma cavilha pequena, com diâmetro de $0.7 \mathrm{~cm}$, ou uma cavilha grande, com diâmetro de $8 \mathrm{~cm}$, que foram 
posicionadas verticalmente em distâncias que variavam de 15 a $40 \mathrm{~cm}$. O resultado encontrado mostrou que os pacientes com DP demonstraram anormalidade da coordenação entre os dois componentes do movimento: alcance e preensão, de maneira que o início do componente de manipulação ocorria depois do início do componente de transporte, quando o apropriado seria que ocorressem de modo quase simultâneo. E quanto mais preciso deveria ser o movimento maior era o atraso apresentado entre os dois componentes.

Alberts et al. (2000) investigaram a trajetória do movimento de pacientes com DP durante o alcance, preensão e elevação de cilindros de diferentes diâmetros $(1 \mathrm{~cm}$ e $8 \mathrm{~cm})$ que requeriam diferentes níveis de precisão e que foram posicionados a uma distância de $30 \mathrm{~cm}$ da posição inicial da mão do participante. Os resultados apontaram que sob condições de maior precisão, os participantes com DP produziram trajetórias de transporte menos contínua, porque eles realizavam primeiramente o movimento do membro no plano vertical antes de avançar para o plano horizontal, apresentando uma dissociação na ação de alcançar e apreender um objeto. Esta inabilidade para coordenar precisamente os componentes do movimento de alcançar-para-preensão seria resultado da disfunção do gânglio basal observado em indivíduos com DP. Outros estudos apontam resultados semelhantes (Flash, Inzelberg, Schechtman, \& Korczyn, 1992).

As pesquisas de Castiello et al. (1993) e Alberts et al. (2000) confirmam a suposição de que as diferenças encontradas entre o grupo com DP e o GC em relação às categorias de manipulação seriam em decorrência de anormalidades na integração e no desempenho de tarefas que exigem alcance e preensão, como a que foi proposta neste estudo. Assim, a maior proporção e frequência de toques realizados pelos participantes com DP seria resultado da incoordenação entre os componentes de preensão e da produção de movimentos que são mais segmentados.

Este déficit, associado às disfunções cognitivas mencionadas anteriormente, também pode explicar porque para o grupo com DP a proporção de toques e as frequências das categorias Movimentar, Deslocar e Soltar mostraram-se semelhantes no manuseio das obras independentemente do nível de complexidade, enquanto que para o $\mathrm{GC}$, as proporções e frequências das mesmas categorias exibiram diferenças entre as obras de arte, de maneira que o estímulo com menor nível de complexidade, quando comparado ao estímulo com maior nível de complexidade, recebeu uma proporção menor de toques e foi movimentado, deslocado e solto com maior frequência.

Berlyne (1963) ao propor tarefas de escolha exploratória, encontrou que mudanças no tempo de exposição de pares de imagens, com diferentes níveis de complexidade, de curto 
(0.5 ou 1 segundo) para longo (3 ou 4 segundos) diminuíam a probabilidade de que os estímulos mais complexos fossem escolhidos para uma melhor inspeção, isto porque existiria uma preferência ótima de conteúdo de informação a qual os participantes buscariam expor a si mesmos e ainda, porque os padrões de maior e menor complexidade dos pares de estímulos continham exatamente o mesmo material, diferindo apenas na irregularidade da estrutura, assim, observar um deles possibilitaria apreender especificidades do outro.

Considerando isto, as diferenças observadas nas categorias de manipulação dos distintos estímulos para o GC, que pareceu ter realizado uma maior exploração do estímulo com menor nível de complexidade, estariam relacionadas com uma tendência dos indivíduos para preferir estímulos que estejam mais próximos do conteúdo de informação ótimo a ser processado, e que ao explorar o conteúdo da obra de arte com menor nível de complexidade teria sido possível identificar o conteúdo do estímulo correspondente com maior nível de complexidade, ou ainda assimilar sua característica particular.

Mas, em seus trabalhos sobre a percepção de propriedades colativas de imagens, Berlynee colaboradores (1957, 1958, 1966; Berlyne \& Crozier, 1971; Berlyne \& Lawrence, 1964; Berlyne et al., 1968) ao verificarem o tempo de exploração dos estímulos, encontraram que quanto maior o nível de complexidade de um objeto, mais tempo o indivíduo gastava em observá-lo, isto porque atributos como o grau de complexidade chamariam mais atenção, e assim despertariam maior curiosidade, aumentando o grau de excitação do organismo (arousal) e gerando desconforto, e para eliminá-lo, o participante levaria mais tempo inspecionando o estímulo. Mediante isto, o resultado encontrado nesta pesquisa que mostra que o estímulo com menor nível de complexidade foi mais explorado pelos participantes do GC, parece ir em direção oposta ao que Berlyne apresenta. Contudo, esta aparente contradição pode ser desfeita quando se considera que as pesquisas realizadas por Berlyne tinham como tarefa a exploração visual dos estímulos apresentados, diferindo do presente estudo, cuja tarefa consistia em explorar o estímulo através do manuseio, desta forma exigindo uma integração do componente visual com o componente motor, e, portanto, implicando em mecanismos perceptivos outros que podem ter contribuído para comportamentos de apreciação de obras de arte diferentes daqueles observados por Berlyne.

Em relação à percepção do tempo diferente para o mesmo tempo de manipulação dos estímulos apresentado pelos participantes do GC, que julgaram como maior o tempo de manuseio do estímulo com menor nível de complexidade quando comparado ao estímulo com maior nível de complexidade, é possível supor que a duração lembrada foi alongada em 
função do grau de atenção demandado pelo processamento da informação da tarefa durante o intervalo de tempo (Underwood, 1975; Underwood \& Swain, 1973).

Deste modo, os participantes do GC teriam despendido maior atenção à obra de arte com menor nível de complexidade - aspecto que é confirmado pela análise das categorias de manipulação que revelou uma maior exploração deste estímulo - e assim, teria ocorrido uma maior demanda para o processamento de seu conteúdo e mais informações teriam sido armazenadas a seu respeito, o que, portanto, teria contribuído para que o tempo de manipulação deste estímulo fosse percebido como maior em relação ao tempo de manuseio do estímulo mais complexo.

O estudo realizado por Block (1974) confirma esta hipótese. Neste trabalho, o autor investigando a experiência de duração para intervalo retrospectivo de tempo, utilizou como estímulos sequencias de palavras que variavam em nível de complexidade. E encontrou que os julgamentos da duração foram maiores para a sequência de palavras com menor nível de complexidade; isto refletiria que o tamanho do armazenamento de um intervalo no momento do julgamento da duração estaria relacionado com o grau de organização do evento na memória. Assim, quando a sequência do evento é mais organizada, mais informações a seu respeito seriam retidas na memória, e a experiência de duração seria alongada.

Outro fator que pode explicar as diferenças observadas na estimação do tempo de manipulação dos estímulos (em que os participantes do grupo com DP apresentaram menor superestimação quando comparados aos integrantes do GC) e as diferenças nas categorias de manipulação (que revelaram que, em relação ao GC, os indivíduos com DP movimentaram e deslocaram menos os estímulos, e os tocaram e soltaram mais) é a estrutura neural envolvida com a percepção do tempo e as funções motoras. O circuito cortico-tálamo-estriato-cortical envolvido no controle motor (Harrington, Haaland, \& Hermanowicz, 1998), seria o mesmo relacionado com a experiência temporal (Harrington \& Jahanshahi, 2016), e apresentaria atividade anormal em pacientes com DP (Braak et al., 2003; Braak et al., 2004; Harrington et al, 2011; Allman \& Meck, 2012), assim, déficits na percepção do tempo e na atividade motora, como os observados no presente estudo, podem ser resultados do prejuízo apresentado por este circuito em pessoas diagnosticadas com DP.

Em resumo, o presente experimento revelou que a manipulação de obras de arte altera a percepção subjetiva do tempo de indivíduos com DP, que superestimam a duração experienciada. Uma possível explicação para o achado está relacionada com a quantidade de tempo de manipulação das obras, a consequente exploração das mesmas, e o processamento cognitivo-motor da informação. 


\section{CONSIDERAÇÕES FINAIS}

Os dados obtidos no presente estudo mostraram que a manipulação de obras de arte móveis altera a percepção subjetiva do tempo de indivíduos com diagnóstico de Doença de Parkinson (DP). A manipulação possibilita a interação com o meio, sendo que através dela o ambiente é modificado; estas mudanças ocorreriam durante a passagem do tempo, o que confere importância à percepção temporal.

Quando um ambiente é manipulado entram em jogo processos perceptivos, cognitivos e motores, que quando integrados e processados permitem que as vivências no mundo sejam interpretadas e significadas, e a experiência temporal subjetiva seria diretamente influenciada por estes aspectos. Assim, quando se analisa o contato de um indivíduo com uma obra de arte, contato este que se dá em um espaço-tempo, algumas considerações se tornam necessárias.

As características e propriedades presentes numa obra de arte são aspectos relevantes no encontro com a mesma, e podem determinar impressões e comportamentos exploratórios, como os observados neste estudo, em que o nível de complexidade presente em uma obra pode suscitar interesse, produzir sensação de agradabilidade e instigar a manipulação.

Uma alta demanda da tarefa associada com um alto nível de conteúdo e consequentemente uma alta exigência para seu processamento demonstra ser crucial para a percepção temporal, de maneira que, subjetivamente, produz a impressão de um alongamento do tempo. Estes fatores também parecem estar relacionados com a quantidade de atenção investida no evento, de modo que uma maior atenção dirigida conduz a alteração da percepção temporal.

A condição na qual se apresenta um indivíduo demonstra ser de grande importância, especificamente no caso de pessoas com diagnóstico de DP, nas quais a patologia inevitavelmente implica em modificações na interação com o ambiente, e estas por sua vez conduzem a uma percepção e ação sobre o mundo de modo distinto e a experiência temporal assumiria característica particular. No caso desta pesquisa, a apreciação de uma obra de arte, através da manipulação, evidenciou uma superestimação do tempo pelos indivíduos com DP.

Assim, os dados apresentados nesta pesquisa mostram que a manipulação de uma obra de arte móvel alonga a percepção subjetiva do tempo de indivíduos com DP, que demonstram uma superestimação menor do que aquela apresentada pelos participantes sem a doença. $\mathrm{O}$ tempo despendido pelos pacientes com DP para a manipulação do estímulo associado ao 
comportamento exploratório observado a partir das categorias de manipulação e relacionados com aspectos da patologia estariam implicados nos resultados obtidos.

Levando-se em conta os vários aspectos aqui apresentados, considera-se que a manipulação de obras de arte permitiu novas possibilidades de estudo de tempo subjetivo, no sentido de promover novas informações a respeito de como se dá a percepção subjetiva do tempo e como as pessoas com alterações dos padrões motores reagem mediante o contato com uma obra de arte. 


\section{REFERÊNCIAS}

Agostino, P. V. \& Cheng, R. K. (2016). Contributions of dopaminergic signaling to timing accuracy and precision. Current Opinion in Behavioral Sciences, 8, 153-160.

Alberts, J. L., Saling, M., Adler, C. H., \& Stelmach, G. E. (2000).Disruptions in the reach-tograsp actions of Parkinson's patients. Experimental Brain Research, 134, 353-362.

Allman, M. J., \& Meck, W. H. (2012). Pathophysiological distortions in time perception and timed performance. Brain: A Journal of Neurology, 135, 656-677.

Allman, M. J., Teki, S., Griffiths, T. D., \& Meck, W. H. (2014). Properties of the internal clock: first- and second-order principles of subjective time. Annual Review of Psychology, 65, 743-771.

Angrilli, A., Cherubini, P., Pavese, A., \& Manfredini, S. (1997). The influence of affective factors on time perception. Perception \& Psychophysics, 59(6), 972-982.

Barbieri, C. P. (2008). Lygia Clark, da vida à arte e de volta à vida. Estudos de Psicanálise, $31,36-42$.

Barbosa, E. R., \& Sallem, F. A. S. (2005). Doença de Parkinson - Diagnóstico. Revista Neurociências, 13(3), 158-165.

Barkley, R. A., Koplowitz, S., Anderson, T., \& McMurray, M.B. (1997). Sense of time in children with ADHD: effects of duration, distraction and stimulant medication. Journal of the International Neuropsychological Society, 3(4), 359-69.

Behman, A. L., Teitelbaum, P., \& Cauraugh, J. H. (1998). Verbal instructional sets to normalize the temporal and spatial gait variable in Parkinson's disease. Journal of Neurology, Neurosurgery, and Psychiatry, 65, 580-582.

Berlyne, D. E. (1957). Conflict and information-theory variables as determinants of human perceptual curiosity. Journal of Experimental Psychology, 53(6), 399-404.

Berlyne, D. E. (1958). The influence of complexity and novelty in visual figures on orienting responses. Journal of experimental psychology, 55(3), 289-296.

Berlyne, D. E. (1961). Conflict and the orientation reaction. Journal of Experimental Psychology, 62(5), 476-483.

Berlyne, D. E. (1963). Complexity and incongruity variables as determinants of exploratory choice and evaluative ratings. Canadian Journal of Psychology, 17(3), 274-290.

Berlyne, D. E. (1966). Curiosity and exploration. Science, 153(3731), 25-33.

Berlyne, D. E. (1973). Interrelations of verbal and nonverbal measures used in experimental aesthetics. Scandinavian Journal of Psychology, 14, 177-184. 
Berlyne, D. E. (1974). The new experimental aesthetics. In D. E. Berlyne (Ed.), Studies in the new experimental aesthetics (pp. 1-25). Toronto, Canada: University of Toronto.

Berlyne, D. E. (1976). Similarity and preference judgments of Indian and Canadian subjects exposed to Western paintings. International Journal of Psychology, 11(1), 43-55.

Berlyne, D. E., Craw, M. A., Salapatek, P. H., \& Lewis, J. L. (1963). Novelty, complexity, incongruity, extrinsic motivation, and the GSR. Journal of Experimental Psychology, 66(6), 560-567.

Berlyne, D. E., \& Crozier, J. B (1971). Effects of complexity and prochoice stimulation on exploratory choice. Perception \& Psychophysics, 10, 242-246.

Berlyne, D. E., \& Lawrence, G. H. (1964). Effects of complexity and incongruity variables on GSR, investigatory behavior, and verbally expressed preference. The Journal of General Psychology, 71(1), 21-45.

Berlyne, D. E., Ogilvie, J. C., \& Parham, L. C. C. (1968). The dimensionality of visual complexity, interestingness, and pleasingness. Canadian Journal of Psychology, 22(5), 376387.

Berlyne, D. E., \& Peckham, S. (1966). The semantic differential and other measures of reaction to visual complexity. Canadian Journal of Psychology, 20(2), 125-135.

Berry, A. S., Li. X., Lin, Z., \& Lustig, C. (2014). Shared and distinct factors driving attention and temporal processing across modalities. Acta Psychologica, 147, 42-50.

Bherer, L., Desjardins, S., \& Fortin, C. (2007). Age-related differences in timing with breaks. Psychology and aging, 22(2), 398-403.

Blewett, A. E. (1992). Abnormal subjective time experience in depression. The British Journal of Psychiatry, 161(2), 195-200.

Block, R. A. (1974). Memory and the experience of duration in retrospect. Memory \& Cognition, 2(1A), 153-160.

Block, R. A. (1978). Remembered duration: effects of event and sequence complexity. Memory \& Cognition, 6(3), 320-326.

Block, R. A. (1985). Contextual coding in memory: studies of remembered duration. In J. A. Michon, \& J. L. Jackson (Ed.). Time, mind and behavior (pp. 169-178). Berlin, Germany: Springer-Verlog.

Block, R. A. (1990) Models of psychological time. In R. A. Block. (Ed.). Cognitive Models of Psychological Time (pp. 1-35). Hillsdale, NJ: Lea Publishers.

Block, R. A., \& Reed, M. A. (1978). Remembered duration: evidence for a contextual-change hypothesis. Journal of Experimental Psychology: Human Learning \& Memory, 4(6), 656665.

Block, R. A., \& Zakay, D. (1996). Models of psychological time revisited. In H. Helfrich (1996). Time and Mind. (pp. 171-195). Kirkland, WA: Hogrefe \& Huber. 
Block, R. A., \& Zakay, D. (1997). Prospective and retrospective duration judgments: a metaanalytic review. Psychonomic Bulletin \& Review, 4(2), 184-197.

Boltz, M. (1989). Time judgments of musical endings: effects of expectancies on the "filled interval effect". Perception \& Psychophysics, 46(5), 409-418.

Braak, H., Ghebremedhin, E., Rüb, U., Bratzke, H., \& Tredici, K. Del. (2004). Stages in the development of Parkinson's disease-related pathology. Cell and Tissue Research, 318(1), $121-134$

Braak, H., Tredici, K. Del, Rüb, U., Vos, R. A. I. de, Steur, E. N. H. J., \& Braak, E. (2003). Staging of brain pathology related to sporadic Parkinson's disease. Neurobiology of Aging, 24(2), 197-211.

Brett, G. (1994). Lygia Clark: in search of the body. Art in America, 82, 56-63.

Brito, R. (1999). Neoconcretismo: vértice e ruptura do projeto construtivo brasileiro. Rio de Janeiro: FUNARTE/Instituto Nacional de Artes Plásticas.

Brown, R. G., \& Marsden, C. D. (1990). Cognitive function in Parkinson's disease: from description to theory. Trends in Neurosciences, 13(1), 21-29.

Brown, S. W. (1985). Time perception and attention: the effects of prospective versus retrospective paradigms and task demands on perceived duration. Perception \& Psychophysics, 38(2), 115-124.

Brown, S. W. (1995). Time, change, and motion: the effects of stimulus movement on temporal perception. Perception \& Psychophysics, 57(1), 105-116.

Brown, S. W. (1997). Attentional resources in timing: interference effects in concurrent temporal and nontemporal working memory tasks. Perception \& Psychophysics, 59(7), 11181140.

Brown, S. W., \& Stubbs, D. A. (1992). Attention and interference in prospective and retrospective timing. Perception 21, 545-557.

Bueno, J. L. O. (1985). A questão do tempo. In: A. Jacquemim (Ed), Anais da XV Reunião Anual de Psicologia da Sociedade de Psicologia de Ribeirão Preto (pp.196-198). Ribeirão Preto: Sociedade de Psicologia de Ribeirão Preto.

Bueno, J. L. O., \& Engelmann, A. (1976). A influência de estimulações musicais sobre estimação de tempo: estudo preliminar. Resumos da XXVIII da Reunião Anual da Sociedade Brasil para o Progresso da Ciência. Brasília, DF, Brasil.

Bueno, J. L. O., Firmino, E. A., \& Engelmann, A. (2002). Influence of generalized complexity of a music event in subjective time estimation. Perceptual and Motor Skills, 94, 541-547. 
Bueno, J. L. O., \& Ramos, D. (2007). Musical mode and estimation of time. Perceptual and Motor Skills, 105, 1087-1092.

Buhusi, C. V., \& Meck W. H. (2009). Relative time sharing: new findings and an extension of the resource allocation model of temporal processing. Philosophical Transactions of the Royal Society B, 364, 1875-1885.

Butler, C. H., \& Pérez-Oramas, L. (2014). Lygia Clark. The abandonment of art, 1948-1988. New York: The Museum of Modern Art.

Canning, C. G. (2005). The effect of directing attention during walking under dual-task conditions in Parkinson's disease. Parkinsonism and Related Disorders, 11, 95-99.

Carroll, C.A., Boggs, J., O’Donnell, B. F., Shekhar, A., \& Hetrick, W.P. (2008). Temporal processing dysfunction in schizophrenia. Brain and Cognition, 67(2), 150-61.

Carvalho, D. H. B. de. (2011). O corpo na poética de Lygia Clark e a participação do espectador. Moringa-Artes do Espetáculo, 2(2), 131-142.

Castiello, U., Bennett, K. M. B., \& Paulignan, Y. (1992). Does the type of prehension influence the kinematics of reaching? Behavioural Brain Research, 50, 7-15.

Castiello, U., Stelmach, G. E., \& Lieberman, A. N. (1993). Temporal dissociation of the prehension pattern in Parkinson's disease. Neuropsychologia, 31(4), 395-402.

Church, R. M. (1984). Properties of the internal clock. Annals of the New York Academy of Sciences, 423, 566-582.

Cocenas-Silva, R., Bueno, J. L. O., Bigand, E., \& Molin, P. (2009). Escala multidimensional aplicada aos estudos de apreciação musical. Paideia, 19(43), 153-158.

Cocenas-Silva, R., Bueno, J. L. O., Molin, P., \& Bigand, E. (2011). Multidimensional scaling of musical time estimations. Perceptual and Motor Skills, 112(3), 737-748.

Cope, T. E., Grube, M., Mandal, A., Cooper, F. E., Brechany, U., Burn, D. J., \& Griffiths, T. D. (2014). Subthalamic deep brain stimulation in Parkinson's disease has no significant effect on perceptual timing in the hundreds of milliseconds range. Neuropsychologia, 57(1), 29-37.

Coulangeon, P., Ravet, H., \& Roharik, I. (2005). Gender differentiated effect of time in performing arts professions: musicians, actors and dancers in contemporary France. Poetics, 33(5), 369-387.

Coull, J. T., Nazarian, B., \& Vidal, F. (2008). Timing, storage, and comparison of stimulus duration engage discrete anatomical components of a perceptual timing network. Journal of Cognitive Neuroscience, 20, 2185-2197.

Coull, J., \& Nobre, A. (2008). Dissociating explicit timing from temporal expectation with fMRI. Current Opinion Neurobiology, 18, 137-144.

CupChik, G. C. (1986). A decade after Berlyne. Poetics, 15, 345-396. 
CupChik, G. C., \& Berlyne, D. E. (1979). The perception of collative properties in visual stimuli. Scandinavian Journal of Psychology, 20, 93-104.

CupChik, G. C., \& Gebotys, R. (1988). The experience of time, pleasure, and interest during aesthetic episodes. Empirical Studies of the Arts, 6(1), 1-12.

Cutting, J. E. (2002). Representing motion in a static image: constraints and parallels in art, science, and popular culture. Perception, 31(10), 1165-1193.

Davidsont, P. W., Abbott, S., \& Gershenfeld, J. (1974). Influence of exploration time on haptic and visual rnatching of complex shape. Perception \& Psychophysics, 15(3), 539-543.

Debaere, F., Wenderoth, N., Sunaert, S., Hecke, P. van., \& Swinnen, S. P. (2003). Internal vs external generation of movements: differential neural pathways involved in bimanual coordination performed in the presence or absence of augmented visual feedback. NeuroImage, 19(3), 764-776.

Droit-Volet, S., Bigand, E., Ramos, D., \& Bueno, J. L. O. (2010). Time flies with music whatever its emotional valence. Acta Psychologica, 135, 226-232.

Droit-Volet, S., Meck, W. H., \& Penney, T. B. (2007). Sensory modality and time perception in children and adults. Behavioural Processes, 74(2), 244-250.

Droit-Volet, S., Ramos, D., Bueno, J. L. O., \& Bigand, E. (2013). Music, emotion, and time perception: the influence of subjective emotional valence and arousal? Frontiers in Psychology, doi: 10.3389/fpsyg.2013.00417

Dušek, P., Jech, R., Sieger, T., Vymazal, J., Růžička, E., Wackermann, J., \& Mueller, K. (2012). Abnormal activity in the precuneus during time perception in Parkinson's disease: an fMRI study. PLoS ONE, 7(1), e29635.

Eagleman, D. M. (2008). Human time perception and its illusions. Current Opinion in Neurobiology, 18(2), 131-136.

Espinosa-Fernández, L., Miró, E., Cano, M., \& Buela-Casal, G. (2003). Age-related changes and gender differences in time estimation. Acta Psychologica, 112(3), 221-232.

Ferreira, V. F. M., Paiva, G. P., Prando, N., Graça, C. R., \& Kouyoumdjian, J. A. (2016). Time perception and age. Arquivos de neuro-psiquiatria, 74(4), 299-302.

Firmino, E. A., \& Bueno, J. L. O. (2008). Tonal modulation and subjective time.Journal of New Music Research, 37(4), 275-297.

Firmino, E. A., \& Bueno, J. L. O. (2016). Interkey distances also shorten subjective time reproductions in real modulating tonal music. Music Perception, 33(5), 613-630.

Firmino, E. A., Bueno, J. L. O., \& Bigand, E. (2009). Travelling through pitch space speeds up musical time. Music Perception, 26(3), 205-209. 
Flash, T., Inzelberg, R., Schechtman, E., \& Korczyn, A. D. (1992). Kinematic analysis of upper limb trajectories in Parkinson's disease. Experimental Neurology, 118(2), 215-226.

Foss-Feig, J. H., Kwakye, L.D., Cascio, C.J., Burnette, C.P., Kadivar, H., Stone, W.L., Wallace, M. T. (2010). An extended multisensory temporal binding window in autism spectrum disorder. Experimental Brain Research, 203(2), 381-389.

Fraisse, P. (1984) Perception and estimation of time. Annual Review of Psychology, 35,1-36.

Gentilucci, M., \& Negrotti, A. (1999a). The control of an action in Parkinson's disease. Experimental Brain Research, 129(2), 269-277.

Gentilucci, M., \& Negrotti, A. (1999b). Planning and executing and action in Parkinson's disease patients. Movement disorders, 14(1), 69-79.

Gibbon, J., \& Church, R. (1984). Sources of variance in an information processing theory of timing.In H. L. Roiblatt, T. G. Bever, \& H. S. Terrace (Ed.). Animal cognition (pp. 465-488). Hillsdale, NJ: Erlbaum.

Gibbon, J., Church, R., \& Meck, W. (1984). Scalar timing in memory. In J. Gibbon, \& L. G. Allan (Ed.), Timing and time perception (Vol. 423, pp. 52-77). New York: New York Academy of Sciences.

Gibson, J. J. (1975) Events are perceivable but time is not. In J. T. Fraser, \& N. Laurence. The Study of Time (Vol. 2). Berlin: Springer.

Grondin, S. (2008). Methods for Studying Psychological Time. In S. Grondin (Ed.), Psychology of Time. Emerald Group Publishing.

Grondin, S. (2010). Timing and time perception: a review of recent behavioral and neuroscience findings and theoretical directions. Attention, Perception \& Psychophysics, $72(3), 561-582$.

Harrington, D. L., Castillo, G.N., Greenberg, P. A., Song, D. D., Lessig, S., Lee, R. R., \& Rao, S. M. (2011). Neurobehavioural mechanisms of temporal processing deficits in Parkinson's Disease. Plos One, 6(2), e17461. doi:10.1371/journal.pone.0017461

Harrington, D. L., Haaland, K. Y., \& Hermanowicz, N. (1998). Temporal Processing in the Basal Ganglia. Neuropsychology, 12(1), 3-12.

Harrington, D. L. \& Jahanshahi, M. (2016).Reconfiguration of striatal connectivity for timing and action. Current Opinion in Behavioral Sciences, 8, 78-84.

Hicks, R. E., Miller, G. W., \& Kinsbourne, M. (1976). Prospective and retrospective judgments of time as a function of amount of information processed. American Journal of Psychology, 89(4), 719-730.

Horne, D. J. L. (1973). Sensorimotor control in Parkinsonism. Journal of Neurology, Neurosurgery \& Psychiatry, 36, 742-746.

Horstink, M. W. I. M., Berger, H. J. C., Spaendonck, K. P. M. van, Bercken, J. H. L. van den, Cools, A. R. (1990). Bimanual simultaneous motor performance and impaired ability to shift 
attention in Parkinson's disease. Journal of Neurology, Neurosurgery, and Psychiatry, 53, 685-690.

Jankovic, J. (2008). Parkinson's disease: clinical features and diagnosis. Journal of Neurology, Neurosurgery, and Psychiatry, 79(4), 368-76.

Jones, M. R., \& Boltz, M. (1989). Dynamic attending and responses to time. Psychological Review, 96, 459-491.

Jones, C. R. G., Malone, T. J. L., Dirnberger, G., Edwards, M., \& Jahanshahi, M. (2008). Basal ganglia, dopamine and temporal processing: performance on three timing tasks on and off medication in Parkinson's disease. Brain and Cognition, 68(1), 30-41.

Kamakura, N., Matsuo, M., Ishii, H., Mitsuboshi, F., \& Miura, Y. (1980). Patterns of static prehension in normal hands.The American Journal of Occupational Therapy, 34(7), 437-445.

Kyota, F., \& Saito, S. (2012). Fast Grasp Synthesis for Various Shaped Objects. In Computer graphics forum (Vol. 31, No. 2pt4, pp. 765-774). Blackwell Publishing Ltd.

Lee, K. S., \& Jung, M. C. (2014). Common patterns of voluntary grasp types according to object shape, size, and direction. International Journal of Industrial Ergonomics, 44, 761-768.

Lewis, P. A., \& Miall, R. C. (2003). Distinct systems for automatic and cognitively controlled time measurement: evidence from neuroimaging. Current Opinion Neurobiology, 13, 250255 .

Livesey, A. C., Wall, M. B., \& Smith, A. T. (2007). Time perception: manipulation of task difficulty dissociates clock functions from other cognitive demands. Neuropsychologia, 45, 321-331.

Lustig, C., Matell, M. S., \& Meck, W. H. (2005). Not “just” a coincidence: frontal-striatal synchronization in working memory and interval timing. Memory, 13, 441-448.

Malapani, C., Deweer, B., \& Gibbon, J. (2002). Separating storage from retrieval dysfunction of temporal memory in Parkinson's disease. Journal of Cognitive Neuroscience, 14(2), 311322.

Malapani, C., Rakitin, B. C., Levy, R., Meck, W. H., Deweer, B., Dubois, B., \& Gibbon, J. (1998). Coupled temporal memories in Parkinson's disease: a dopamine-related dysfunction. Journal of Cognitive Neuroscience, 10(3), 316-331.

Matell, M. S., \& Meck, W. H. (2000). Neuropsychological mechanisms of interval timing behavior. BioEssays, 22, 94-103.

Matell, M. S., \& Meck, W. H. (2004). Cortico-striatal circuits and interval timing: coincidence-detection of oscillatory processes. Cognitive Brain Research, 21, 139-170.

Matell, M. S., Meck, W. H., \& Nicolelis, M. A. L. (2003). Interval timing and the encoding of signal duration by ensembles of cortical and striatal neurons. Behavioral Neuroscience, 117, 760-773. 
McClain, L. (1983). Interval estimation: effect of processing demands on prospective and retrospective reports. Perception \& Psychophysics, 34(2), 185-189.

Meck, W. H. (1984). Attentional bias between modalities: effect on the internal clock, memory, and decision stages used in animal time discrimination. Annals of the New York Academy of Sciences, 423, 528-541.

Medeiros, I. da S., \& Soares, P. (2009). Experimentalismo artístico e a década de 60 no Brasil: por um novo sentido de participação social. Anais, XVII Congresso de Iniciação Científica e I Congresso de Iniciação em Desenvolvimento Tecnológico e Inovação. Universidade Federal de Pernambuco.

Mella, N., Conty, L., \& Pouthas, V. (2011). The role of physiological arousal in time perception: psychophysiological evidence from na emotion regulation paradigm. Brain and Cognition, 75(2), 182-187.

Merchant, H., Luciana, M., Hooper, C., Majestic, S., \& Tuite, P. (2008). Interval timing and Parkinson's disease: heterogeneity in temporal performance. Experimental Brain Research, 184(2), 233-248.

Middleton, F. A., \& Strick, P. L. (1994). Anatomical evidence for cerebellar and basal ganglia involvement in higher cognitive function. Science, 266, 458-461.

Nather, F.C., \& Bueno, J. L. O. (2006a). Efeitos de imagens estáticas com diferentes representações de movimento sobre a percepção subjetiva de tempo. Psicologia: Reflexão $e$ Crítica, 19(2), 217-224.

Nather, F.C., \& Bueno, J. L. O. (2006b). Tempo subjetivo e percepção de movimento em obras de arte. Estudos de Psicologia, 11(3), 265-274.

Nather, F.C., \& Bueno, J. L. O. (2011). Static images with different induced intensities of human body movements affect subjective time. Perceptual and Motor Skills, 113(1), 157-170.

Nather, F.C., \& Bueno, J. L. O. (2012a). Timing perception in painting and sculptures of Edgar Degas. KronoScope, 12(1), 16-30.

Nather, F. C., \& Bueno, J. L. O. (2012b). Exploration time of static images implying different body movements causes time distortions. Perceptual and motor skills, 115(1), 105-110.

Nather, F. C., Bueno, J. L. O., \& Bigand, E. (2013). Body movement implied by static images modulates eye movements and subjective time estimation. Psychology \& Neuroscience, 6(3), 261-270.

Nather, F. C., Bueno, J. L. O., Bigand, E., \& Droit-Volet, S. (2011). Time changes with the embodiment of another's body posture. Plos One, 6(5), doi: 10.1371/journal.pone.0019818

Nather, F. C., Fernandes, P. A. M., \& Bueno, J. L. O. (2012). Timing perception is affected by cubist paintings representing human figures. Proceedings of Fechner Day, 28(1), 292-297. 
Nather, F. C., Fernandes, P. A. M., \& Bueno, J. L. O. (2014). Subjective time perception is affected by different durations of exposure to abstract paintings that represent human movement. Psychology \& Neuroscience, 7(3), 381-392.

Nather, F. C., Mecca, F. F., \& Bueno, J. L. O. (2013). Motion illusions in Optical Art presented for long duration are temporally distorced. Perception, 42, 742-750.

Nenadic, I., Gaser, C., Volz, H. P., Rammsayer, T., Häger, F. \& Sauer, H. (2003). Processing of temporal information and the basal ganglia: new evidence from fMRI. Experimental Brain Research, 148, 238-246.

Ornstein, R. E. (1969). On the experience of time. Baltimore: Penguin.

Ottoni, E. B. (2000). EthoLog 2.2: a tool for the transcription and timing of behavior observation sessions. Behavior Research Methods, Instruments, \& Computers, 32(3), 446449.

Pastor, M. A., Artieda, J., Jahanshahi, M, \& Obeso, J. A. (1992). Time estimation and reproduction is abnormal in Parkinson's disease. Brain, 115, 211-225.

Perbal, S., Deweer, B., Pillon, B., Vidailhet, M., Dubois, B., \& Pouthas, V. (2005).Effects of internal clock and memory disorders on duration reproductions and duration productions in patients with Parkinson's disease. Brain and Cognition, 58(1), 35-48.

Ramos, D., \& Bueno, J. L. O. (2012a). A percepção de emoções em trechos de música ocidental erudita. Per Musi, 26, 21-30.

Ramos, D., \& Bueno, J. L. O. (2012b). Emoções de uma escuta musical afetam a percepção subjetiva de tempo. Psicologia: Reflexão e Crítica, 25(2), 286-292.

Riesen, J. M., \& Schnider, A. (2001). Time estimation in Parkinson's disease: normal long duration estimation despite impaired short duration discrimination. Journal of Neurology, $248,27-35$.

Rijn, H. van., Kononowicz, T. W., Meck, W. H., Ng, K. K., \& Penney, T. B. (2011). Contingent negative variation and its relation to time estimation: a theoretical evaluation. Frontiers in Integrative Neuroscience, 5(91), 10-3389.

Rowe, J., Stephan, K. E., Friston, K., Frackowiak, R., Lees, A., \& Passingham, R. (2002). Attention to action in Parkinson's disease. Brain, 125(2), 276-289.

Salzstein, S. (2011). Construção, desconstrução: o legado do neoconcretismo. Novos EstudosCEBRAP, 90, 103-113.

Sanes, J. N. (1985). Information processing deficits in Parkinson's Disease during movement. Neuropsychologia, 23(3), 381-392.

Scovino, F. (2003). A vontade poética no diálogo com os Bichos: o ponto de chegada de uma arte participative no Brasil. Revista do Programa de Pós-Graduação em Artes Visuais EBAUFRJ, 27-35. 
Smith, J. G., Harper, D. N., Gittings, D., \& Abernethy, D. (2007). The effect of Parkinson's disease on time estimation as a function of stimulus duration range and modality. Brain and Cognition, 64(2), 130-43.

Stern, Y., Mayeux, R., Rosen, J., \& Ilson, J. (1983). Perceptual motor dysfunction in Parkinson's disease: a deficit in sequential and predictive voluntary movement. Journal of Neurology, Neurosurgery, and Psychiatry, 46, 145-151.

Sveinbjornsdottir, S. (2016). The clinical symptoms of Parkinson's disease. Journal of Neurochemistry, doi: 10.1111/jnc.13691

Thomas, E. A. C., \& Brown, I. Jr. (1974). Time perception and the filled duration illusion. Perception \& Psychophysics, 16(3), 449-458.

Thomas, E. A. C., \& Weaver, W. B. (1975). Cognitive processing and time perception. Perception \&Psychophysics, 17, 363-367.

Torta, D. M. E., Castelli, L., Latini-Corazzini, L., Banche, A., Lopiano, L., \& Geminiani, G. (2010). Dissociation between time reproduction of actions and of intervals in patients with Parkinson's disease. Journal of Neurology, 257(8), 1356-1361.

Treisman, M. (1963). Temporal discrimination and the indifference interval: implications for a model of the "internal clock". Psychological Monographs, 77, 1-13.

Underwood, G. (1975). Attention and the perception of duration during encoding and retrieval. Perception, 4, 291-296.

Underwood, G., \& Swain, R. A. (1973). Selectivity of attention and the perception of duration. Perception, 2(1), 101-105.

Valdivieso, T. V., \& Freitas, A. (2012). Do objetual ao coletivo: Lygia Clark e a participação do espectador nos anos 1960. O Mosaico, 8, 30-42.

Vroon, P. A. (1970). Effects of presented and processed information on duration experience. ActaPsychologica, 34, 115-121.

Wearden, J. H., Smith-Spark, J. H., Cousins, R., Edelstyn, N. M. J., Cody, F. W. J., Y O'Boyle, D. J. (2008). Stimulus timing by people with Parkinson's disease. Brain and Cognition, 67, 264-279.

Wild-Wall, N., Willemssen, R., Falkenstein, M., \& Beste, C. (2008). Time estimation in healthy ageing and neurodegenerative basal ganglia disorders. Neuroscience Letters, 442(1), 34-38.

Zakay, D., \& Block, R. A. (2004). Prospective and retrospective duration judgments: an executive-control perspective. Acta Neurobiologiae Experimentalis, 64, 319-328. 


\section{APÊNDICE A - Escalas De Diferencial Semântico}

1 O objeto é capaz de evocar percepção de complexidade?

\begin{tabular}{|c|c|c|c|c|c|c|}
\hline 1 & 2 & 3 & 4 & 5 & 6 & 7 \\
\hline Simples
\end{tabular}

2 A representação da forma do objeto é regular?

\begin{tabular}{|r|l|l|l|l|l|l|}
\hline 1 & 2 & 3 & 4 & 5 & 6 & 7 \\
Regular
\end{tabular}

3Para uma obra de arte a quantidade de material usado na sua opinião é...

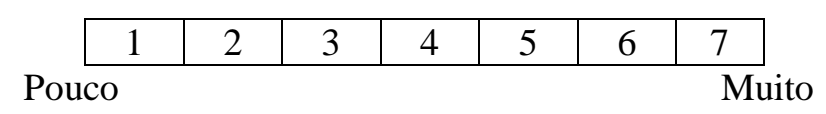

4 O objeto desperta interesse?

\begin{tabular}{|c|c|c|c|c|c|c|}
\hline 1 & 2 & 3 & 4 & 5 & 6 & 7 \\
\hline
\end{tabular}
Interessante

5 Quão agradável você achou este objeto?

\begin{tabular}{|c|c|c|c|c|c|c|}
\hline 1 & 2 & 3 & 4 & 5 & 6 & 7 \\
\hline Agradável
\end{tabular}




\section{APÊNDICE B - Termo de Consentimento Livre e Esclarecido (Paciente)}

$\mathrm{O}(\mathrm{A})$ senhor(a) está sendo convidado(a) a participar de um estudo que acontecerá no Hospital das Clínicas da Faculdade de Medicina de Ribeirão Preto-USP. O nome do estudo é: "Efeitos da Percepção Tátil de uma Obra de Arte Sobre o Tempo Subjetivo de Pacientes com Doença de Parkinson".

Os pesquisadores responsáveis são o Prof. Dr. José Lino Oliveira Bueno, do Departamento de Psicologia da Faculdade de Filosofia, Ciências e Letras de Ribeirão Preto da USP, o Prof. Dr. Vitor Tumas, do Departamento de Neurociências e Ciências do Comportamento da Faculdade de Medicina de Ribeirão Preto da USP e a Mestranda Marcia Regina Motta do Programa de Pós Graduação em Psicobiologia da Faculdade de Filosofia, Ciências e Letras de Ribeirão Preto da USP.

Este estudo quer saber como que usar as mãos para mexer em um objeto pode afetar a maneira como as pessoas com Doença de Parkinson percebem o tempo, pois o tempo é importante na vida e muitos comportamentos no dia a dia dependem do modo como sentimos o tempo passar.

Para a pesquisa participarão pessoas que tenham Doença de Parkinson. Como o(a) senhor(a) tem Doença de Parkinson está sendo convidado(a) a participar.

Caso o(a) senhor(a) aceite participar, será examinado(a) por um(a) médico(a). Em seguida, realizará uma tarefa de cerca de 45 minutos, na qual será necessário que o senhor(a), com suas mãos, mexa em obras artísticas. $\mathrm{O}(\mathrm{A})$ senhor (a) será gravado enquanto faz isso, para que depois seja possível descrever os movimentos que o(a) senhor(a) fez. As gravações serão guardadas por um período de 5 anos. Depois de ter manipulado a obra artística, você reproduzirá o tempo da atividade e responderá a algumas perguntas sobre sua participação.

É importante destacar que sua participação nesta pesquisa é voluntária, ou seja, o(a) senhor(a) tem liberdade de recusar a participar da mesma, ou, se aceitar participar, retirar seu consentimento a qualquer momento. Esta sua atitude não terá como consequência a interrupção do seu tratamento.

Como a tarefa será realizada preferencialmente no dia de sua consulta médica, o(a) senhor(a) não receberá qualquer benefício financeiro por participar da pesquisa. No entanto, caso o senhor(a) seja convidado(a) a comparecer no ambulatório em dia que não seja de sua consulta de rotina, o(a) senhor (a) será ressarcido(a) quanto a transporte e alimentação.

Os procedimentos adotados nesta pesquisa obedecem aos Critérios da Ética em Pesquisa com Seres Humanos conforme Resolução $n^{o}$ 466/12 do Conselho Nacional de Saúde e foram aprovados pelo Comitê de Ética local, que o(a) senhor(a) pode entrar em contato somente no caso de ter dúvidas com relação as questões éticas do projeto:

Comitê de Ética em Pesquisa da Faculdade de Filosofia, Ciências e Letras de Ribeirão Preto - USP. Avenida Bandeirantes, 3900 - Bloco 23 - Casa 37 - 14040-901 - Ribeirão Preto - SP - Brasil. Fone: (16) 3315-4811 / Fax: (16) 3315-910. E-mail: coetp@ffclrp.usp.br

$\mathrm{O}(\mathrm{A})$ senhor(a) tem garantidas todas as informações que queira, antes, durante e depois do estudo, tendo a liberdade para fazer qualquer pergunta sobre os objetivos da pesquisa, as tarefas realizadas e as informações que der.

As informações desta pesquisa poderão ser vistas pelos pesquisadores responsáveis e pelas autoridades legais, no entanto, se qualquer informação for divulgada em relatório ou publicação, isto será feito de forma codificada, para que seu nome seja mantido em sigilo. Isto significa que, quando os resultados forem publicados, não aparecerá seu nome, e sim um código.

Não existe a previsão de riscos a sua dignidade ou saúde nas tarefas realizadas nesta pesquisa. No entanto, caso sinta qualquer desconforto, poderá comunicar aos responsáveis pela pesquisa, que então lhe encaminharão para os atendimentos que avaliarem necessários. 
A sua participação neste estudo ajudará para que possamos melhorar nossa compreensão a respeito de como pessoas com Doença de Parkinson percebem o tempo. Com estas informações poderemos aprender mais sobre o assunto e no futuro ajudar as pessoas que têm o mesmo problema. Além disso, se nesse estudo algum problema for identificado durante sua avaliação clínica, o médico responsável pelo estudo lhe informará a esse respeito e lhe indicará o tratamento mais apropriado.

$\mathrm{Eu}, \ldots$ __ abaixo assinado, tendo recebido as informações acima, e sabendo dos meus direitos abaixo listados, concordo em participar com:

1. A garantia de receber a resposta a qualquer pergunta ou esclarecimento a qualquer dúvida com relação aos procedimentos, riscos, benefícios, e outros aspectos relacionados à pesquisa em que participarei;

2. A garantia de que não serei identificado e que será mantido o caráter confidencial das informações que prestarei;

3. A liberdade de interromper a participação no estudo a qualquer momento sem que isso traga prejuízo à continuidade do meu cuidado e tratamento;

4. O compromisso de me proporcionar informação atualizada durante o estudo, ainda que esta possa afetar minha vontade de continuar participando;

5. A garantia de que caso algum problema clínico tenha sido identificado em mim, receberei as informações necessárias sobre ele e o tratamento indicado.

Declaro, ainda, que recebi uma via assinada com todas as páginas rubricadas deste termo de consentimento e que concordo inteiramente com as condições que me foram apresentadas e que, livremente, manifesto a minha vontade em participar do referido projeto.

Ribeirão Preto, de de

Assinatura do Paciente ou responsável

Nome Legível:

Ribeirão Preto, de de

\section{PESQUISADOR RESPONSÁVEL:}

Assinatura do responsável pela pesquisa

Nome Legível:

\section{PESQUISADORES RESPONSÁVEIS:}

Prof. Dr. José Lino Oliveira Bueno

Departamento de Psicologia da Faculdade de Filosofia, Ciências e Letras de Ribeirão Preto da USP. Ribeirão Preto SP / CEP 14090-901

Telefone: Laboratório de Processos Associativos, Controle Temporal e Memória: (16) 3315-3697. 
Prof. Dr. Vitor Tumas

Departamento de Neurociências e Ciências do Comportamento da Faculdade de Medicina de Ribeirão Preto da USP. Ribeirão Preto SP / CEP 14048-900

Telefones: Departamento de Neurologia: (16) 3315-2548 ou (16) 3315-2391.

Mestranda Marcia Regina Motta

Programa de Pós Graduação em Psicobiologia da Faculdade de Filosofia, Ciências e Letras de Ribeirão Preto da USP. Ribeirão Preto/SP / CEP 14090-901

Telefone: Laboratório de Processos Associativos, Controle Temporal e Memória: (16) 3315-3697.

Contato Comitê de Ética: Comitê de Ética em Pesquisa da Faculdade de Filosofia, Ciências e Letras de Ribeirão Preto - USP

Avenida Bandeirantes, 3900 - Bloco 23 - Casa 37 - 14040-901 - Ribeirão Preto - SP - Brasil

Fone: (16) 3315-4811 / Fax: (16) 3315-9101

E-mail: coetp@ffclrp.usp.br 


\section{APÊNDICE C - Termo de Consentimento Livre e Esclarecido (Voluntário)}

$\mathrm{O}(\mathrm{A})$ senhor(a) está sendo convidado(a) a participar de um estudo que será desenvolvido no Hospital das Clínicas da Faculdade de Medicina de Ribeirão Preto-USP. O nome do estudo é: "Efeitos da Percepção Tátil de uma Obra de Arte Sobre o Tempo Subjetivo de Pacientes com Doença de Parkinson".

Os pesquisadores responsáveis são o Prof. Dr. José Lino Oliveira Bueno, do Departamento de Psicologia da Faculdade de Filosofia, Ciências e Letras de Ribeirão Preto da USP, o Prof. Dr. Vitor Tumas, do Departamento de Neurociências e Ciências do Comportamento da Faculdade de Medicina de Ribeirão Preto da USP e a Mestranda Marcia Regina Motta do Programa de Pós Graduação em Psicobiologia da Faculdade de Filosofia, Ciências e Letras de Ribeirão Preto da USP.

Este estudo quer saber como que usar as mãos para mexer em um objeto pode afetar a maneira como as pessoas com Doença de Parkinson percebem o tempo, pois o tempo é importante na vida e muitos comportamentos no dia a dia dependem do modo como sentimos o tempo passar.

Neste estudo, nós precisamos da participação de voluntários que, como o(a) senhor(a), não tem Doença de Parkinson, por isso o(a) senhor(a) está sendo convidado(a) a participar. Sua participação é importante para que possamos melhor conhecer as alterações no modo de perceber a passagem do tempo e manipulação de objetos das pessoas que tem Doença de Parkinson comparando com aquelas pessoas que não tem a doença.

Caso o(a) senhor(a) aceite participar, será examinado(a) por um(a) médico(a). Em seguida, realizará uma tarefa de cerca de 45 minutos, na qual será necessário que o senhor(a), com suas mãos, mexa em obras artísticas. O(A) senhor(a) será gravado enquanto faz isso, para que depois seja possível descrever os movimentos que o(a) senhor(a) fez. As gravações serão guardadas por um período de 5 anos. Depois de ter manipulado a obra artística, você reproduzirá o tempo da atividade e responderá a algumas perguntas sobre sua participação.

É importante destacar que sua participação nesta pesquisa é voluntária, ou seja, o(a) senhor(a) tem liberdade de recusar a participar da mesma, ou, se aceitar participar, retirar seu consentimento a qualquer momento sem que haja qualquer prejuízo ou penalidade.

Como a tarefa será realizada preferencialmente no dia da consulta médica do paciente que o(a) senhor(a) acompanha, não receberá qualquer benefício financeiro por participar da pesquisa. No entanto, caso o senhor(a) seja convidado(a) a vir ao ambulatório apenas para participar da pesquisa, $o$ (a) senhor(a) será ressarcido(a) quanto a transporte e alimentação.

Os procedimentos adotados nesta pesquisa obedecem aos Critérios da Ética em Pesquisa com Seres Humanos conforme Resolução $n^{o} 466 / 12$ do Conselho Nacional de Saúde e foram aprovados pelo Comitê de Ética local, que o(a) senhor(a) pode entrar em contato somente no caso de ter dúvidas com relação as questões éticas do projeto:

Comitê de Ética em Pesquisa da Faculdade de Filosofia, Ciências e Letras de Ribeirão Preto - USP. Avenida Bandeirantes, 3900 - Bloco 23 - Casa 37 - 14040-901 - Ribeirão Preto - SP - Brasil. Fone: (16)3315-4811 / Fax: (16) 3315-910.E-mail: coetp@ffclrp.usp.br

$\mathrm{O}$ (A) senhor(a) tem garantidas todas as informações que queira, antes, durante e depois do estudo, tendo a liberdade para fazer qualquer pergunta sobre os objetivos da pesquisa, as tarefas realizadas e as informações que der.

As informações desta pesquisa poderão ser vistas pelos pesquisadores responsáveis e pelas autoridades legais, no entanto, se qualquer informação for divulgada em relatório ou publicação, isto será feito de forma codificada, para que seu nome seja mantido em sigilo. Isto significa que, quando os resultados forem publicados, não aparecerá seu nome, e sim um código. 
Não existe a previsão de riscos a sua dignidade ou saúde nas tarefas realizadas nesta pesquisa. No entanto, caso sinta qualquer desconforto, poderá comunicar aos responsáveis pela pesquisa, que então lhe encaminharão para os atendimentos que avaliarem necessários.

A sua participação neste estudo ajudará para que possamos melhorar nossa compreensão a respeito de como pessoas com Doença de Parkinson percebem o tempo. Com estas informações poderemos aprender mais sobre o assunto e no futuro ajudar as pessoas que têm o mesmo problema. Além disso, se nesse estudo algum problema for identificado durante sua avaliação clínica, o médico responsável pelo estudo lhe informará a esse respeito e lhe indicará o tratamento mais apropriado.

$\mathrm{Eu}$, , abaixo assinado, tendo recebido as informações acima, e sabendo dos meus direitos abaixo listados, concordo em participar com:

1. A garantia de receber a resposta a qualquer pergunta ou esclarecimento a qualquer dúvida com relação aos procedimentos, riscos, benefícios, e outros aspectos relacionados à pesquisa em que participarei;

2. A garantia de que não serei identificado e que será mantido o caráter confidencial das informações que prestarei;

3. A liberdade de interromper a participação no estudo a qualquer momento sem que haja qualquer prejuízo ou penalidade;

4. O compromisso de me proporcionar informação atualizada durante o estudo, ainda que esta possa afetar minha vontade de continuar participando;

5. A garantia de que caso algum problema clínico tenha sido identificado em mim, receberei as informações necessárias sobre ele e o tratamento indicado.

Declaro, ainda, que recebi uma via assinada com todas as páginas rubricadas deste termo de consentimento e que concordo inteiramente com as condições que me foram apresentadas e que, livremente, manifesto a minha vontade em participar do referido projeto.

Ribeirão Preto, de de

Assinatura do voluntário ou responsável

Nome Legível:

Ribeirão Preto, de de

\section{PESQUISADOR RESPONSÁVEL:}

Assinatura do responsável pela pesquisa

Nome Legível:

\section{PESQUISADORES RESPONSÁVEIS:}

Prof. Dr. José Lino Oliveira Bueno

Departamento de Psicologia da Faculdade de Filosofia, Ciências e Letras de Ribeirão Preto da USP. Ribeirão Preto SP / CEP 14090-901

Telefone: Laboratório de Processos Associativos, Controle Temporal e Memória: (16) 3315-3697. 
Prof. Dr. Vitor Tumas

Departamento de Neurociências e Ciências do Comportamento da Faculdade de Medicina de Ribeirão Preto da USP. Ribeirão Preto SP / CEP 14048-900

Telefones: Departamento de Neurologia: (16) 3315-2548 ou (16) 3315-2391.

Mestranda Marcia Regina Motta

Programa de Pós Graduação em Psicobiologia da Faculdade de Filosofia, Ciências e Letras de Ribeirão Preto da USP. Ribeirão Preto/SP / CEP 14090-901

Telefone: Laboratório de Processos Associativos, Controle Temporal e Memória: (16) 3315-3697.

Contato Comitê de Ética: Comitê de Ética em Pesquisa da Faculdade de Filosofia, Ciências e Letras de Ribeirão Preto - USP

Avenida Bandeirantes, 3900 - Bloco 23 - Casa 37 - 14040-901 - Ribeirão Preto - SP - Brasil

Fone: (16) 3315-4811 / Fax: (16) 3315-9101

E-mail: coetp@ffclrp.usp.br 


\section{APÊNDICE D - Questionário}

1. Dados Pessoais:

Nascimento:

Sexo: ( ) Feminino ( ) Masculino

Escolaridade:

2. Você já conhecia esses objetos? De onde?

3. Os objetos produziram alguma emoção e, ou, sentimentos em você.

4. Fale sobre os objetos ou algo específico que mais chamou sua atenção.

5.

6. Algo na tarefa chamou sua atenção? 
7. Quanto tempo durou a exposição a cada objeto?

Estímulo A:

Estímulo B:

8. Você fez alguma coisa para contar o tempo em que ficou mexendo nos objetos? O que?

9. Observações: 
ANEXOS

Anexo A - Modelos baseados na série "Bichos" de Lygia Clark que foram utilizados como estímulos no experimento 2

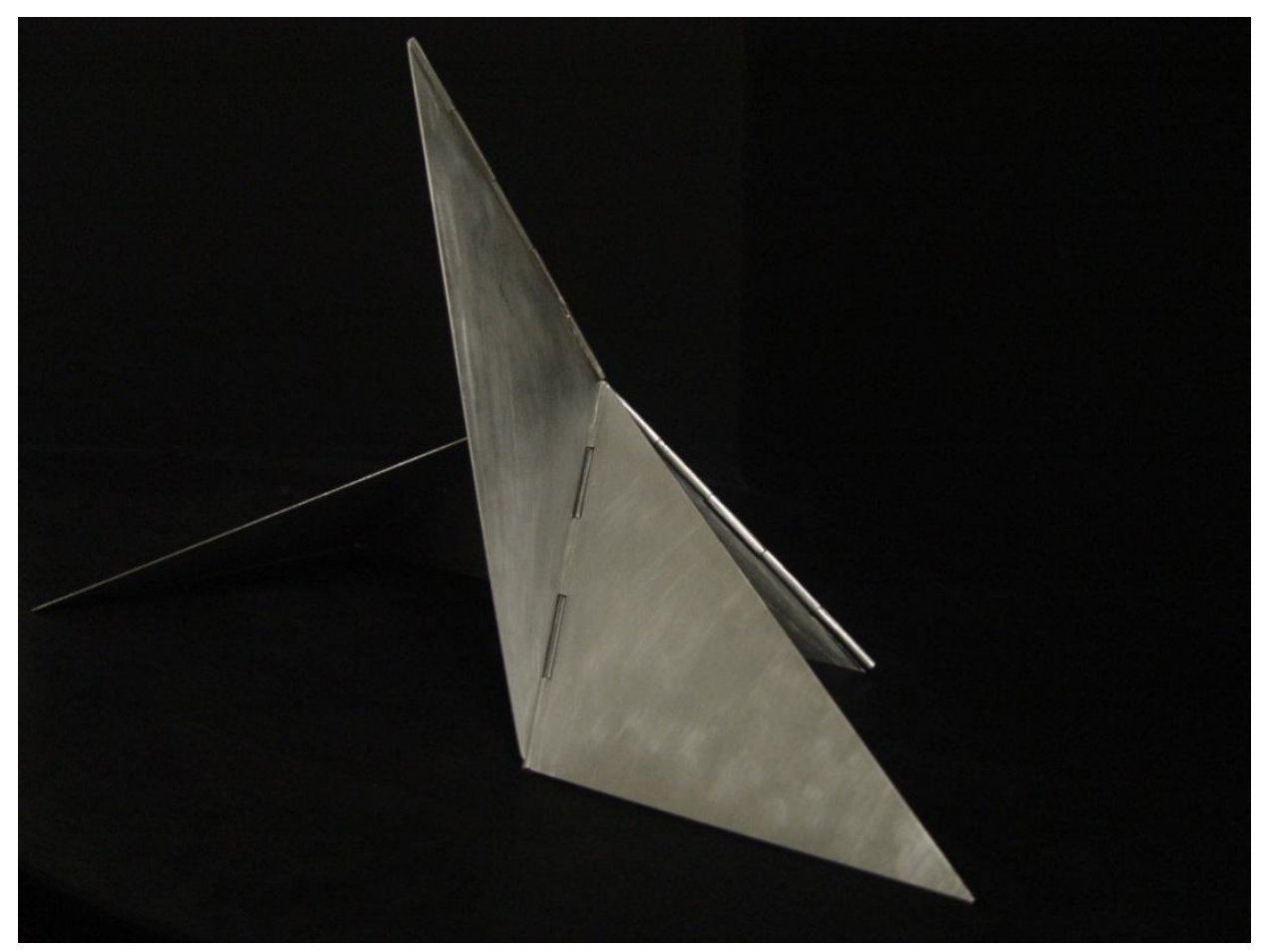

Estímulo A - Composto de seis peças

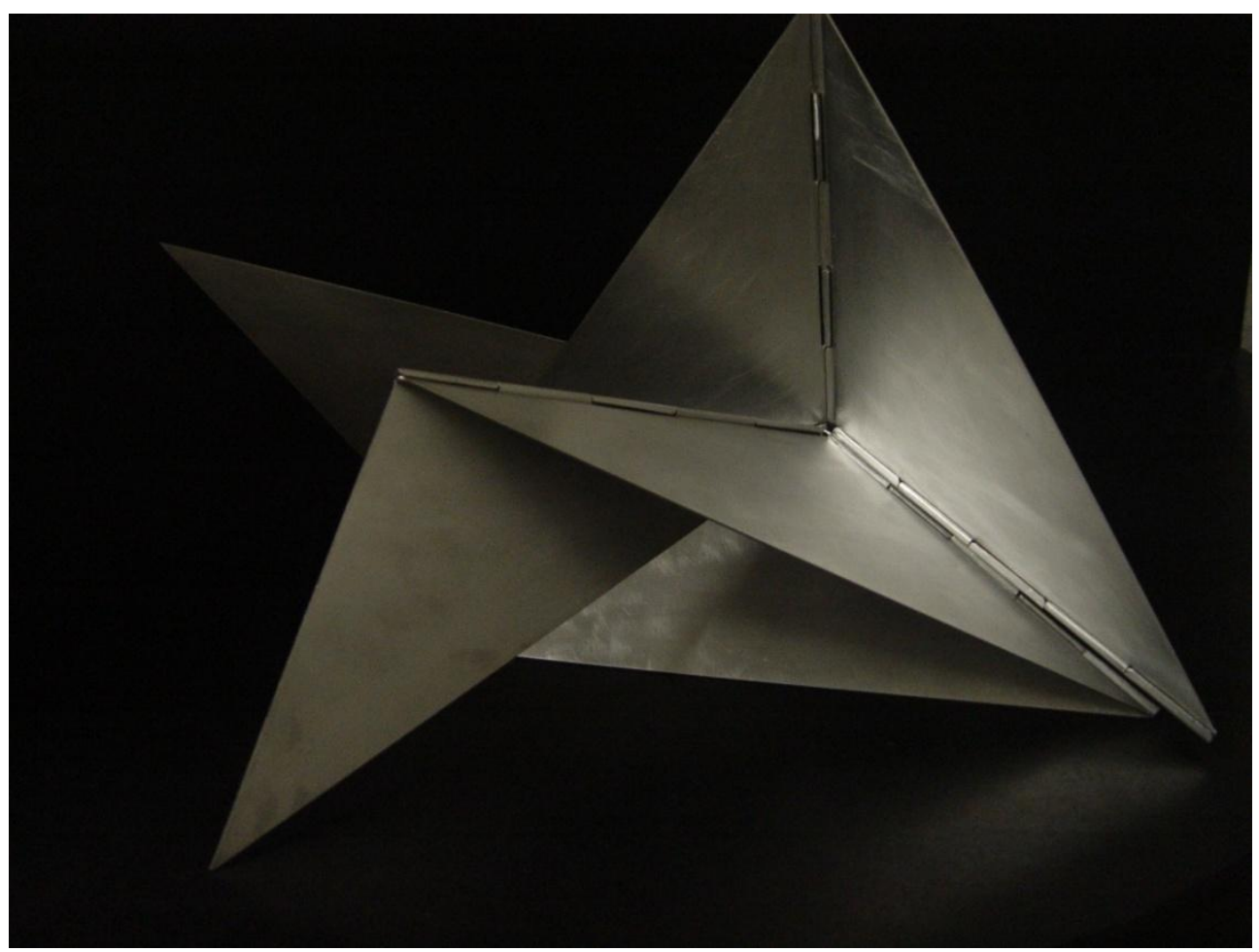

Estímulo B - Composto de dez peças 
Anexo B - Equipamento

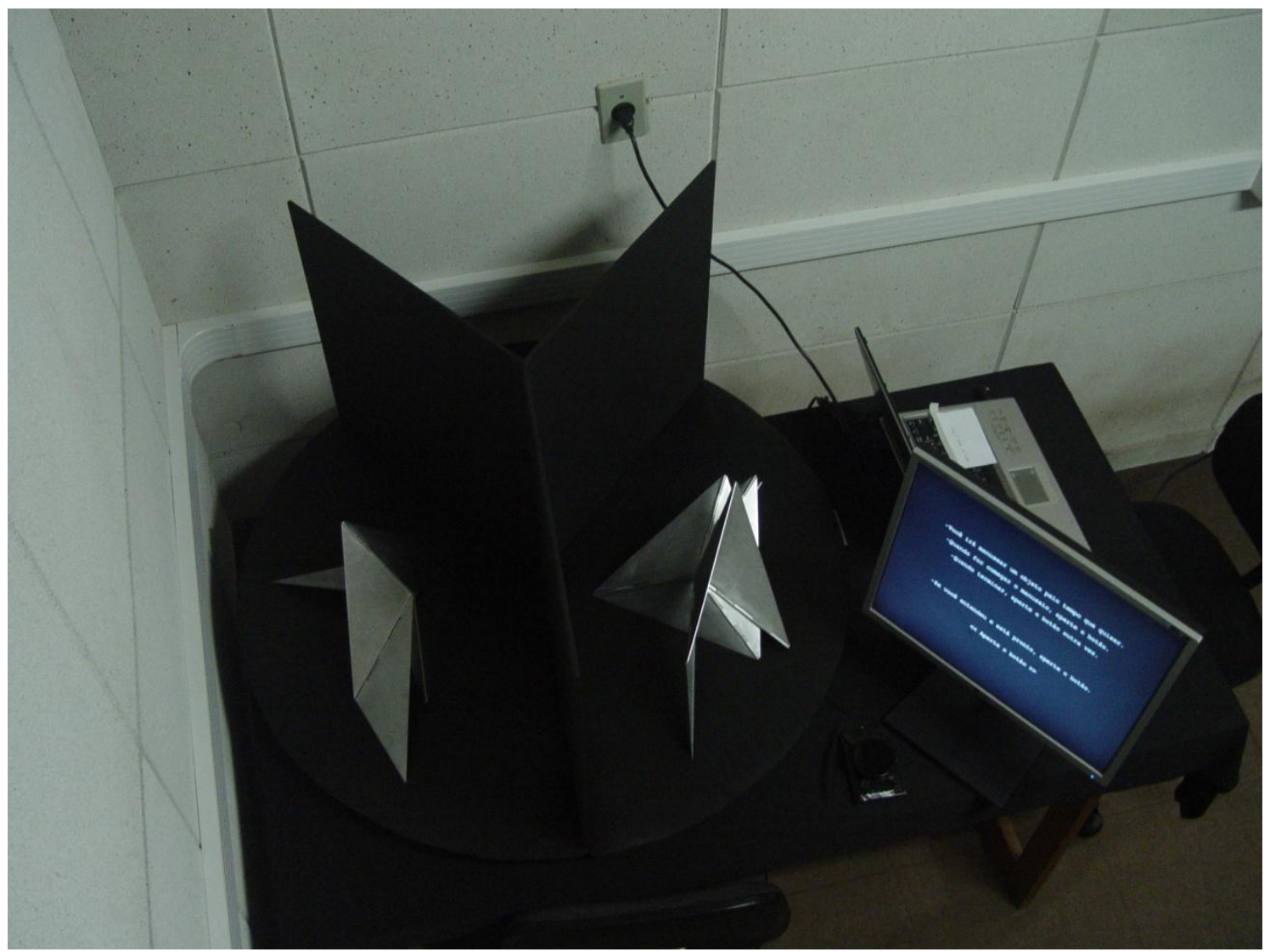

Equipamento utilizado no experimento 2 
